Key Words:

Waste Solidification Building

Mixability - Yield Stress

Variability Study

Retention: Permanent

\title{
WASTE SOLIDIFICATION BUILDING - BENCH SCALE HIGH ACTIVITY WASTE SIMULANT VARIABILITY STUDY FY-2008
}

\author{
Erich Hansen \\ Timothy Jones \\ Tommy Edwards \\ Alex Cozzi
}

MARCH 2009

Savannah River National Laboratory

Savannah River Nuclear Solutions

Aiken, SC 29808

Prepared for the U.S. Department of Energy Under Contract Number DE-AC09-08SR22470

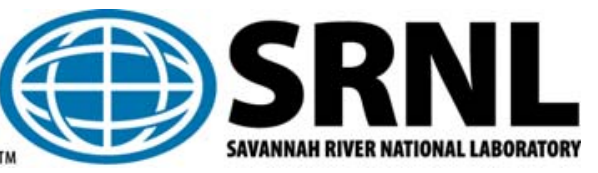




\section{DISCLAIMER}

This work was prepared under an agreement with and funded by the U.S. Government. Neither the U. S. Government or its employees, nor any of its contractors, subcontractors or their employees, makes any express or implied:

1. warranty or assumes any legal liability for the accuracy, completeness, or for the use or results of such use of any information, product, or process disclosed; or

2. representation that such use or results of such use would not infringe privately owned rights; or

3. endorsement or recommendation of any specifically identified commercial product, process, or service.

Any views and opinions of authors expressed in this work do not necessarily state or reflect those of the United States Government, or its contractors, or subcontractors.

Printed in the United States of America

Prepared for

U.S. Department of Energy 
Key Words:

Waste Solidification Building

Mixability - Yield Stress

Variability

Retention: Permanent

\title{
WASTE SOLIDIFICATION BUILDING - BENCH SCALE HIGH ACTIVITY WASTE SIMULANT VARIABILITY STUDY FY-2008
}

\author{
Erich Hansen \\ Timothy Jones \\ Tommy Edwards \\ Alex Cozzi
}

MARCH 2009

Savannah River National Laboratory

Savannah River Nuclear Solutions

Savannah River Site

Aiken, SC 29808 


\section{REVIEWS AND APPROVALS}

\section{AUTHORS}

E. K. Hansen, Engineering Process Development

Date

T. M. Jones, Engineering Process Development

Date

T. B. Edwards, Statistical Consulting

Date

A. D. Cozzi, Engineering Process Development

Date

\section{TECHNICAL REVIEWR}

R. E. Eibling, Engineering Process Development

Date

\section{APPROVALS}

A. B. Barnes, Manager, Engineering Process Development

Date

S. L. Marra, Manager, Environmental and Chemical Processing Technology

Date

S. J. Robertson, Design Authority Manager, Waste Solidification Building

Date 


\section{TABLE OF CONTENTS}

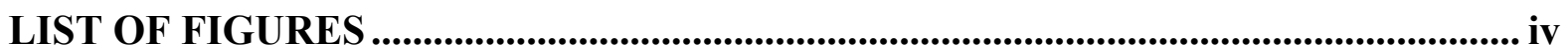

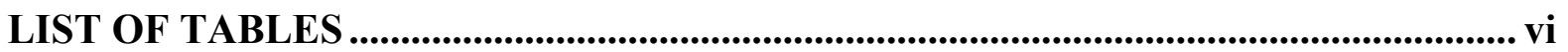

LIST OF ACRONYMS ................................................................................................................ vii

1.0 EXECUTIVE SUMMARY .................................................................................. 1

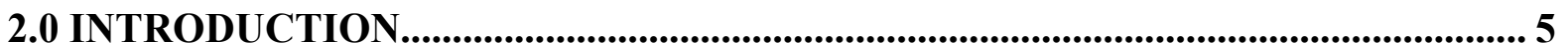

2.1 FACILITY BACKGROUND ....................................................................................... 5

2.2 SIMULANT SELECTION, VARiability AND SCOPE OF TESTING ..................... 6

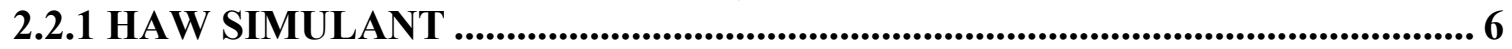

2.2.2 VARIABILITY STUDY ............................................................................................... 9

2.3 PHYSICAL PROCESS STEPS................................................................................. 12

2.3.1 PROCESSING HAW ACID SOLUTIONS .............................................................. 12

2.3.2 NEUTRALIZATION AND PH ADJUSTMENT .................................................... 13

2.3.3 GROUT MIXING ......................................................................................................... 17

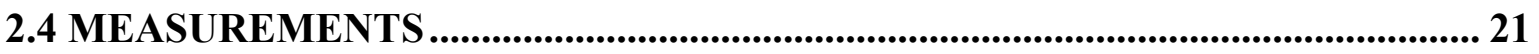

2.4.1 RHEOLOGY MEASUREMENT ............................................................ 21

2.4.2 SOLIDS ANALYSIS ............................................................................................... 25

2.4.3 DENSITY MEASUREMENT AND CALCULATIONS ...................................... 26

2.4.4 BLEED WATER ......................................................................................... 28

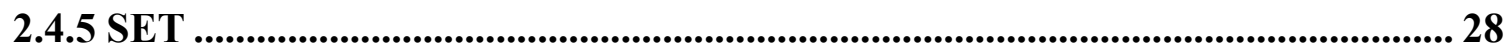

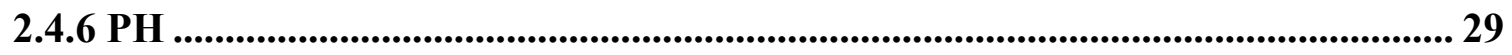

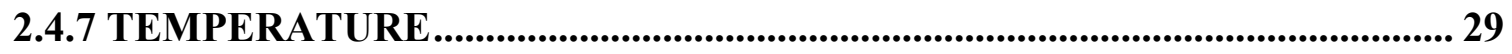

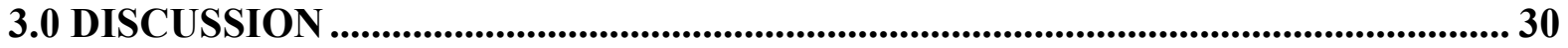

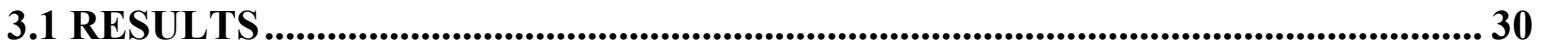

3.2 INITIAL REVIEW OF THE TEST MEASUREMENTS .......................................... 38

3.3 STATISTICAL ANALYSis .............................................................................................. 42

3.4 ELEMENTAL SUBSTITIONS...................................................................................... 43

3.5 GROUT BLENDS WITH INITIAL WETTING ISSUES ......................................... 50

3.6 FULL SCALE SIMULANT COMPARISON TO VARIABILITY HAW

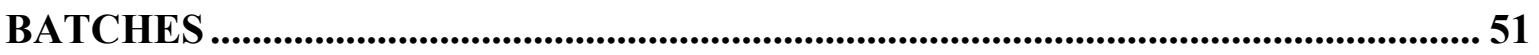

3.7 WATER ONLY GROUT BATCHES........................................................................ 52

3.8 WSB FLOWSHEET - SRNL WSB SIMULANT COMPARISION ......................... 53

4.0 CONCLUSIONS .........................................................................................................5 59

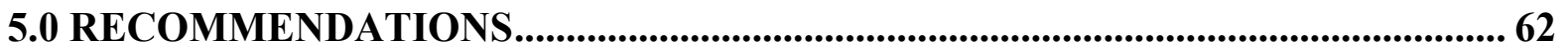

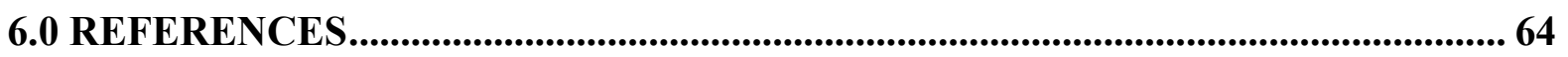

APPENDIX A. KESTERSON 9/15/2008 Email ........................................................................ 66

APPENDIX B. SCHAFNER 9/18/2008 EMAIL ...................................................................... 68

APPENDIX C. EXAMPLES OF BATCH SHEETS ............................................................. 70

APPENDIX D. VANE MEASUREMENTS ............................................................................. 74

APPENDIX E. STATISTICAL ANALYSIS FIGURES .......................................................... 91 


\section{LIST OF FIGURES}

Figure 2-1 Simplified WSB - LAW and HAW Systems ............................................... 6

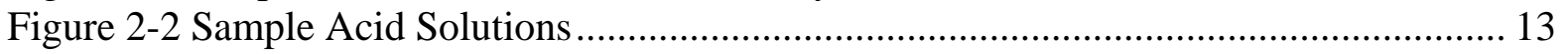

Figure 2-3 Neutralization/pH adjustment Process for HAW-24......................................... 16

Figure 2-4 Agitator Used In "Proof of Concept” Mixing Tests............................................ 17

Figure 2-5 Agitator Used In "Proof of Concept Mixing Tests".......................................... 20

Figure 2-6 Vane Requirements and Actual Vane ......................................................... 23

Figure 2-7 Typical Vane Torque versus Time/Displacement Curve ..................................... 24

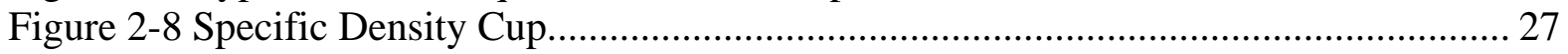

Figure 2-9 Measurement Points to Determine Grout Volume.............................................. 27

Figure 2-10 Modified Vicat Needle ................................................................................ 29

Figure 3-1 Set of Yield Stress Measurements by Test Run, HAW-0 Through HAW-41 ..... 40

Figure 3-2 First Yield Stress Measurement by Batching Variables, HAW-1 Through HAW40 .

Figure 3-3 Modeling of Natural Logarithm of First Yield Stress Measurements (all acid batching variables)

Figure 3-4 Leverage Plots of Natural Logarithm of First Yield Stress Measurements Against

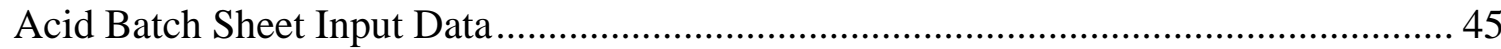

Figure 3-5 Modeling of Natural Logarithm of First Yield Stress Measurements (excluding runs with substitution variables) 46

Figure 3-6 Modeling of Natural Logarithm of First Yield Stress Measurements (excluding

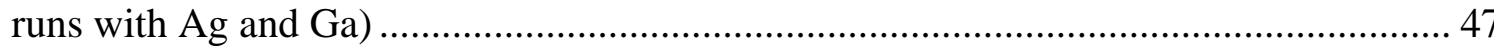

Figure 3-7 Plot of natural logarithm of first yield stress measurement (Pa) for trials investigating substitutability grouped as indicated by the information provided on the $\mathrm{x}$ axis. This plot is arranged to help investigate the viability of substituting $\mathrm{Cu}$ for $\mathrm{Ag}$. Arrows show direction of yield stress change during substitution. .............................. 48

Figure 3-8 Plot of natural logarithm of first yield stress measurement $(\mathrm{Pa})$ for trials investigating substitutability grouped as indicated by the information provided on the $\mathrm{x}$ axis. This plot is arranged to help investigate the viability of substituting Al for Ga.

Arrows show direction of yield stress change during substitution. .............................. 49

Figure 3-9 Initial Wetting Mix Batches and Other High Yield Stress Results ...................... 50

Figure 3-10 First Yield Stress Measurement Versus HAW Tests with Averaged Yield Stress

HAW-0/HAW-41 Line Reference 51

Figure 3-11 First Yield Stress Versus Sodium Molarity in Final Grout for All HAW with Averaged Yield Stress HAW-0/HAW-41 Line Reference ........................................... 51

Figure 3-12 Averaged Water to Cement Mass Ratio Batches for First Yield Stress

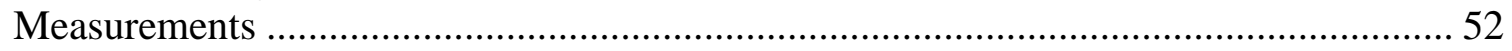

Figure C - 1 Example of HAW Acid Solution: HAW-36A............................................... 71

Figure C - 2 Example of HAW Neutralization/pH Adjustment Batch Sheet: HAW-36A ..... 72

Figure C - 3 Example of HAW Grout Batch Sheet: HAW-36 ......................................... 73

Figure D - 1 Vane Measurements for HAW-0, HAW-1, and HAW-2 2.............................. 75

Figure D - 2 Vane Measurements for HAW-3, HAW-4, and HAW-5 ............................... 76 
Figure D - 3 Vane Measurements for HAW-6, HAW-7, and HAW-8 ………………............. 77

Figure D - 4 Vane Measurements for HAW-9, HAW-10, and HAW-11 ............................... 78

Figure D - 5 Vane Measurements for HAW-12, HAW-13, and HAW-14 ............................. 79

Figure D - 6 Vane Measurements for HAW-15, HAW-16, and HAW-17 .............................. 80

Figure D - 7 Vane Measurements for HAW-18, HAW-19, and HAW-20 ............................... 81

Figure D - 8 Vane Measurements for HAW-21, HAW-22, and HAW-23 ……....................... 82

Figure D - 9 Vane Measurements for HAW-24, HAW-25, and HAW-26 ................................ 83

Figure D - 10 Vane Measurements for HAW-27, HAW-28, and HAW-29 ............................. 84

Figure D - 11 Vane Measurements for HAW-30, HAW-31, and HAW-32 ............................ 85

Figure D - 12 Vane Measurements for HAW-33, HAW-34, and HAW-35 ………….............. 86

Figure D - 13 Vane Measurements for HAW-36, HAW-37, and HAW-38 ............................. 87

Figure D - 14 Vane Measurements for HAW-39, HAW-40, and HAW-41 ............................ 88

Figure D - 15 Repeated Vane Measurements for HAW-9A, HAW-20A, and HAW-24A .... 89

Figure D - 16 Repeated Vane Measurements for HAW-37A and HAW-17A ......................... 90

Figure E - 1 Linear Correlations Among Set of Yield Stress Measurements.......................... 92

Figure E - 2 Plot of $\ln \left(1^{\text {st }}\right.$ yield stress $)$ Versus Molarity of Batch Sheet Input Data $\mathrm{HNO}_{3}$, Ag,

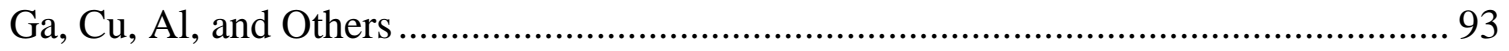

Figure E - 3 Plot of $\ln \left(1^{\text {st }}\right.$ yield stress $)$ Versus Density and Wt\% TS of Acid Solutions........ 94

Figure E - 4 Plot of $\ln \left(1^{\text {st }}\right.$ yield stress) Versus Physical Properties of Neutralized-pH Adjusted

Fluids; Density, Wt\% TS, Wt\% SSS, Wt\% UDS, and pH.............................................. 95

Figure E - 5 Plot of $\ln \left(1^{\text {st }}\right.$ yield stress) Versus Mass Fraction of Cement, Zircon Flour,

Simulant, and Water and Density and Ga Molarity in Final Grout ................................. 96

Figure E - 6 Plot of $\ln \left(1^{\text {st }}\right.$ yield stress $)$ Versus Molarity of Al, Ag, Cu, Er, Ba, and Ca in Final

Grout ........................................................................................................ 97

Figure E - 7 Plot of $\ln \left(1^{\text {st }}\right.$ yield stress $)$ Versus Molarity of $\mathrm{Cd}, \mathrm{K}, \mathrm{Mg}, \mathrm{Na}$, and $\mathrm{NO}_{3}{ }^{-}$in Final

Grout 98

Figure E - 8 Plot of $\ln \left(1^{\text {st }}\right.$ yield stress) Versus Molarity of $\mathrm{Ga}, \mathrm{Ag}, \mathrm{Al}, \mathrm{Cu}$ and "Others" in

Final Grout Keeping “Others” as a Group 


\section{LIST OF TABLES}

Table 2-1 Batch Sheet to Make 1-Liter of the HAW Simulant ................................................ 7

Table 2-2 Metals Concentrations from MOX and Maximums in WSB .................................... 8

Table 2-3 Previous Maximum Metals Basis for HAW Acid Stream............................................ 8

Table 2-4 Maximum Chemical Composition of HAW Acidic Waste Stream Simulant Used in this Variability Study …………………................................................................. 9

Table 2-5 Variable for the Initial Factor Space ………….................................................... 10

Table 2-6 Composition of Other Metals .............................................................................. 10

Table 2-7 Final Test Matrix - Variability Study for the HA Waste Variability Study ........... 11

Table 2-8 Variables Used to Determine Effect on Response Variable..................................... 12

Table 2-9 Chemical Used to Make the HAW Acidified Solutions........................................... 13

Table 2-10 Hobart N50 Mixer Specifications................................................................... 18

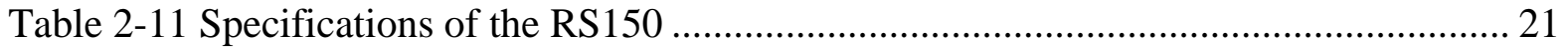

Table 2-12 Z41 Rotor Specification and Program Ramp Rates .............................................. 22

Table 3-1 Final Mixing Speeds at the End of the Neutralization/pH Adjustment Process..... 30

Table 3-2 Temperature Increase In Grout During Mixing....................................................... 31

Table 3-3 Results - Acidified Fluids and Grout Yield Stress................................................. 33

Table 3-4 Results - Neutralized/pH Adjusted Fluids and Grout Yield Stress.......................... 34

Table 3-5 Results - Grout Physical Properties and Yield Stress Measurements...................... 35

Table 3-6 Results - Grout Element and Compound Concentrations and Yield Stress............ 36

Table 3-7 Results - Grout Element and "Others" Concentration and Yield Stress................. 37

Table 3-8 Effect on Yield Stress as Input Variable Increases ................................................ 39

Table 3-9 Result Using Two Different Mixing Method for the Initial Mixes that Provided

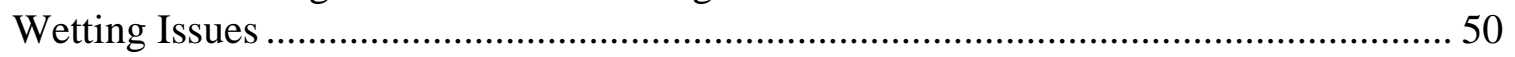

Table 3-10 Water Grout Batches - 1400 mL Total Volume ..................................................... 52

Table 3-11 Impact of Increased NaOH Addition to Neutralized HAW Solution..................... 55

Table 3-12 Impact on Density Due to Increases in $\mathrm{NaOH}$ and Zircon Flour .......................... 56

Table 3-13 Cement, Zicron Flour and Salt Solution Mass Contribution for 1-Liter of Grout for Z/C Mass Ratio of 1/12 for $\mathrm{pH} 12$ and + 10\% NaOH Salt Solutions......................... 57

Table 3-14 Cement, Zicron Flour and Salt Solution Mass Contribution for 1-Liter of Grout for Z/C Mass Ratio of 1/4 for pH 12 and + 10\% NaOH Salt Solutions........................... 58 


\section{LIST OF ACRONYMS}

\begin{tabular}{|c|l|}
\hline DA & Design Authority \\
\hline DSS & Dissolved solids in the Supernate \\
\hline HAW & High Activity Waste \\
\hline LAW & Low Activity Waste \\
\hline MFFF & Mixed Oxide Fuel Fabrication Facility \\
\hline N/C & Not Calculated \\
\hline N/M & Not Measured \\
\hline NIST & National Institute of Standards and Technology \\
\hline PDCF & Pit Disassembly and Conversion Facility \\
\hline PVVS & Process Vessel Vent Subsystem \\
\hline RPM & Revolutions Per Minute \\
\hline SRNL & Savannah River National Laboratory \\
\hline TS & Total Solids in the Fluid \\
\hline UDS & Undissolved Solids in the Fluid \\
\hline W/C & Water To Cement Mass Ratio \\
\hline WIPP & Waste Isolation Pilot Plant \\
\hline WSB & Waste Solidification Building \\
\hline Wt\% & Weight Percent \\
\hline Z/C & Zircon Flour To Cement Mass Ratio \\
\hline
\end{tabular}


SRNL-STI-2009-00101, REVISION 0

\subsection{EXECUTIVE SUMMARY}

The primary objective of this task was to perform a variability study of the high activity waste (HAW) acidic feed to determine the impact of feed variability on the quality of the final grout and on the mixability of the salt solution into the dry powders. The HAW acidic feeds were processed through the neutralization/ $\mathrm{pH}$ process, targeting a final $\mathrm{pH}$ of 12 . These fluids were then blended with the dry materials to make the final waste forms. A secondary objective was to determine if elemental substitution for cost prohibitive or toxic elements in the simulant affects the mixing response, thus providing a more economical simulant for use in full scale tests. Though not an objective, the HAW simulant used in the full scale tests was also tested and compared to the results from this task.

A statistically designed test matrix was developed based on the maximum molarity inputs used to make the acidic solutions. The maximum molarity inputs were: $7.39 \mathrm{HNO}_{3}, 0.11618$ gallium, 0.5423 silver, and 1.1032 "other" metals based on their $\mathrm{NO}_{3}{ }^{-}$contribution. Substitution of the elements aluminum for gallium and copper for silver was also considered in this test matrix, resulting in a total of 40 tests. During the $\mathrm{NaOH}$ addition, the neutralization $/ \mathrm{pH}$ adjustment process was controlled to a maximum temperature of $60{ }^{\circ} \mathrm{C}$. The neutralized/pH adjusted simulants were blended with Portland cement and zircon flour at a water to cement mass ratio of 0.30 . The mass ratio of zircon flour to Portland cement was 1/12. The grout was made using a Hobart N-50 mixer running at low speed for two minutes to incorporate and properly wet the dry solids with liquid and at medium speed for five minutes for mixing. The resulting fresh grout was measured for three consecutive yield stress measurements. The cured grout was measured for set, bleed, and density.

Given the conditions of preparing the grout in this task, all of the grouts were visually well mixed prior to preparing the grouts for measurements. All of the cured grouts were measured for bleed and set. All of the cured grouts satisfied the bleed and set requirements, where no bleed water was observed on any of the grout samples after one day and all had set within 3 days of curing. This data indicates, for a well mixed product, bleed and set requirement are satisfied for the range of acidic feeds tested in this task.

The yield stress measurements provide both an indication on the mixability of the salt solution with dry materials and an indication of how quickly the grout is starting to form structure. The inability to properly mix these two streams into a well mixed grout product will lead to a non-homogeneous mixture that will impact product quality. Product quality issues could be unmixed regions of dry material and hot spots having high concentrations of americium 241. Mixes that were more difficult to incorporate typically resulted in grouts with higher yield stresses. The mixability from these tests will provide Waste Solidification Building (WSB) an indication of which grouts will be more challenging to mix. The first yield stress measurements were statistically compared to a list of variables, specifically the batched chemicals used to make the acidic solutions. The first yield stress was also compared to the physical properties of the acidic solutions, physical and $\mathrm{pH}$ properties of the neutralized/pH adjusted solutions, and chemical and physical properties of the grout. 
The conclusions from this testing that impact the mixability/yield stress are:

- Statistically the yield stress decreases with increasing $\mathrm{HNO}_{3}$ concentration and increases with increasing gallium and "Other" metals concentration.

- Statistically, silver had no impact on the yield stress.

- Increasing the sodium nitrate concentration causes a decrease in the yield stress.

- As the water content in the neutralized/pH adjusted solution increases, the yield stress increases.

- The undissolved solids fraction, $\mathrm{pH}$, and density of the neutralized/pH adjusted solution do not cause the yield stress to trend.

- The simulant used in the full scale tests resulted in yield stresses that are bounded by the testing performed in this task and the results were toward the lower bounds of HAW simulant used in the variability study.

Recommendations related to mixability are:

1. If the WSB expects the acid concentration in the HAW Neutralization/Cement head tanks is equal to or greater than 3.695 $\mathrm{M} \mathrm{HNO}_{3}$ prior to neutralization/pH adjustment, perform functional testing of full scale mixing systems using water (rather than salt simulant) at a water to cement ratio of 0.3 . The zircon flour should also be included with the cement.

2. Perform testing for mixability in a full scale mixing system using one of the simulants that had an initial wetting issue or a high yield stress. This will provide engineering/operations additional insight on the capabilities of the mixing equipment and, if necessary, on how to recover from off-normal operations.

3. Perform additional testing with $\mathrm{HNO}_{3}$ ranging from 0 to $3.695 \mathrm{M}$ in the acidic solution. Testing will determine if there are non-linear responses in this range. It is expected that this range of $\mathrm{HNO}_{3}$ will provide a more difficult grout to mix.

4. The current WSB intention to pre-batch the 55 gallon drums with dry materials and operate with a water to cement mass ratio of 0.30 requires that the WSB concentrate to a fixed weight percent solids. Water runs indicate variation in $\mathrm{W} / \mathrm{C}$ ratio can result in significantly different grout yield stress. The water content of the neutralized $/ \mathrm{pH}$ adjusted solutions, unless controlled by the WSB, will be a variable. Perform additional testing to determine mixability, water content, and set issues.

5. The dry materials, Portland Cement and zircon flour used for future testing, including both bench and full scale, should be those chemicals used in the actual process. Variability in the dry feed material can impact the mixability results.

These tests showed that the substitution elements, aluminum for gallium and copper for silver are not good substitutes. Statistically, as the concentration of aluminum and copper increased the yield stress decreased. This is contrary to the gallium, where the yield stress increased with increasing gallium concentration. Silver was shown not to impact yield stress.

Recommendations related to using substitution elements are:

1. Perform additional testing to identify more suitable surrogates for gallium. The selected substitution element, aluminum, is not recommended since it provides a nonconservative simulant for testing.

2. Silver was shown to have no impact on the yield stress. Additional testing, without silver may show that no substitute element is required. 
During the processing of HAW simulant solutions, from making of the acidic solution and processing the acidic solution through the neutralization $/ \mathrm{pH}$ adjustment, the following conclusions were observed:

- Mixing during the neutralization/pH adjustment process of the different acidic solutions required different agitator speeds to incorporate and disperse the $\mathrm{NaOH}$ solution. The resulting solutions were either Newtonian or non-Newtonian.

- During the neutralization $/ \mathrm{pH}$ adjustment phase, where the concentrated $\mathrm{NaOH}$ solution was added to the surface of the agitated fluid and between a $\mathrm{pH}$ of 5 to 10, cavern mixing was observed on some of the solutions that contained high acids and metals. To overcome cavern mixing, the agitator speed was increased to incorporate the $\mathrm{NaOH}$ solution and to provide complete mixing to occur.

- Active cooling was required during the $\mathrm{NaOH}$ addition in the neutralization $/ \mathrm{pH}$ adjustment process when the $\mathrm{HNO}_{3}$ concentration was greater than or equal to $3.695 \mathrm{M}$ in the acid solution.

- Additional conclusions from this testing are provided in the conclusions section of this report, section 4.0 .

The following are recommendations based upon the testing performed in this task.

1. The HAW Neutralization/Cement head tank design should consider the ability to effectively mix a range of solutions that have non-Newtonian fluid properties. The mixer must be able to overcome the changes in the fluid properties, specifically the yield stress of the fluid, as the $\mathrm{NaOH}$ solution is added to change the $\mathrm{pH}$ in the range of 3 to 10 .

2. Functional testing of the WSB neutralization/cementation head tank should be performed using a solution with non-Newtonian properties. This will evaluate the mixing/pumping capabilities of the facility.

3. Perform functional testing of the WSB facility using a solution that has Newtonian properties throughout processing.

4. If undissolved solids are expected in the acidic waste coming from the Mixed Oxide Fuel Fabrication Facility, perform functional testing of the WSB facility using an acidic fluid that contains undissolved solids. Undissolved solids in the acidic waste streams may require agitation of the process tanks and flushing of process lines in the WSB facility.

5. The use of sodium nitrate $\left(\mathrm{NaNO}_{3}\right)$ rather than performing the full neutralization/pH adjustment phase will reduce the cost of the HAW simulant. The substitution of $\mathrm{NaNO}_{3}$ would remove the cooling required during the neutralization step. Direct use of $\mathrm{NaNO}_{3}$ may also prove beneficial to control the sodium level in the WSB for mixability. Testing would be required to determine the impact of this substitution.

6. Testing of actual waste should be performed prior to commencement of full operations of the WSB. This will provide an additional level of confidence in the WSB process.

7. Changes to the WSB flowsheet or process influents would require that the changes be evaluated against the testing performed in this study to determine if the current testing bounds the altered process. 
8. The impacts of salt solution chemistry and water content on the heat of hydration were not investigated. Chemistry and water content will impact the heat of hydration, resulting in a different heat generation rates, which could cause operational issues during the handling of the 55 gallon drums.

Calculations of the physical properties and batching composition for a fixed volume between the SRNL's and WSB's flowsheet was performed. The differences are in the endpoint of $\mathrm{NaOH}$ addition to the acid solution and the zircon/cement mass ratio. SRNL targeted a pH of 12 and WSB states an additional $+10 \% \mathrm{NaOH}$ required to neutralize the $\mathrm{HNO}_{3}$ concentration in the acidified solution. SRNL used a Z/C mass ratio of $1 / 12$ and for WSB it is $1 / 4$. These calculations result in the following conclusions:

- Slightly more $\mathrm{NaOH}$ solution is required for the $+10 \% \mathrm{NaOH}$ solution as compared to the $\mathrm{pH} 12$ cases.

- Salt solution density for the $+10 \% \mathrm{NaOH}$ fluid is slightly greater than the $\mathrm{pH} 12$ fluid, due to the addition of $51 \mathrm{wt} \% \mathrm{NaOH}$ solution.

- The grout densities of the $\mathrm{pH} 12$ and $+10 \% \mathrm{NaOH}$, for a given $\mathrm{Z} / \mathrm{C}$ mass ratio are similar, for a given HAW case. The mass contributions of the Portland cement, zircon flour and salt solution are also very similar, for producing one liter of grout.

- There are significant differences in densities and mass contribution of the components when comparing the $\mathrm{pH} 12$ for $\mathrm{Z} / \mathrm{C}$ mass ratios of $1 / 12$ to that of the $1 / 4$. The large increase in zircon flour in the $\mathrm{Z} / \mathrm{C}$ mass ratio of $1 / 4$ results in a decrease in both the Portland cement and salt solution.

The following are recommendations based upon comparing the differences in the SRNL and WSB flowsheet:

1. Perform tests to determine if the increased hydroxide concentration in the salt solution impacts grout properties and mixability.

2. Perform tests to determine the impact in the variability in the $\mathrm{Z} / \mathrm{C}$ mass ratios on grout properties and mixability, if the $\mathrm{Z} / \mathrm{C}$ mass ratio is different than $1 / 12$. 


\subsection{INTRODUCTION}

The primary objective of this task is to perform a variability study on the composition of an acidic waste stream that will be processed through the Waste Solidification Building (WSB) into a final grout waste form. The acidic waste streams will be neutralized and $\mathrm{pH}$ adjusted, and the resulting salt solution blended with cementitious materials to make grout. The cured grout properties that satisfy WSB processing requirements and the mixability of the grouts will be measured. A secondary objective is to determine if elemental substitution of cost prohibitive elements in the simulant results in the same type of mixing response, thus reducing the cost of simulant use in full scale tests.

The Savannah River National Laboratory (SRNL) has been requested to perform testing to support technical decisions for the WSB as described in item \#3 of the Technical Task Request ${ }^{1}$ :

3. Using the composition in NNP-WSB-2006-00009 Revision 1, estimate whether there will be a likely or unlikely effect on wasteform properties at the concentrations listed. For the waste components that will have a likely effect, estimate whether there will be a major or minor effect (at the concentrations listed). The WSB-DA will then provide ranges of composition for the waste components. Using these ranges, develop simulants and prepare wasteforms to determine the sensitivity of the wasteform to compositional variations.

The work performed in this task was controlled as described in the Task Technical and Quality Assurance Plan document ${ }^{2}$.

\subsection{FACILITY BACKGROUND}

The Waste Solidification Building (WSB) will accept three different influent liquid waste streams for processing. The waste will be combined with cementitious materials to produce waste form for disposal. A simplified schematic of the process can be seen in Figure 2-1. The Pit Disassembly and Conversion Facility (PDCF) will provide a low activity waste (LAW) effluent from lab operations. The Mixed Oxide Fuel Fabrication Facility (MFFF) will provide two liquid waste streams; an LAW and HAW. The LAW effluent is the stripped uranium stream from the plutonium separation operations. The HAW effluent containing the high alpha feed is primarily Am-241, separated from the plutonium. Since the objective of this task is the processing of the HAW fluid, the processing of LAW through the WSB will not be discussed.

The HAW effluent received from the MFFF is stored in two High Alpha Receipt tanks in the WSB receipt subsystem. An acid overflow tank, also in the receipt subsystem, is used to receive wastes from various WSB internal HAW generation sources, such as overflows from other HAW tanks, sampling glovebox drain, HAW tank cleaning flushes, and condensate from the Process Vessel Vent Subsystem (PVVS). The contents in the receipt subsystem tanks are pumped into a single HAW Head tank. Based on the composition of the HAW in the Head tank, the contents can be diluted using the overheads from the LAW evaporator or 
the HAW Condensate Hold tank, sent to the evaporator or sent directly to the Bottoms tank. The liquid from the evaporator is sent to the HAW Condensate Hold Tank. Where based upon its chemical analysis, it can either be reprocessed back into the HAW Head tank or to the LAW system, though the typical path is the LAW system. The HAW liquid in the Bottoms Tank is then analyzed to ensure it meets the requirements for disposal at the Waste Isolation Pilot Plant (WIPP). The acid HAW solution is first neutralized and $\mathrm{pH}$ adjusted to a $\mathrm{pH}$ of 12. During the neutralization process, heat generation due to exothermal reactions with the acid and base may require active cooling. The neutralized/pH adjusted HAW solution, which can contain undissolved solids (UDS), is fed into a 55 gallon drum preloaded with dry materials-Portland cement and zircon flour. A mechanical mixing system is used to blend the two materials into a well mixed product with no bleed water. The cementitious HAW waste is then sent to WIPP for final disposal. Additional details can be found in Reference 3.

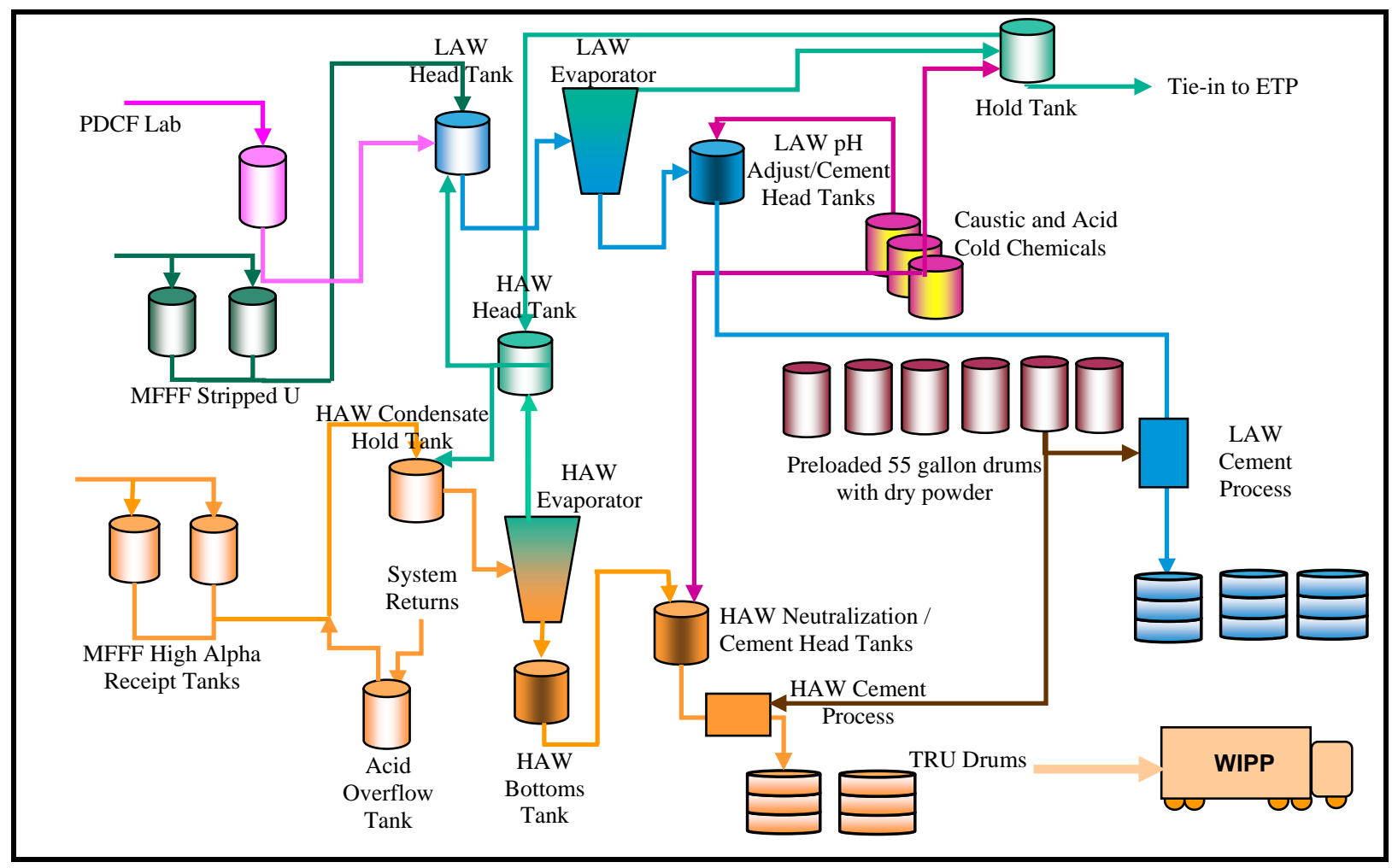

Figure 2-1 Simplified WSB - LAW and HAW Systems

\subsection{SIMULANT SELECTION, VARIABILITY AND SCOPE OF TESTING}

\subsubsection{HAW SIMULANT}

\subsubsection{ORIGINAL HAW SIMULANT USED IN FULL SCALE TESTS}

The original HAW simulant was based on the composition of the HAW stream provided by WSB engineering. ${ }^{4}$ Upon review of the HAW metals composition, a baseline non-hazardous simulant developed by SRNL was provided as shown in Table 2-1. This non-hazardous 
simulant is based on a starting volume of one liter of acidified HAW, containing 7.856 moles of nitrate. Concentrated sodium hydroxide solution was used to neutralize and adjust the $\mathrm{pH}$ to 12. The simulant was used in two full scale tests. The first set of tests was "proof of concept" tests which were performed to show that using an unconventional mixing methodliquid added to the dry solids rather than the traditional method of making slurries - which is the addition of solids to liquid was viable. ${ }^{5}$ The "proof of concept" tests were successful for this HAW simulant, showing that a well mixed product can be produced. ${ }^{6}$ The second set of tests was performed to determine the effect of both the potential rise in skin temperature of the 55 gallon drum with respect to the impact of the increased temperature on the ability to move the drums soon after mixing and during the curing of the grout on the performance of the proposed vent (to be installed on the 55 gallon drum upon completion of mixing). The testing $^{7}$ was successful in showing that the vents performed without issue. Testing also showed that the skin temperature of the 55 gallon drum may require additional personal protective equipment for contact handling of the drum within 24 hours of processing.

Note that there are chemicals listed in Table 2-1 that were not present in the simulant used in full-scale testing and are those chemicals which are listed with a target value of zero. These chemicals are listed to provide a reference to compare the full-scale simulant to the simulant selected for the variability test. The full-scale simulant was added as part of the testing, since it has a basis with respect to the two full scale tests that were performed. Two batches of this simulant, shown in Table 2-1, were made for characterization, but are not considered part of the variability test. The blue highlighted boxes are chemicals in the variability study that are grouped as "other" metals, which shows the full-scale simulant contributes only a fraction of

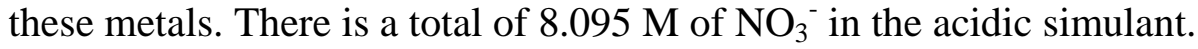

Table 2-1 Batch Sheet to Make 1-Liter of the HAW Simulant

\begin{tabular}{|c|c|c|}
\hline Chemical Name & Compound & Target (g) \\
\hline Nitric Acid & $\mathrm{HNO}_{3}(70.1 \%-15.8 \mathrm{~N}, 1.42 \mathrm{sg})$ & 664.3 \\
\hline Gallium Nitrate Hexahydrate & $\mathrm{Ga}\left(\mathrm{NO}_{3}\right)_{3} \times 6 \mathrm{H}_{2} \mathrm{O}$ & 0.000 \\
\hline Aluminum Nitrate & $\mathrm{Al}\left(\mathrm{NO}_{3}\right)_{3} \times 9 \mathrm{H}_{2} \mathrm{O}$ & 5.600 \\
\hline Silver Nitrate $(100 \%)$ & $\mathrm{AgNO}_{3}$ & 0.000 \\
\hline Copper Nitrate & $\mathrm{Cu}\left(\mathrm{NO}_{3}\right)_{2} \times 2.5 \mathrm{H}_{2} \mathrm{O}$ & 7.614 \\
\hline Erbium Nitrate Pentahydrate & $\mathrm{Er}\left(\mathrm{NO}_{3}\right)_{3} \times 5 \mathrm{H}_{2} \mathrm{O}$ & 0.000 \\
\hline Barium Nitrate & $\mathrm{Ba}\left(\mathrm{NO}_{3}\right)_{2}$ & 0.000 \\
\hline Calcium Nitrate Tetrahydrate & $\mathrm{Ca}\left(\mathrm{NO}_{3}\right)_{2} \times 4 \mathrm{H}_{2} \mathrm{O}$ & 23.000 \\
\hline Cadmium Nitrate Tetrahydrate & $\mathrm{Cd}\left(\mathrm{NO}_{3}\right)_{2} \times 4 \mathrm{H}_{2} \mathrm{O}$ & 0.000 \\
\hline Potassium Nitrate & $\mathrm{KNO}_{3}$ & 15.400 \\
\hline Magnesium Nitrate Hexahydrate & $\mathrm{Mg}\left(\mathrm{NO}_{3}\right)_{2} \times 6 \mathrm{H}_{2} \mathrm{O}$ & 23.300 \\
\hline Aluminum Nitrate & $\mathrm{Al}\left(\mathrm{NO}_{3}\right)_{3} \times 9 \mathrm{H}_{2} \mathrm{O}$ & 0.000 \\
\hline Copper Nitrate & $\mathrm{Cu}\left(\mathrm{NO}_{3}\right)_{2} \times 2.5 \mathrm{H}_{2} \mathrm{O}$ & 0.000 \\
\hline Sodium Nitrate & $\mathrm{NaNO}_{3}$ & 5.600 \\
\hline DI Water & $\mathrm{H}_{2} \mathrm{O}$ & 514.8 \\
\hline Sodium Hydroxide for $\mathrm{pH}=12$ & $\mathrm{NaOH}\left(51 \mathrm{wt}^{2}\right)$ & 611.8 \\
\hline Volume of pH = 12 solution & $\mathrm{Liters}$ & 1.451 \\
\hline
\end{tabular}




\subsubsection{SELECTED HAW SIMULANT}

Kesterson * provided a new basis for the HAW waste stream coming from MFFF, which was approved by WSB design authority (DA) for use in this task. This HAW waste stream is significantly different from the HAW stream used for the HAW simulant for full-scale testing.

The composition of the revised HAW metals is summarized in Table 2-2. The concentrations of these metals in this HAW stream were further increased by a factor of five in the WSB ${ }^{\dagger}$ flowsheet due to the concentration of the HAW stream if the evaporator is implemented in the WSB. These values are also provided in Table 2-2. The previous maximum metals concentrations $^{4}$ for the full-scale tests are provided in Table 2-3, as a reference. The following maximums were also specified in the previous HAW simulant, where the acid stream contained $7.39 \mathrm{M} \mathrm{HNO}_{3}$, an erbium concentration of $0.0021 \mathrm{M}$ (substitute for Americium $^{8}$, equivalent to $0.507 \mathrm{~g} / \mathrm{L}$ of $\mathrm{Am}$ ) and a sodium concentration of $3.794 \mathrm{~g} / \mathrm{L}$. The acid and erbium concentrations will be maintained in this variability study and were approved by WSB-DA.

Table 2-2 Metals Concentrations from MOX and Maximums in WSB

\begin{tabular}{|c|c|c|c|c|c|}
\hline \multirow{2}{*}{ Metal } & \multicolumn{2}{|c|}{ Concentration (g/L) } & \multirow{2}{*}{ Metal } & \multicolumn{2}{c|}{ Concentration (g/L) } \\
\cline { 2 - 3 } \cline { 5 - 6 } & From MOX & $5 \mathrm{X}$ & & From MOX & $5 \mathrm{X}$ \\
\hline $\mathrm{Ag}$ & 11.7 & 58.5 & $\mathrm{Au}$ & 0.10 & 0.50 \\
\hline $\mathrm{Ba}$ & 0.8 & 4.00 & $\mathrm{Al}$ & 0.86 & 4.30 \\
\hline $\mathrm{Cd}$ & 0.13 & 0.65 & $\mathrm{Cu}$ & 0.15 & 0.75 \\
\hline $\mathrm{Pb}$ & 0.18 & 0.90 & $\mathrm{Ta}$ & 0.70 & 3.5 \\
\hline $\mathrm{Hg}$ & 0.003 & 0.015 & $\mathrm{~V}$ & 0.30 & 1.5 \\
\hline $\mathrm{Cr}$ & 0.54 & 2.7 & $\mathrm{As}$ & 0.003 & 0.015 \\
\hline $\mathrm{Ga}$ & 1.62 & 8.1 & \multicolumn{3}{|l}{} \\
\hline
\end{tabular}

Table 2-3 Previous Maximum Metals Basis for HAW Acid Stream

\begin{tabular}{|c|c|c|c|}
\hline Metal & $\mathrm{g} / \mathrm{L}$ & Metal & $\mathrm{g} / \mathrm{L}$ \\
\hline $\mathrm{Ga}$ & 1.050 & $\mathrm{Ca}$ & 3.78 \\
\hline $\mathrm{Na}$ & 3.794 & $\mathrm{Cd}$ & 0.135 \\
\hline $\mathrm{Ag}$ & 3.480 & $\mathrm{~K}$ & 5.95 \\
\hline $\mathrm{Ba}$ & 0.838 & $\mathrm{Mg}$ & 2.21 \\
\hline
\end{tabular}

Since, the contribution from sodium is small compared to the other metals stated in Table 2-3, sodium was not included as one of the variables in this study. The maximum concentrations of the chemicals that provide the acid and metals for this new HAW acidic waste stream are provided in Table 2-4. Note that the chemicals in blue in Table 2-4 are considered the "Other Metals", are maintained as a group, and are considered as a single variable in the variability study. Also note that the "Other Metals" composition is

\footnotetext{
* Kesterson, M., “Metals Limit From MOX to WSB”, e-mail, 9/15/2008, see Appendix A

† Schafner, J., “Re: Fw: Waste Constituents ICD”, e-mail, 9/18/2008, see Appendix B
} 
significantly different than that of the simulant described in Section 2.2.1.1. Additional information about this simulant can be found in Reference 9.

Table 2-4 Maximum Chemical Composition of HAW Acidic Waste Stream Simulant Used in this Variability Study

\begin{tabular}{|c|c|c|}
\hline Chemical Name & Compound & Target $(\mathrm{g})$ \\
\hline Nitric Acid & $\mathrm{HNO}_{3}(70.1 \%-15.8 \mathrm{~N}, 1.42 \mathrm{sg})$ & 664.278 \\
\hline Gallium Nitrate Hexahydrate & $\mathrm{Ga}\left(\mathrm{NO}_{3}\right)_{3} \times 6 \mathrm{H}_{2} \mathrm{O}$ & 42.268 \\
\hline Aluminum Nitrate & $\mathrm{Al}\left(\mathrm{NO}_{3}\right)_{3} \times 9 \mathrm{H}_{2} \mathrm{O}$ & 0.000 \\
\hline Silver Nitrate $(100 \%)$ & $\mathrm{AgNO}_{3}$ & 92.126 \\
\hline Copper Nitrate & $\mathrm{Cu}\left(\mathrm{NO}_{3}\right)_{2} \times 2.5 \mathrm{H}_{2} \mathrm{O}$ & 0.000 \\
\hline Erbium Nitrate Pentadydrate & $\mathrm{Er}\left(\mathrm{NO}_{3}\right)_{3} \times 5 \mathrm{H}_{2} \mathrm{O}$ & 0.925 \\
\hline Barium Nitrate & $\mathrm{Ba}\left(\mathrm{NO}_{3}\right)_{2}$ & 7.612 \\
\hline Calcium Nitrate Tetrahydrate & $\mathrm{Ca}\left(\mathrm{NO}_{3}\right)_{2} \times 4 \mathrm{H}_{2} \mathrm{O}$ & 22.271 \\
\hline Cadmium Nitrate Tetrahydrate & $\mathrm{Cd}\left(\mathrm{NO}_{3}\right)_{2} \times 4 \mathrm{H}_{2} \mathrm{O}$ & 1.784 \\
\hline Potassium Nitrate & $\mathrm{KNO}_{3}$ & 15.385 \\
\hline Magnesium Nitrate Hexahydrate & $\mathrm{Mg}\left(\mathrm{NO}_{3}\right)_{2} \times 6 \mathrm{H}_{2} \mathrm{O}$ & 23.308 \\
\hline Aluminum Nitrate & $\mathrm{Al}\left(\mathrm{NO}_{3}\right)_{3} \times 9 \mathrm{H}_{2} \mathrm{O}$ & 59.783 \\
\hline Copper Nitrate & $\mathrm{Cu}\left(\mathrm{NO}_{3}\right)_{2} \times 2.5 \mathrm{H}_{2} \mathrm{O}$ & 2.787 \\
\hline
\end{tabular}

\subsubsection{SELECTED METAL SUBSTITUTES}

The cost for gallium and silver is the bulk of the expenditure for full scale or integrated tests. Surrogate elements were selected and additional variability tests were determined, so as to establish if these replacement elements are suitable. Aluminum was selected to replace gallium and copper was selected to replace silver, as cost-saving replacement metals. Each of these replacement metals was selected since it is in the same quantum group as the metal it is replacing; thus, in each case, the same number of free electrons exists in the outermost shells. Elements in the same quantum group typically have similar chemical properties. The replacement of one element for the other was molar basis. Barium and cadmium were not included in the simulant used for the full-scale tests, but were included in the simulants for the variability testing.

\subsubsection{VARIABILITY STUDY}

The variables that were used in the factor space $^{9}$ for this variability study are provided in Table 2-5, and they are based on the starting composition of the acid solutions. The "other metals" are incorporated as a variable since their contribution is now fairly large. The composition of the "other metals" is provided in Table 2-6. A lower limit of zero is placed on all of the variables, thereby incorporating a water run or very dilute condition. Note that $\mathrm{Al}$ and $\mathrm{Cu}$ are present in the "other metals" and will remain as such. Additional tests will be performed to determine the impact of the substitution of $\mathrm{Al}$ for $\mathrm{Ga}$ and $\mathrm{Cu}$ for $\mathrm{Ag}$. 
Given the constraints on four variables-gallium, silver, nitrates and "others" - and the substitution of aluminum and copper for gallium and silver, respectively, a statistical design was developed to investigate for main effects and possible interactions. The baseline tests (16 total) investigate pair wise interactions between Ga, Ag, HNO3 and "others" in the HA waste. The "others" are metals that are added as a group. Replacing Ga with $\mathrm{Al}$ and Ag with $\mathrm{Cu}$ resulted in 34 tests and was based on a linear model of the major components with both single and double substitutions. Incorporating all the tests into one matrix after removing overlapping test points and adding replicates to determine variability in the measurement led to a total of 40 test points in the final test matrix, see Table 2-7. Two other HAW tests, HAW-0 and HAW-41 were made and processed to reflect the simulant used in the full scale tests as described in Section 2.2.1.1, but these points will not be considered as part of the variability test, but will be compared to the data generated in the variability study, e.g., was the mixing of this simulant bounding or representative.

Table 2-5 Variable for the Initial Factor Space

\begin{tabular}{|c|c|c|}
\hline Variable & Min Values & Max Values \\
\hline Solution Molarity & 0 & 7.39 Molar HNO3 \\
\hline Ga & 0 & 0.11618 Molar Ga \\
\hline $\mathrm{Ag}$ & 0 & 0.5423 Molar Ag \\
\hline “Other metals" & 0 & See Table 2-6 for breakdown 1.1032 ${\mathrm{M}\left(\mathrm{NO}_{3}\right)}$ \\
\hline
\end{tabular}

Table 2-6 Composition of Other Metals

\begin{tabular}{|c|c|c|c|}
\hline Metal & $\mathrm{g} / \mathrm{L}$ & Metal & $\mathrm{g} / \mathrm{L}$ \\
\hline $\mathrm{Ba}$ & 4.00 & $\mathrm{~K}$ & 5.95 \\
\hline $\mathrm{Cd}$ & 0.65 & $\mathrm{Mg}$ & 2.21 \\
\hline $\mathrm{Al}$ & 4.30 & $\mathrm{Ca}$ & 3.78 \\
\hline $\mathrm{Cu}$ & 0.75 & $\mathrm{Am} *$ & 0.507 \\
\hline
\end{tabular}

*Er will be used in place of Am, at equal molarity

To further limit variability in this study, the acidic solutions were neutralized/pH adjusted to a final $\mathrm{pH}$ value of 12, providing the same concentration (molar basis) of free hydroxides in the salt solution. This is also consistent with the full scale simulants, were a final $\mathrm{pH}$ value of 12 were targeted.

The response variable that was measured is the yield stress as determined using the vane method (see section 2.4.1.3). Three vane measurements on the same sample were performed. This response variable, specifically the first measurement, was statistically analyzed against the input/measured/calculated variables as listed in Table 2-8. The calculated undissolved solids were determined using equation [9], see Section 2.4.2. The molarity of the chemical or "others" was calculated by determining the number of moles of each prior to being neutralized/pH adjusted. Based on the dilution due to neutralization/ $\mathrm{pH}$ adjustment and grout formulation, the molarity was determined by dividing the starting moles with the final grout volumes. 
JMP Version 7.0.2 ${ }^{10}$ was used to determine the test matrix and to perform the statistical analyses.

Table 2-7 Final Test Matrix - Variability Study for the HA Waste Variability Study

\begin{tabular}{|c|c|c|c|c|c|c|}
\hline \multirow{2}{*}{ HAW } & \multicolumn{7}{|c|}{ Molarity } \\
\cline { 2 - 7 } & $\mathrm{HNO}_{3}$ & $\mathrm{Ga}$ & $\mathrm{Al}$ & $\mathrm{Ag}$ & $\mathrm{Cu}$ & Others \\
\hline 1 & 0 & 0 & 0 & 0 & 0 & 0 \\
\hline 2 & 0 & 0 & 0 & 0.5423 & 0 & 0 \\
\hline 3 & 3.695 & 0 & 0.05809 & 0.27115 & 0 & 0.5516 \\
\hline 4 & 7.39 & 0 & 0 & 0 & 0 & 1.1032 \\
\hline 5 & 0 & 0 & 0 & 0 & 0 & 0 \\
\hline 6 & 7.39 & 0 & 0 & 0.5423 & 0 & 0 \\
\hline 7 & 3.695 & 0.05809 & 0 & 0 & 0.27115 & 0.5516 \\
\hline 8 & 7.39 & 0 & 0 & 0 & 0.5423 & 1.1032 \\
\hline 9 & 0 & 0.11618 & 0 & 0 & 0 & 1.1032 \\
\hline 10 & 0 & 0 & 0 & 0 & 0.5423 & 0 \\
\hline 11 & 0 & 0.11618 & 0 & 0 & 0 & 0 \\
\hline 12 & 3.695 & 0.05809 & 0 & 0.27115 & 0 & 0.5516 \\
\hline 13 & 7.39 & 0 & 0.11618 & 0 & 0 & 1.1032 \\
\hline 14 & 7.39 & 0.11618 & 0 & 0 & 0 & 1.1032 \\
\hline 15 & 0 & 0 & 0.11618 & 0 & 0 & 0 \\
\hline 16 & 7.39 & 0.11618 & 0 & 0 & 0 & 0 \\
\hline 17 & 3.695 & 0.05809 & 0 & 0.27115 & 0 & 0.5516 \\
\hline 18 & 7.39 & 0 & 0.11618 & 0 & 0.5423 & 1.1032 \\
\hline 19 & 7.39 & 0.11618 & 0 & 0 & 0.5423 & 1.1032 \\
\hline 20 & 0 & 0 & 0.11618 & 0 & 0.5423 & 0 \\
\hline 21 & 0 & 0.11618 & 0 & 0.5423 & 0 & 0 \\
\hline 22 & 0 & 0 & 0 & 0 & 0 & 1.1032 \\
\hline 23 & 0 & 0 & 0 & 0.5423 & 0 & 1.1032 \\
\hline 24 & 7.39 & 0.11618 & 0 & 0 & 0.5423 & 1.1032 \\
\hline 25 & 7.39 & 0 & 0 & 0 & 0 & 0 \\
\hline 26 & 7.39 & 0.11618 & 0 & 0.5423 & 0 & 0 \\
\hline 27 & 0 & 0 & 0 & 0 & 0.5423 & 1.1032 \\
\hline 28 & 7.39 & 0 & 0 & 0.5423 & 0 & 1.1032 \\
\hline 29 & 0 & 0.11618 & 0 & 0.5423 & 0 & 1.1032 \\
\hline 30 & 7.39 & 0 & 0 & 0 & 0.5423 & 0 \\
\hline 31 & 3.695 & 0 & 0.05809 & 0 & 0.27115 & 0.5516 \\
\hline 32 & 0 & 0 & 0.11618 & 0 & 0 & 1.1032 \\
\hline 33 & 7.39 & 0 & 0.11618 & 0.5423 & 0 & 1.1032 \\
\hline 34 & 7.39 & 0.11618 & 0 & 0.5423 & 0 & 1.1032 \\
\hline 35 & 7.39 & 0 & 0.11618 & 0 & 0 & 0 \\
\hline 36 & 3.695 & 0 & 0.05809 & 0 & 0.27115 & 0.5516 \\
\hline 37 & 0 & 0 & 0.11618 & 0 & 0.5423 & 1.1032 \\
\hline 38 & 7.39 & 0 & 0.11618 & 0.5423 & 0 & 1.1032 \\
\hline 39 & 7.39 & 0.11618 & 0 & 0.5423 & 0 & 1.1032 \\
\hline 40 & 7.39 & 0 & 0.11618 & 0 & 0.5423 & 0 \\
\hline & & & & & & \\
\hline 5 & & & 0 & 0 & 0 & 0 \\
\hline
\end{tabular}


SRNL-STI-2009-00101, REVISION 0

Table 2-8 Variables Used to Determine Effect on Response Variable

\begin{tabular}{|c|c|}
\hline \multicolumn{2}{|c|}{ Parameters from Input data used to make Acidic Solutions } \\
\hline $\mathrm{HNO}_{3}$ Batch Sheet Molarity & Ag Batch Sheet Molarity \\
\hline Ga Batch Sheet Molarity & Cu Batch Sheet Molarity \\
\hline Al Batch Sheet Molarity & Others Batch Sheet Molarity \\
\hline $\mathrm{NO}_{3}$ Batch Sheet Molarity & \\
\hline \multicolumn{2}{|c|}{ Measured Properties of Acidic Solution } \\
\hline Wt\% total solids & Density \\
\hline \multicolumn{2}{|c|}{ Measured Properties of Neutralized/pH Adjusted Solution } \\
\hline Density & $\mathrm{pH}$ \\
\hline Wt\% soluble solids in supernate & Wt\% total solids in solution \\
\hline \multicolumn{2}{|c|}{ Calculated Variables in Neutralized/pH adjusted solution } \\
\hline \multicolumn{2}{|c|}{$\mathrm{Wt} \%$ undissolved solids in solution } \\
\hline \multicolumn{2}{|c|}{ Calculated Variables in grout } \\
\hline Zircon flour fraction & Cement fraction \\
\hline Water fraction & Neutralized $\mathrm{pH}$ adjusted solution fraction \\
\hline Ga molarity & Density of grout \\
\hline Ag molarity & Al molarity \\
\hline Er molarity & Cu molarity \\
\hline Ca molarity & Ba molarity \\
\hline K molarity & Cd molarity \\
\hline Na molarity & Mg molarity \\
\hline \multicolumn{2}{|c|}{$\mathrm{NO}_{3}$ molarity } \\
\hline \multicolumn{2}{|c|}{ Calculated Variables in grout - "Others" is grouped } \\
\hline Ga molarity & Al molarity \\
\hline Ag molarity & Cu molarity \\
\hline Na Molarity & Others Molarity \\
\hline
\end{tabular}

\subsection{PHYSICAL PROCESS STEPS}

There are three physical processes used in this task; making the acidified solutions, neutralization/ $\mathrm{pH}$ adjustment of the acid solution, and mixing of the neutralized/pH solution with dry materials into grout. Each of these tasks will be discussed separately.

\subsubsection{PROCESSING HAW ACID SOLUTIONS}

All the acid solutions were made using reagent grade chemicals as stated in Table 2-9. The acid solutions are made in one liter (1-L) volumetric flasks. Approximately $200 \mathrm{~mL}$ of deionized (DI) water is initially added and then the chemicals having the largest to least mass contributions are added. During the addition of each component, the contents are mixed until the solids have dissolved. At this point, DI water is added to the 1-L mark on the flask. Two subsamples of the acid solution are pulled and analyzed for total solids and density. If during the addition of metals complete dissolution is not achieved, then the total solids and density measurements were not performed. Mixing temperatures as high as $80{ }^{\circ} \mathrm{C}$ was used to try to dissolve all of the solids. Acid simulants HAW-4, 8, 12, 14, 18, 19, 24, 28, 33, 34, 38 and 39 contained undissolved solids after processing was complete. Appendix $\mathrm{C}$ contains an 
example acid batch sheet. Figure 2-2 provides examples of the resulting acid solutions. A completed batch sheet is provided in Reference 11 .

Table 2-9 Chemical Used to Make the HAW Acidified Solutions

\begin{tabular}{|c|c|c|}
\hline Chemical Name & Compound & Vendor \\
\hline Aluminum Nitrate Nonahydrate & $\mathrm{Al}\left(\mathrm{NO}_{3}\right)_{3} \times 9 \mathrm{H}_{2} \mathrm{O}$ & GFS Chemicals, Assay $100 \%$ \\
\hline Barium Nitrate & $\mathrm{Ba}\left(\mathrm{NO}_{3}\right)_{2}$ & Fisher Scientific \\
\hline Cadmium Nitrate Tetrahydrate & $\mathrm{Cd}\left(\mathrm{NO}_{3}\right)_{2} \times 4 \mathrm{H}_{2} \mathrm{O}$ & Fisher Scientific \\
\hline Calcium Nitrate Tetrahydrate & $\mathrm{Ca}\left(\mathrm{NO}_{3}\right)_{2} \times 4 \mathrm{H}_{2} \mathrm{O}$ & Fisher Scientific \\
\hline Cupric Nitrate & $\mathrm{Cu}\left(\mathrm{NO}_{3}\right)_{2} \times 2.5 \mathrm{H}_{2} \mathrm{O}$ & Fisher Scientific, Assay 98.5\% \\
\hline Erbium II Nitrate Pentahydrate & $\mathrm{Er}\left(\mathrm{NO}_{3}\right)_{3} \times 5 \mathrm{H}_{2} \mathrm{O}$ & Fisher Scientific, Assay 99.9 \\
\hline Gallium III Nitrate Hydrate & $\mathrm{Ga}\left(\mathrm{NO}_{3}\right)_{3} \times 6 \mathrm{H}_{2} \mathrm{O}$ & Alfa Aesar \\
\hline Magnesium Nitrate Hexahydrate & $\mathrm{Mg}\left(\mathrm{NO}_{3}\right)_{2} \times 6 \mathrm{H}_{2} \mathrm{O}$ & Fisher Scientific, Assay 100\% \\
\hline Nitric Acid & $\mathrm{HNO}_{3}\left(70.1 \%-15.8 \mathrm{~N}_{1} 1.42 \mathrm{sg}\right)$ & Fisher Scientific \\
\hline Potassium Nitrate & $\mathrm{KNO}_{3}$ & Fisher Scientific, Assay 99.6\% \\
\hline Silver Nitrate (100\%) & $\mathrm{AgNO}_{3}$ & Colonial Metals Company \\
\hline Sodium Nitrate & $\mathrm{NaNO}_{3}$ & Fisher Scientific, Assay 99.6\% \\
\hline
\end{tabular}

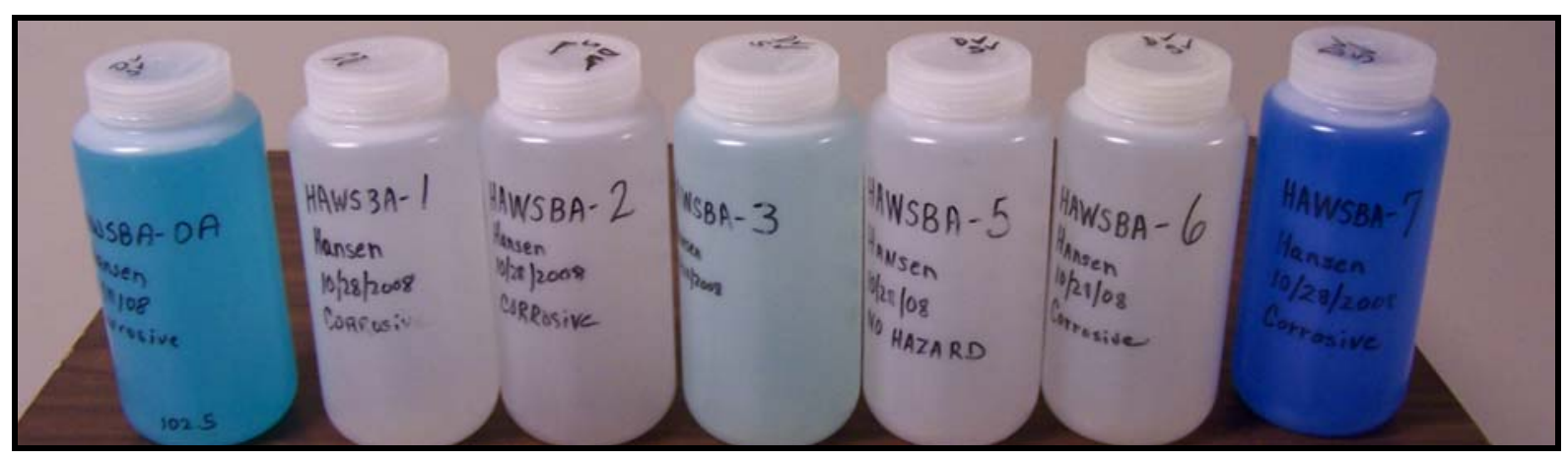

Figure 2-2 Sample Acid Solutions

\subsubsection{NEUTRALIZATION AND PH ADJUSTMENT}

During the neutralization/pH adjustment process for samples which were analyzed for total solids and density, a $800 \mathrm{~mL}$ batch of acid solution was used. For acid solutions which were not analyzed for total solids/density, the complete batch was used. The neutralization/pH adjustment was performed using a two liter glass reactor with a cooling jacket. A single four blade, $45^{\circ}$ pitch, $6 \mathrm{~cm}$ diameter and $2.8 \mathrm{~cm}$ blade width impeller was used for mixing. The inside diameter of the mixing vessel is approximately $11.75 \mathrm{~cm}$. The impeller was located slightly off-center and off-bottom, so as not to generate a centralized vortex that would result in bad mixing and a starting rotational speed of 120 revolutions per minute (RPM) for entrainment/dispersion of the base solution. A water bath was used to control the temperature of the cooling water jacket to $10{ }^{\circ} \mathrm{C}$ and to remove heat generated during the exothermic reaction between the sodium hydroxide, nitric acid, and nitrates. The flowrate of the cooling water bath is unknown. The $\mathrm{NaOH}$ solution used during this process was a $50.7 \mathrm{wt} \% \mathrm{NaOH}$ solution from Fisher Scientific. The targeted quantity of $\mathrm{NaOH}$ solution was based on the 
quantity required to neutralize the nitric acid and convert the metal nitrates to hydroxides in the acid solution based on the chemical composition provided in Table 2-9 and quantities used in the batch sheet. Therefore no titration of the solution to determine $\mathrm{NaOH}$ addition requirements was necessary. The rate of $\mathrm{NaOH}$ addition during mixing was slowed when approaching the final $\mathrm{pH}$ 12. The $\mathrm{pH}$ of the mixing system was measured using a calibrated $\mathrm{pH}$ probe as described in Section 2.4.6. During operations, the $\mathrm{NaOH}$ solution was added to the top surface of the fluid and entrained into the fluid via the vortex created during mixing. The $\mathrm{NaOH}$ addition to the reactor continued until the temperature of the mixing solution reached $60{ }^{\circ} \mathrm{C}$, at which point $\mathrm{NaOH}$ addition was stopped and then recommenced when the temperature was reduced to $55^{\circ} \mathrm{C}$. The exothermic reactions primarily occur at pHs below 1 to 2, after which no additional heating was observed based on the mixing system configuration. Visual observations of additional reactions were noted since the large precipitated flocs were breaking up into smaller flocs or color changes were noticed when additional $\mathrm{NaOH}$ was added to reach the final $\mathrm{pH}$ of 12 . During the $\mathrm{NaOH}$ addition, the agitator speed varied from the initial 120 RPM to 450 RPM upon completion of the mixing. This is due to the non-Newtonian behavior of some of the solutions during the neutralization/pH process. During $\mathrm{NaOH}$ addition for some of the samples between $\mathrm{pH} 5$ to 10 , the agitator speed was increased above the final agitator speed and these data were not required to be recorded. This increase in agitator speed was required due to cavern mixing. As the additional $\mathrm{NaOH}$ solution was incorporated into the slurry, the rheological properties decreased (visually), with a resulting decrease in required agitator speed. In all cases where there were undissolved solids in the acid solution during the neutralization/pH adjustment process, all of the solids dissolved prior to re-precipitating. The neutralization/pH adjustment process for HAW-24 is shown in Figure 2-3, which also includes a clear view of the impeller. This set of pictures also shows that large black precipitates are originally formed, but as additional $\mathrm{NaOH}$ solution is added, they are reduced in size. This could be due to other metal nitrates being trapped in the large particles, and as they react with the $\mathrm{NaOH}$; the larger particles break apart or the dissolution of the amphoteric species for Al and Ga would lead to the floc size being reduced. Note the slight vortex at the end of mixing with an agitator speed of 400 RPM. The resulting solutions were analyzed for total solids in the slurry, soluble solids in the supernate, density and rheology of the slurry. Undissolved solids were calculated as described in Section 2.4.3.

For the two solutions which contained silver as the only metal nitrate in the acidic solution, HAW-2 and HAW-6, the neutralization/pH adjustment process resulted in a black colored precipitated solids that quickly settled. This type of settling behavior was not observed in any of the other simulants that had any other metal nitrate blended with the silver nitrate. The following reaction was assumed to occur (the intermediate silver hydroxide step is skipped), $2 \mathrm{AgNO}_{3}+2 \mathrm{NaOH} \rightarrow \mathrm{Ag}_{2} \mathrm{O}+2 \mathrm{NaNO}_{3}+\mathrm{H}_{2} \mathrm{O}$. The density and total solids analyses of the neutralized/pH adjusted solution for these two test mixtures were biased high, leading to a grout batch that would be inconsistent with the other batches thereby containing a much higher concentration of dry powder (Portland cement and zircon flour). This was due to sampling, as excessive silver oxide was being sampled. To correct for the density and total solids in these samples, SRNL calculated the mass fraction of $\mathrm{NaNO}_{3}$ in the supernate assuming that all of the $\mathrm{NaOH}$ solution would react with the $\mathrm{AgNO}_{3}$. The additional water was also included for dilution purposes. The calculated mass fraction of $\mathrm{NaOH}$ in solution agreed well with the measured soluble solids in the supernate. SRNL used published data ${ }^{12}$ to 
determine the density of the $\mathrm{NaNO}_{3}$ solution for the given mass fraction of $\mathrm{NaNO}_{3}$. SRNL used the density of silver oxide, $7.143 \mathrm{~g} / \mathrm{mL}^{\ddagger}$. The mass fractions of $\mathrm{NaNO}_{3}$ solution and $\mathrm{Ag}_{2} \mathrm{O}$ were calculated. The density of the resulting slurry was determined using volume additivity (see equation [11], Section 2.4.3 as an example). A completed batching sheet is provided in Reference 11.

${ }^{\ddagger}$ CRC Handbook of Chemistry and Physics, $71^{\text {st }}$ ed. (1991) 


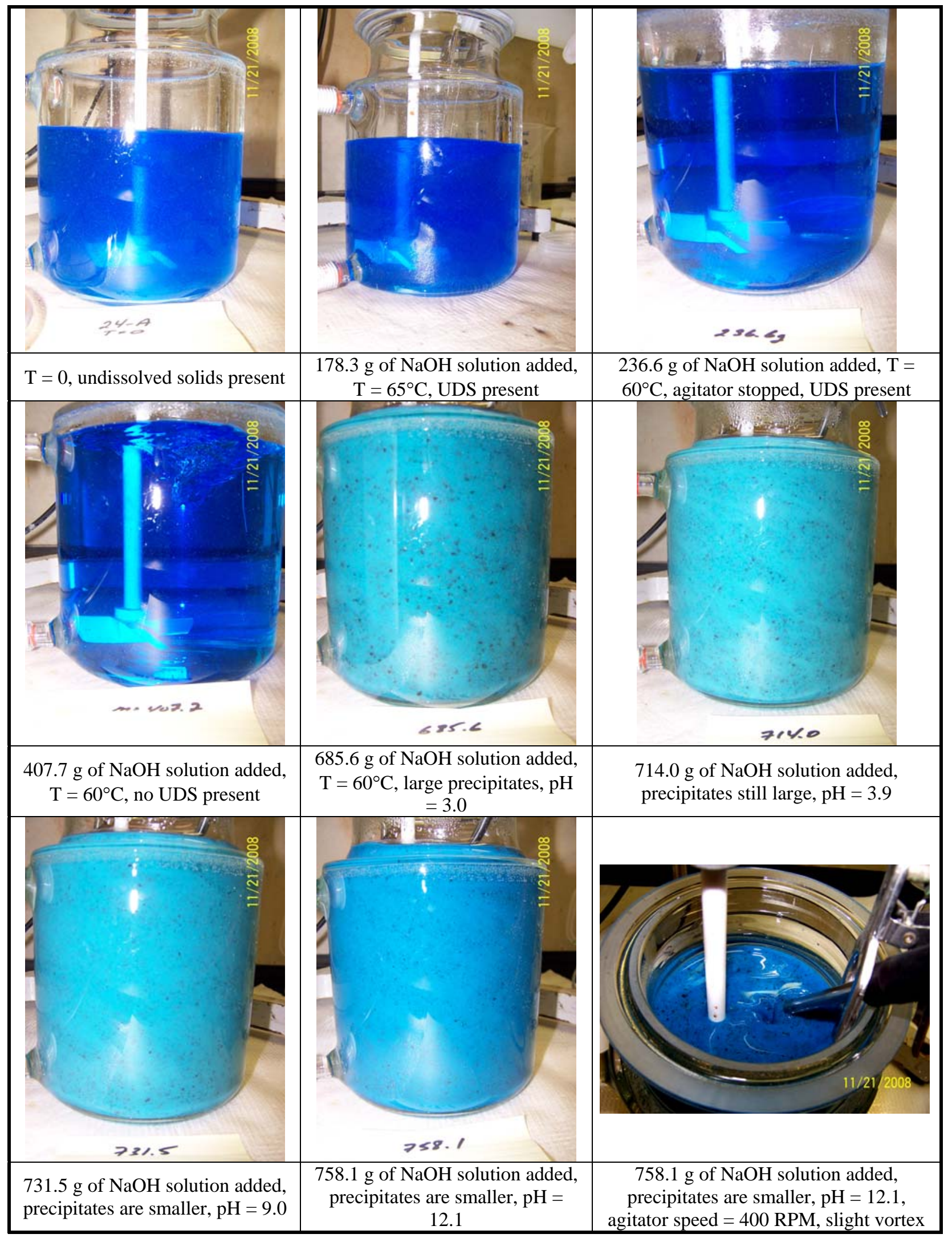

Figure 2-3 Neutralization/pH adjustment Process for HAW-24 


\subsubsection{GROUT MIXING}

During the full scale "proof of concept" tests at the vendor's shop, ${ }^{5}$ a conventional agitator design shown in Figure 2-4 was used to produce grout mixtures. The mode of operation was to initially agitate the dry materials in the 55 gallon drum so as to fluidize them by increasing the agitator speed from 50, to 100, and finally to 150 RPM for one minute at each speed. Immediately after the dry materials reached final speed, 75 percent of the HAW simulant was added and the agitator was started at 150 RPM and was maintained at this speed for 30 minutes after fluid addition was compete. The type of testing performed was used to determine a mixing speed that can be utilized for all batch types and was tested with a simulant LAW in the "proof of concept" tests. In essence, the concept of using a single mixing speed was sufficient to produce well mixed grout mixtures.

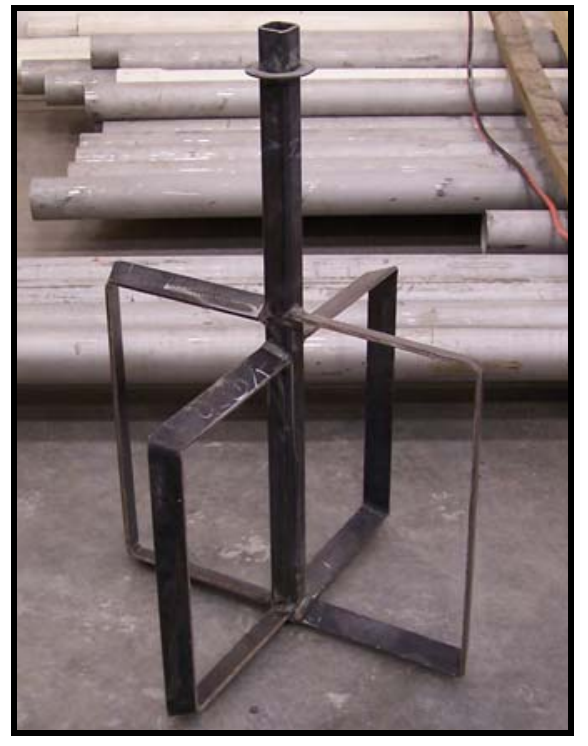

Figure 2-4 Agitator Used In "Proof of Concept" Mixing Tests

Discussions with WSB-DA indicate that 55 gallon drums will be filled with a predetermined amount of dry material. The basis for the quantity of materials to place in the 55 gallon drum has yet to be determined.

The mixing employed by SRNL used a mixing system that provided constant mixing speeds, similar to that employed during the "Proof of Concept" Mixing Tests and to maintain a specific mixing volume for all grout batches. This mixing process was selected by SRNL based on the method of mixing employed by Mid-Columbia Engineering (MCE) ${ }^{5}$, where a constant speed is used for mixing, inconsequential of the material properties during mixing. The constant volume was used to remove any variability on batch size. Due to the open mixing system (bowl), the lowest mixing speed (\#1) must be used to initially mix the liquid and solids, if not, initial mixing at intermediate speed \#2 would discharge an appreciable portion of the material from the bowl. The process for preparation of the HAW batches was controlled to be as repeatable and consistent as possible for each test. The specific blend of Portland cement and zircon flour for each test was prepared and stored in a sealed plastic bag prior to preparation of each test mix. The same source of Portland cement (Holcium, Type I) 
and zircon flour (Princess, $<325$ mesh) was used for all of the grout batches. The liquid simulant and bagged dry materials were stored in the lab where the mixing test was to be performed for ample time prior to initiation of the tests to assure each was at ambient conditions. The temperatures of the simulant and dry components were measured and recorded just prior to being added to the mixer at the start of the test. For each test batch composition, batch material temperatures, mixing durations, elapsed time to initiation of rheology vane measurements, and rheology maximum stress values were recorded.

The mixing tests were performed using a $1 / 6^{\text {th }}$ horsepower Hobart N-50 mixer having three defined mixing speeds, low (\#1), intermediate (\#2) and high (\#3). The Hobart N-50 mixing specifications are provided in Table 2-10, where the agitator and attachment rotational speeds are provided. ${ }^{13}$ The Hobart $\mathrm{N}-50$ is an orbital mixer. The agitator speed is the speed at which the mixing blade rotates and the attachment speed is the speed in which the mixing blade rotates around the mixing bowl. To begin each mixing test, approximately $75 \%$ of the liquid was placed into the mixer bowl. Next, the entire batch of cement and zircon flour blend was added to the mixing bowl and spread out evenly. Then the remaining liquid is poured over the top of the cement/zircon flour blend. The mixing bowl was raised into position and the mixer was started at its low speed (\#1) and mixed for two minutes. Material adhered to the upper portion of the mixing bowl or paddle blade was scraped back into the grout mixture during the brief stoppages between mixing speed adjustments. The mixer was then set to speed \#2 and allowed to mix for five minutes. A timer was used for noting the elapsed time from this point forward of each event sequence. Elapsed times for various events were referenced back to the start of the five-minute mixing evolution at speed setting \#2.

Table 2-10 Hobart N50 Mixer Specifications

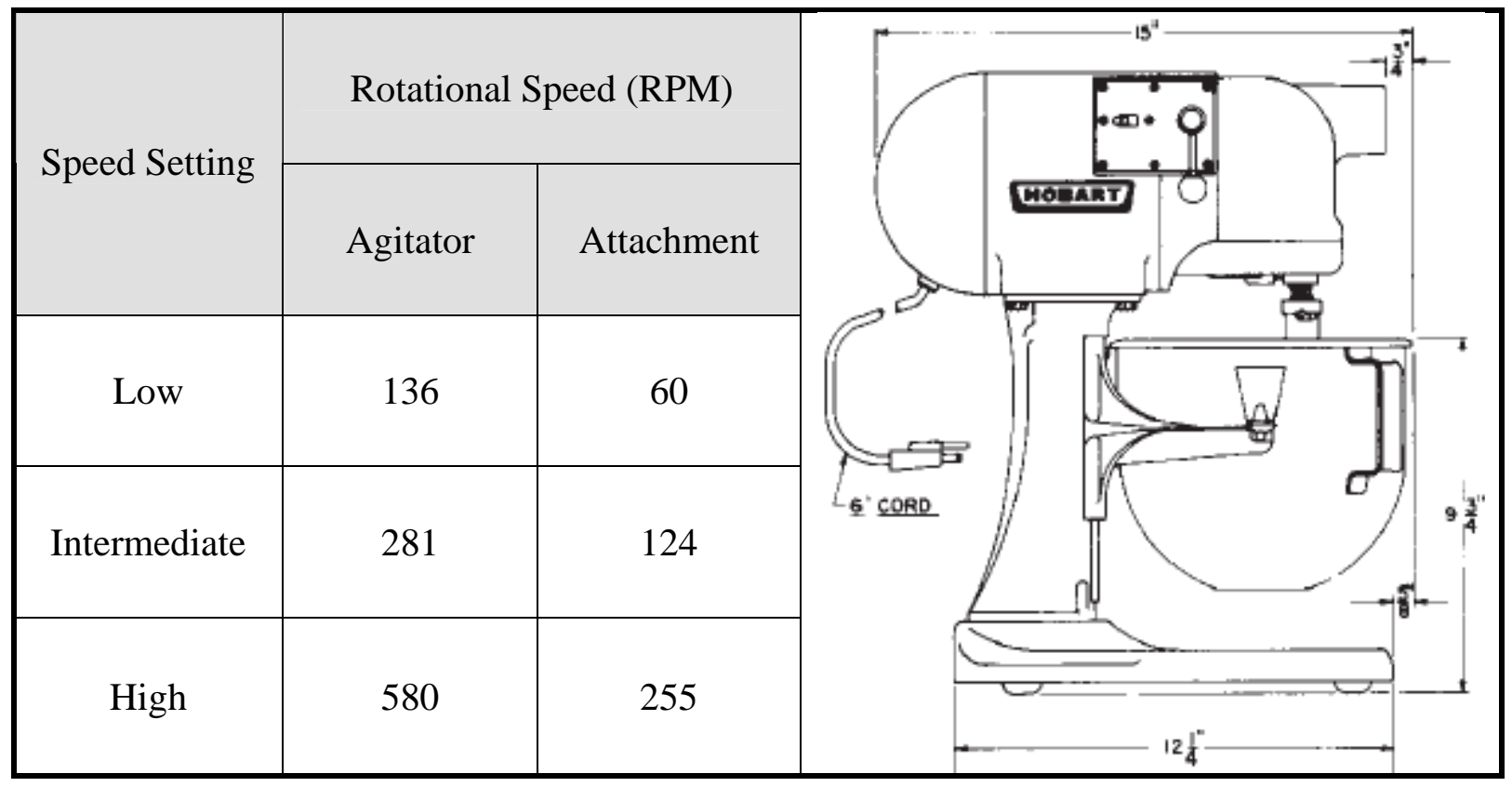

Upon completion of mixing, the mixing bowl and blade were removed from the Hobart mixer and the grout scraped from the blade back into the bowl. The temperature of the grout was measured and recorded. The grout was then ladled into a $1000 \mathrm{ml}$ plastic cup while the 
cup was forcefully rapped to assist releasing air trapped in the grout. When the cup was filled with 800 to $900 \mathrm{~mL}$ of grout, the cup was lifted into the measurement position for the first vane measurement. At the conclusion of the first vane measurement, the sample cup was lowered and repositioned for a second measurement. A third vane measurement was also performed. Approximately 30 seconds were required to position the sample prior to the start of each vane measurement.

At the conclusion of the vane measurements, the grout sample in the $1000 \mathrm{~mL}$ cup was used to provide feed for subsequent measurements. Two 2-inch cylinder sample plastic containers and one 2-inch cube plastic container were loaded with grout, during which time the containers were tapped to remove as much entrained air as possible. The cylinders were capped and the square covered with Parafilm. The cylinder samples were used for bleed and density measurements. The square sample was used for set measurement. Completed batching sheets are provided in Reference 11.

Figure 2-5 shows the processing of the grout using the Hobart mixer as describe above. For all grout batches, the water to Portland cement (W/C) ratio was maintained at 0.30 and the zircon flour to Portland cement (Z/C) ratio was 1/12. A targeted batch volume of $1400 \mathrm{~mL}$ was determined to be achievable using the Hobart mixer capacity. The densities of the Portland cement and zircon flour were assumed to be 3.14 and $4.79 \mathrm{~g} / \mathrm{mL}$, respectively. The density of each grout mixture was determined using the method described in Section 2.4.3. This density was used to determine the mass of grout required and based on the required W/C and $\mathrm{Z} / \mathrm{C}$ ratios, the masses of neutralized/pH adjusted solution, Portland cement, and zircon flour were determined. 


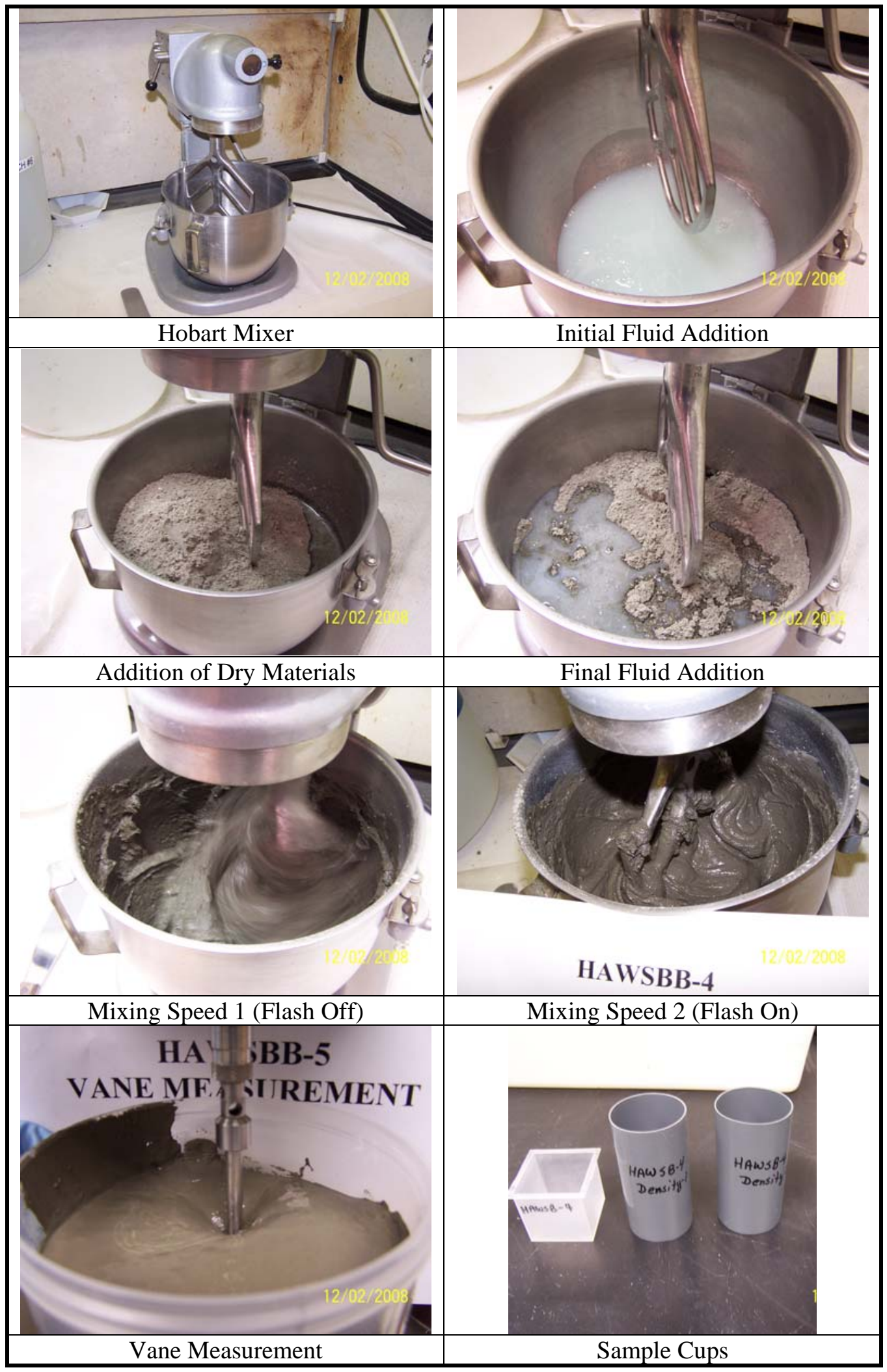

Figure 2-5 Agitator Used In "Proof of Concept Mixing Tests" 


\subsection{MEASUREMENTS}

The measurements to support this task included rheology, solids, density, bleed water, set, $\mathrm{pH}$ and temperature. Each of these measurements is discussed in detail, in this section.

\subsubsection{RHEOLOGY MEASUREMENT}

\subsubsection{Instrumentation}

The Haake RS150 rheometer was used to perform flow curve and vane measurements in this task. The RS150 specifications are provided in Table 2-11.

Table 2-11 Specifications of the RS150

\begin{tabular}{|c|c|c|c|}
\hline Specification & Units & RS150 \\
\hline Maximum Torque & $\mathrm{N}-\mathrm{m}$ & 0.15 & Rheometer \\
\hline Minimum Torque & $\mathrm{N}-\mathrm{m}$ & $0.5 \mathrm{E}-7$ \\
\hline Maximum Speed & $\mathrm{RPM}$ & 1200 & \\
\hline & & \\
\hline
\end{tabular}

\subsubsection{Flow Curve Measurements Using Concentric Geometry}

Flow curve measurements were performed on the neutralized/pH adjusted HAW simulants using a Z41 cylindrical rotor. The Z41 rotor specifications are shown in Table 2-12. A cooling/heating bath is used to control the temperature of the rotor/sample/cup at $25{ }^{\circ} \mathrm{C}$. The rheometer is programmed to control the rate at which the rotor spins and measures both the rotational speed and the torque (the resistance to shear). The shear stress at the wall of the rotating rotor is then calculated (internally by the Haake ${ }^{\mathrm{TM}}$ software) based on the product of the measured torque and geometry (A-factor) of the bob. The shear rate of the rotating rotor is calculated as the product of the measured speed and geometry (this M-factor assumes the fluid is Newtonian) of the rotor. The A-factor, M-factor, shear rate range and the linear ramp up time, hold time at maximum shear rate, and linear ramp down time are provided in Table $2-12$. The linear ramp rates (or acceleration) is $\pm 200 \mathrm{sec}^{-1}$ per minute. 
Table 2-12 Z41 Rotor Specification and Program Ramp Rates

\begin{tabular}{|c|c|}
\hline $\begin{array}{c}\text { Rotor specification and programming input } \\
\text { variables }\end{array}$ & \\
& \\
& \\
\hline Rotor radius (mm) & $\mathrm{R}_{\mathrm{i}}=20.71$ \\
\hline Cup Radius (mm) & $\mathrm{R}_{\mathrm{a}}=21.7$ \\
\hline Height of rotor (mm) & $\mathrm{L}=55$ \\
\hline Distance rotor from bottom of cup $(\mathrm{mm})$ & $\mathrm{D}=3$ \\
\hline Typical Sample Volume $\left(\mathrm{cm}{ }^{3}\right)$ & 6750 \\
\hline A factor (Pa/Nm) & 22.40 \\
\hline M factor (s $\left.\mathrm{s}^{-1} / \mathrm{rad} \mathrm{s}^{-1}\right)$ & $0-1000$ \\
\hline Measuring Range (s $\left.{ }^{-1}\right)$ & 5 \\
\hline Linear ramp up time (min) & 1 \\
\hline Hold time (min) & 5 \\
\hline Linear ramp down time (min) & \\
\hline
\end{tabular}

Prior to any flow curve measurement, the rotor and cup are inspected for visual damage that could potentially impact the rheological measurement. A National Institute of Standards and Technology (NIST) traceable Newtonian oil standard is then used to verify the operability of the rheometer at a measurement temperature of $25^{\circ} \mathrm{C}$. The resulting flow curves are analyzed as a Newtonian fluid and the calculated viscosity is compared to that of the NIST traceable Newtonian oil standard. The rheometer is considered operable if the calculated viscosity is within $\pm 10 \%$ of the NIST traceable Newtonian oil standard viscosity. The NIST traceable Newtonian oil standard was run each day when flow curve measurements were performed.

The flow curves are analyzed using both a Newtonian and Bingham Plastic fluid models. The average of the model fits and the square of the linear-correlation coefficient $\left(\mathrm{R}^{2}\right)$ will be provided. The Newtonian and Bingham Plastic fluid models are shown as equations [1] and [2] respectively.

$$
\begin{aligned}
\tau & =\mu \dot{\gamma} \\
\tau & =\tau_{o}+\mu_{\infty} \dot{\gamma}
\end{aligned}
$$

where $\tau=$ measured shear stress $(\mathrm{Pa})$

$\dot{\gamma}=$ measured shear rate $\left(\mathrm{sec}^{-1}\right)$

$\mu=$ Newtonian viscosity (Pa-sec or centipoises)

$\tau_{o}=$ Bingham Plastic Yield Stress $(\mathrm{Pa})$

$\mu_{\infty}=$ Bingham Plastic Viscosity or Infinite Viscosity (Pa-sec or centipoises) 


\subsubsection{Yield Stress Measurement Using Vane Geometry}

Vanes have been used to measure the yield stress of non-Newtonian fluids as shown in Figure 2-6. ${ }^{14,15,16,17,18,19,20}$ The vane is inserted into the fluid and rotated at a very slow speed. The surface area used to determine the shear stress is the surface area produced by the vane, which is cylindrical. It has been shown that this is a good assumption for determining the yield stress of the fluid as the vane rotates through it. ${ }^{18,20}$ Equation [3] assumes the stress is constant on all surfaces. The shearing due to the immersed section of the vane shaft, stress contribution of the immersed section of the shaft, and the wall effects are negligible when meeting the criteria as shown in Figure 2-6. The length of immersed shaft will need to be considered if its length starts to impact the measured stress. The exclusion of the shear stress contribution of the immersed shaft length over-estimates the shear stress. For the samples measured in this task, the shaft was immerged up to the point where the shaft was turned in.

$$
\tau=\frac{\Gamma}{\frac{\pi \cdot D^{3}}{2}\left(\frac{H}{D}+\frac{1}{3}\right)}=A \cdot \Gamma
$$

$$
\text { Where } \begin{aligned}
\Gamma & =\text { measured torque }(\mathrm{N}-\mathrm{m} \text { or } \% \text { torque }) \\
\mathrm{D} & =\text { diameter of vane }(\mathrm{m}) \\
\mathrm{H} & =\text { height of vane }(\mathrm{m}) \\
\mathrm{A} & =\text { geometric constant }\left(\mathrm{m}^{3} \text { or } \mathrm{Pa} / \% \Gamma\right)
\end{aligned}
$$

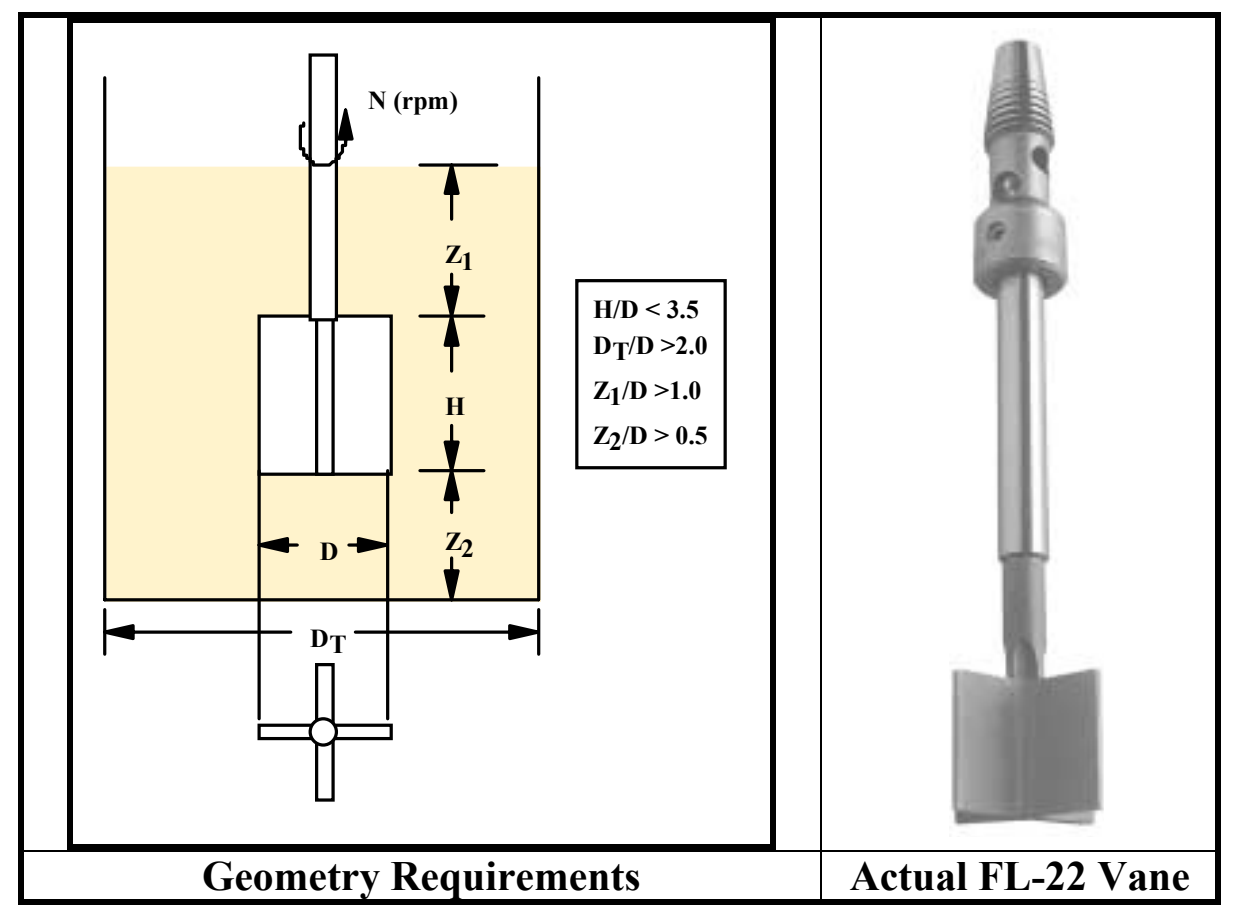

Figure 2-6 Vane Requirements and Actual Vane

A typical stress versus time (or displacement) curve is shown in Figure 2-7. The initial response for a non-Newtonian fluid having a yield stress is typically linear with a slope that 
is called the Hookean elastic modulus $(G)$. The point of departure from this linear region, called the static yield stress, ${ }^{14}$ occurs when the fluid starts to transition from a fully elastic to viscoelastic behavior. At the maximum stress, the behavior of the material transitions between viscoelastic and fully viscous and is called the yield stress (also known as the dynamic yield stress). This yield stress is the recorded value.

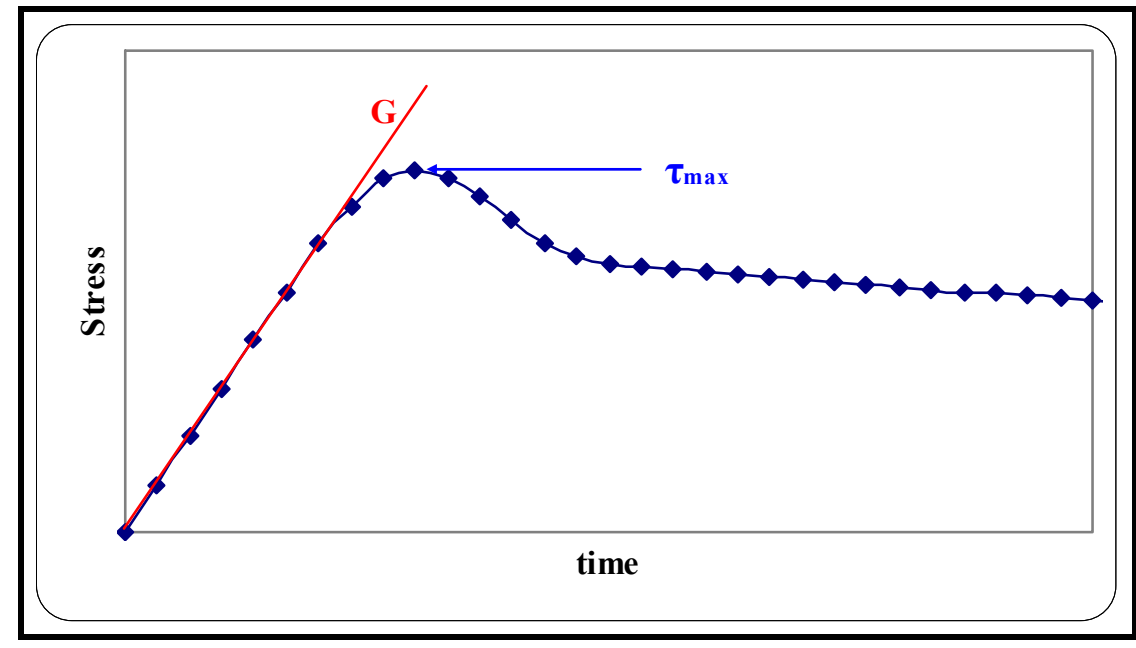

Figure 2-7 Typical Vane Torque versus Time/Displacement Curve

The vane dimensions used in this task were $\mathrm{D}=\mathrm{H}=16 \mathrm{~mm}$. The A factor for this vane was calculated and used in the RS150 to calculate the shear stress from the measured torque, given the measured torque is in $\mathrm{N}-\mathrm{m}$. The A factor used is shown in equation 4.

$$
A=\frac{A}{N \cdot m}=\frac{2}{\pi \cdot(0.016 m)^{3} \cdot\left(\left(\frac{16}{16}\right)+\frac{1}{3}\right)} \cdot \frac{N \cdot m}{N \cdot m} \cdot \frac{P a}{\frac{N}{m^{2}}}=116,568 \frac{P a}{N \cdot m}
$$

The targeted rotational speed of 0.3 RPM was selected from literature ${ }^{14,15}$ and from previous experience gained in performing such measurements for the River Protection Project -Waste Treatment Plant ${ }^{21}$. The $\mathrm{M}$ factor for this vane was set at $1.0 \mathrm{sec}^{-1} /\left(\mathrm{rad} \cdot \mathrm{s}^{-1}\right)$. The shear rate, an input variable into the rheometer, was determined using equation [5]. Hence, a rotational speed of 0.3 RPM equals a shear rate of $0.031 \mathrm{sec}^{-1}$ and this value was used for all vane measurements. The rotational speed was also visually verified at approximately 0.3 RPM and each measurement took 90 seconds to perform.

$$
\dot{\gamma}=\frac{2 \pi}{60} \cdot n=\frac{2 \pi}{60} \cdot 0.3=0.031 \frac{1}{\mathrm{sec}}
$$

The fresh grout sample was placed into a $1000 \mathrm{~mL}$ wide mouth jar, filled to approximately 80 to 90 percent full. During the addition of the fresh grout to the jar, the jar was manually rapped to assist in removing entrained air that resulted as the fresh grout was made. The sample was then lifted into position, where the vane was submerged to the point where the diameter of the shaft changed. After their measurement was complete, the sample was 
lowered, and rotated to a fresh position and raised for a subsequent measurement. A total of three measurements were obtained from each sample.

A $1400 \mathrm{~mL}$ blend of dry materials (Z/C was 1/12) at a water to cement ratio of 0.30 was used on a daily basis to provide confidence that the grout mixer and rheometer were operating consistently when grout was being made. This mixture was made and analyzed prior to processing any WSB grout samples.

\subsubsection{SOLIDS ANALYSIS}

The weight percent total solids in the fluid (wt\% TS) and the dissolved solids in the supernate (wt\% DSS) were determined using a Mettler Toledo HR83 Halogen Moisture analyzer. This moisture analyzer uses a load cell that continuously measures the mass of the sample during the measurement. The moisture is driven off using a halogen heat lamp that is controlled by an infrared thermometer. The mass of a sample pan is first measured and the weight tarred. Approximately a 1.5 to 3 gram sub-sample of the acid or neutralized/pH adjusted sample is placed onto the sample pan and this mass is recorded by the analyzer. The temperature of the sample is then ramped to $105{ }^{\circ} \mathrm{C}$ and maintained at $105{ }^{\circ} \mathrm{C}$ throughout the measurement. The measurement stops when the weight of the sample does not change more than one milligram over a 140 second period and this final mass is recorded by the analyzer. The wt $\%$ TS or wt\% DSS is then determined by taking the ratio of the final mass to initial mass and multiplying this value by $100 \%$. The analyzer load cell is checked on a daily basis (when used) using a 2.0 gram weight and functionally checked using a $8.0 \mathrm{wt} \% \mathrm{NaCl}$ solution.

The wt $\%$ DSS is only measured if the neutralized/pH adjusted sample contains undissolved solids. For samples which have no undissolved solids, the wt\% TS is the same as the wt\% DSS. To obtain a sample of the supernate, a homogenized sample of the fluid is processed through a $0.41 \mu \mathrm{m}$ filter to remove the undissolved solids.

The wt\% undissolved solids in the fluid (wt\% UDS) of neutralized/pH adjusted fluids were calculated using the wt\% TS and wt\% DSS results. The analysis is based on using conservation of mass and is shown below. Equation [6] is the total mass of solids $\left(\mathrm{M}_{\mathrm{TS}}\right)$ in a sample and is the sum of the mass of undissolved solids in the sample $\left(\mathrm{M}_{\mathrm{UDS}}\right)$ and mass of soluble solids in the sample $\left(\mathrm{M}_{\mathrm{SS}}\right)$. Equation [7] is the total mass $\left(\mathrm{M}_{\mathrm{T}}\right)$ of the sample, which is the sum of $\mathrm{M}_{\mathrm{UDS}}$ and mass of supernate in the sample ( $\left.\mathrm{M}_{\mathrm{SUPT}}\right)$. The mass of soluble solids in the sample can be determined by multiplying the mass of the supernate in the sample by the ratio of the mass of the dissolved solids in the supernate by that of the total mass of supernate, equation [8]. Substituting the mass of the supernate in the sample from equation [7] into the first equation in equation [8] yields the second equation in equation [8]. Substituting equation [8] into equation [4], dividing by total mass, and solving for the mass ratio of $\mathrm{M}_{\mathrm{UDS}} / \mathrm{M}_{\mathrm{T}}$ yield the relationship used by SRNL to determine the wt\% UDS, equation [9]. There are no error analyses performed for these results, but it can be calculated by taking the total derivative of the equation of interest and using the errors calculated from the wt $\%$ TS and wt\% DSS analyzes. A minimum of duplicate samples are measured for the wt\% TS 
and wt\% DSS, and the average, standard deviation and percent relative standard deviation are calculated.

$$
\begin{aligned}
& M_{T S}=M_{U D S}+M_{S S} \\
& M_{T}=M_{U D S}+M_{S U P T} \text { or } M_{S U P T}=M_{T}-M_{U D S} \\
& M_{S S}=M_{S U P T} \cdot \frac{M_{D S S}}{M_{S U P}} \text { or } M_{S S}=\left(M_{T}-M_{U D S}\right) \cdot \frac{M_{D S S}}{M_{S U P}} \\
& \frac{M_{U D S}}{M_{T}}=\frac{M_{T}}{M_{D S S}} \frac{M_{S U P}}{M_{S S S}} \text { or } f_{U D S}=\frac{f_{T S}-f_{D S S}}{1-f_{D S S}} \text { or } w t \%_{U D S}=\frac{w t \%_{T S}-w t \%_{D S S}}{100 \%-w t \%_{D S S}} \cdot 100 \% \\
& \text { where } f_{T S}=\frac{M_{T S} \text { or } w t \%_{T S}=f_{T S} \cdot 100 \% \text { (fraction or wt } \% \text { total solids in fluid), }}{M_{T}} \\
& f_{D S S}=\frac{M_{D S S}}{M_{S U P}} \text { or } w t \%_{D S S}=f_{D S S} \cdot 100 \% \text { (fraction or wt } \% \text { dissolved solids in supernate), } \\
& f_{U D S}=\frac{M_{U D S}}{M_{T}} \text { or } w t \%_{U D S}=f_{U D S} \cdot 100 \% \text { (fraction or wt } \% \text { undissolved solids in fluid). }
\end{aligned}
$$

\subsubsection{DENSITY MEASUREMENT AND CALCULATIONS}

The densities of the acid and neutralized/pH adjusted solutions were measured using the Anton Paar DMA 4500 density/specific gravity meter. A sample is pushed into the density analyzer u-tube and the sample temperature controlled to $25^{\circ} \mathrm{C}$. A vibration is then induced on one end of the u-tube and the frequency is measured at the other end. The density of the sample is determined by the shift in the measured frequency. The density analyzer is functionally checked on a daily basis (when used) with DI water. All measurements were performed in duplicates at $25^{\circ} \mathrm{C}$.

If the neutralized/pH solutions contained undissolved solids which were too large to process using the DMA 4500 or settle too quickly, the density was measured using a specific density cup (Figure 2-8), which has a known volume ${ }^{\S}$ at a given temperature. The cup has a volume of $8.32 \mathrm{~cm}^{3}$ at $25{ }^{\circ} \mathrm{C}$. The mass of the cup/cap are weighed first. A sample is then placed into the cup, almost completely filling the cup. The cap (tapered inside) is then placed on top of the cup and excess fluid is forced through a hole located in the center of the cap as the cap is pressed into the cup. The excess fluid is cleaned from the top of the cap and the

\footnotetext{
$\S$ Volume quantified at $25^{\circ} \mathrm{C}$ per ANSI Z540-1, “Calibration Laboratories and Measuring and Test Equipment General Requirements-Replaces Mil-Std-45662”.
} 
cup/cap/sample weighed. The density of the sample is calculated using equation [10]. The sample is measured twice and the results averaged.

$$
\rho=\frac{M_{\text {sample_cup_cap }}-M_{\text {cup_cap }}}{V_{\text {cup }}}\left(\mathrm{g} / \mathrm{cm}^{3}\right)
$$

De-ionized (DI) water samples were analyzed at $25{ }^{\circ} \mathrm{C}$ prior to proceeding with the neutralized/pH adjusted samples.

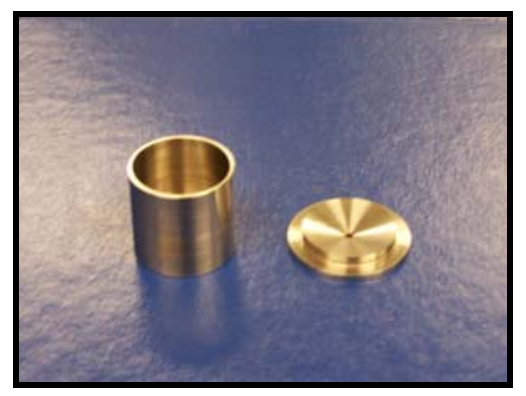

Figure 2-8 Specific Density Cup

For fluid samples that can not be measured, such as containing acidic solutions containing undissolved solids, the density of the fluid will be calculated by dividing the mass of material added to the volumetric mark by the volume of the volumetric mark.

The densities of the cured grouts were measured using cylindrical sample bottles having two inch diameters, an overall height of four inches and a flat bottom. The fresh grout samples were loaded into the sample bottles in the same manner as that for the vane measurements. The objective was to remove as much entrained air by tapping the sample bottle and leveling the top surface of the grout prior to curing. After curing for 3 to 4 days, the sample was removed from the sample bottle, weighed, and four diameter and three height measurements were made (see Figure 2-9). The measurements were averaged to calculate the volume. The density was then calculated by dividing the mass by the volume. Duplicate samples were run.

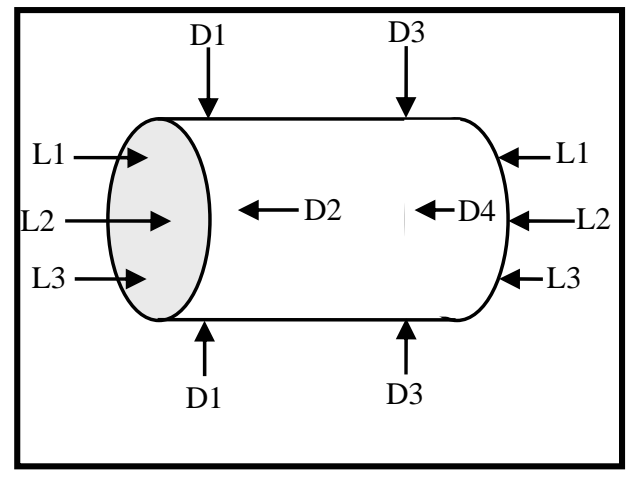

Figure 2-9 Measurement Points to Determine Grout Volume

The densities of the fresh grout were also determined using volume additivity, equation [11], 
since the actual processing of the grout can entrain air, resulting in false and typically low densities.

$$
\rho_{\text {grout }}=\left(\frac{f_{\text {cement }}}{\rho_{\text {cement }}}+\frac{f_{\text {Zircon_flour }}}{\rho_{\text {Zircon_flour }}}+\frac{f_{\text {Salt_solution }}}{\rho_{\text {Salt_solution }}}\right)^{-1}\left(\mathrm{~g} / \mathrm{cm}^{3}\right)
$$

where: $f_{\text {cement }}=$ calculated mass fraction of cement in grout mixture

$f_{\text {Zircon_flour }}=$ calculated mass fraction of zircon flour in grout mixture

$f_{\text {Salt_solution }}=$ calculated mass fraction of salt solution in grout mixture

$\rho_{\text {cement }}=$ density of cement, provided in section $(\mathrm{g} / \mathrm{ml})$

$\rho_{\text {Zircon_flour }}=$ density of zircon flour, provided in section $(\mathrm{g} / \mathrm{ml})$

$\rho_{\text {Salt_solution }}=$ density of salt solution, measured $(\mathrm{g} / \mathrm{ml})$

$\rho_{\text {grout }}=$ density of grout mixture $(\mathrm{g} / \mathrm{ml})$

\subsubsection{BLEED WATER}

Fresh grout samples were prepared in the same manner as that for grout density measurements, but were placed into 2" cubes rather than the 2" cylinders. The cubes were covered/secured with Parafilm to eliminate or minimize evaporation. After 24 hours of curing, the Parafilm was removed and any free liquid captured and weighed. The volume of the fluid is then estimated using the density of the salt solution ${ }^{* *}$ by dividing the measured mass by the density. A single bleed water sample was performed.

\subsubsection{SET}

The fresh grout sample was prepared using the same method as described for bleed water. After three days of setting, a set measurement was performed using a modified Vicat Needle $^{22}$ as shown in Figure 2-10. The needle (2 mm diameter) is placed and secured at the surface of the grout and the position indicator set to zero. The needle assembly, which has a total mass of 300 grams is released and the travel distance is measured. If the distance of travel is less than $10 \mathrm{~mm}$, then the grout is considered set. ${ }^{22}$ In these tests, a $1 \mathrm{~mm}$ travel distance was used as the basis for set.

\footnotetext{
${ }^{* *}$ Previous experience dealing with bleed water indicates that using the density of the fluid utilized to make the grout is appropriate, especially for fluids that contain no undissolved solids. For fluids which contain undissolved solids, this estimate would be slightly non-conservative.
} 


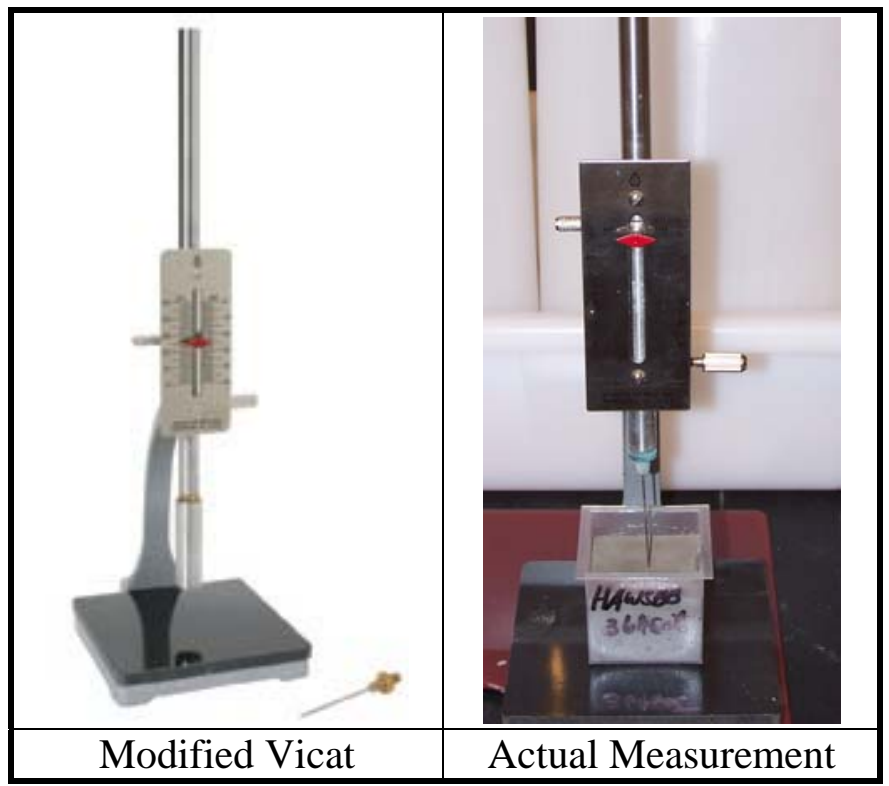

Figure 2-10 Modified Vicat Needle

\subsubsection{PH}

The $\mathrm{pH}$ of the solution during the neutralize/pH process was measured using an IQ Scientific Instruments $\mathrm{pH}$ meter fitted with an IQ Scientific Instruments stainless steel electrode reference $\mathrm{pH}$ probe. The functionality of the $\mathrm{pH}$ meter and probe was confirmed by measuring three different $\mathrm{pH}$ buffers of $\mathrm{pH} 4$, 7, and 10 before measurements were performed. These Fisher Scientific $\mathrm{pH}$ buffers are certified to within $+/-0.02 \mathrm{pH}$ units and were used within the designated expiration date listed on each buffer.

\subsubsection{TEMPERATURE}

The temperatures of the solution and dry materials were measured prior to mixing the two to make a grout, using a calibrated T-type thermocouples (T/C). At the end of the mixing, the final grout temperature was measured, prior to other measurements described above. The temperature increase is then calculated using equation [12]. Note that this equation assumes that the heat capacities are the same for feeds and grout. It does not take into account the temperature of the mixer bowl, mixer blade or the environment of mixing. The mixer is located in a chemical hood that has one pass air flow from outside air, where temperature can change from close to freezing to $70^{\circ} \mathrm{F}$.

$$
\Delta T=T_{\text {grout }}-\left(T_{\text {Salt_solution }} f_{\text {Salt_solution }}+T_{\text {dry_materials }} \times\left(1-f_{\text {Salt_solution }}\right)\right)\left({ }^{\circ} \mathrm{F}\right)
$$




\subsection{DISCUSSION}

\subsection{RESULTS}

The acidic solutions that contained insoluble solids were HAW-4, -8, -12, -14, -18, -19, -24, 28, -33, -34, -38 and -39. During the neutralization/pH adjustment process, all the undissolved solids were observed to completely dissolve prior to precipitation of stable undissolved solids.

Due to the method of $\mathrm{NaOH}$ addition and the use of a self-imposed maximum fluid temperature of $60{ }^{\circ} \mathrm{C}$, continuous addition of $51 \mathrm{wt} \% \mathrm{NaOH}$ solution was not sustained for the majority of the acid solutions. This was the case where the nitric acid concentration in the acidic feed was equal or greater than $3.695 \mathrm{M}$. Acid solutions that did not have any nitric acid addition, e.g. 0 moles of $\mathrm{HNO}_{3}$ solution, did not reach the $60{ }^{\circ} \mathrm{C}$ threshold during neutralization $/ \mathrm{pH}$ adjustment. The final mixing speeds of the neutralization/pH process are provided in Table 3-1. These mixing speeds do not have any quantifiable reference other than these settings provided good mixing where surface motion was noted, upon the completion of $\mathrm{NaOH}$ addition. Higher mixing speeds were required for some of the HAW mixtures when going through the $\mathrm{pH}$ range of 3 to 10 . For HAW-33, the change to a higher mixing speed was recorded. Due to cavern mixing, ${ }^{\dagger \dagger}$ the mixing speed was at 250 RPM and had to be increased to $750 \mathrm{RPM}$ at a $\mathrm{pH}$ of 9 to fully incorporate the $\mathrm{NaOH}$ solution that was added. After $\mathrm{NaOH}$ incorporation, the agitator speed was reduced.

Table 3-1 Final Mixing Speeds at the End of the Neutralization/pH Adjustment Process

\begin{tabular}{|c|c|c|c|c|c|c|c|}
\hline HAW \# & $\begin{array}{c}\text { Final } \\
\text { RPM }\end{array}$ & HAW \# & $\begin{array}{c}\text { Final } \\
\text { RPM }\end{array}$ & HAW \# & $\begin{array}{c}\text { Final } \\
\text { RPM }\end{array}$ & HAW \# & $\begin{array}{c}\text { Final } \\
\text { RPM }\end{array}$ \\
\hline $0^{*}$ & $\mathrm{n} / \mathrm{r}$ & 11 & $\mathrm{n} / \mathrm{r}$ & 22 & $\mathrm{n} / \mathrm{r}$ & $33^{*}$ & 458 \\
\hline 1 & $\mathrm{n} / \mathrm{r}$ & $12^{*}$ & $\mathrm{n} / \mathrm{r}$ & 23 & 306 & $34^{*}$ & 353 \\
\hline 2 & 298 & $13^{*}$ & 200 & $24^{*}$ & 382 & $35^{*}$ & 300 \\
\hline $3^{*}$ & 307 & $14^{*}$ & 300 & $25^{*}$ & $\mathrm{n} / \mathrm{r}$ & $36^{*}$ & 351 \\
\hline $4^{*}$ & 200 & 15 & $\mathrm{n} / \mathrm{r}$ & $26^{*}$ & 250 & 37 & 300 \\
\hline 5 & $\mathrm{n} / \mathrm{r}$ & $16^{*}$ & 300 & 27 & 351 & $38^{*}$ & 473 \\
\hline $6^{*}$ & 310 & $17^{*}$ & $\mathrm{n} / \mathrm{r}$ & $28^{*}$ & 300 & $39 *$ & $\mathrm{n} / \mathrm{r}$ \\
\hline $7^{*}$ & 310 & $18^{*}$ & $\mathrm{n} / \mathrm{r}$ & 29 & 300 & $40^{*}$ & 433 \\
\hline $8^{*}$ & 275 & $19^{*}$ & 392 & $30^{*}$ & 250 & $41^{*}$ & 275 \\
\hline 9 & $\mathrm{n} / \mathrm{r}$ & 20 & 275 & $31^{*}$ & 255 & & \\
\hline 10 & 427 & 21 & $\mathrm{n} / \mathrm{r}$ & 32 & 350 & & \\
\hline
\end{tabular}

HAW-2 and HAW-6 were the only acidic simulants containing only silver nitrates as metals. During the neutralization/pH adjustment process, the resulting precipitates were relatively large and settled more quickly than the precipitates in other mixtures. This behavior impacted the ability to properly quantify the physical properties.

\footnotetext{
${ }^{\dagger \dagger}$ Cavern Mixing - The condition where a "cavern” is formed below the surface and mixing is not evident from the surface. This cavern is created for fluids that have a yield stress and where the shear stresses from mixing do not exceed this yield stress.
} 
For all the HAW grout batches, other than for HAW-9, -20, -29, and -37, the mixing sequences were maintained for 2 minutes at low speed (\#1) using the Hobart mixer. Mixing at medium speed (\#2) was maintained for 5 minutes for all the HAW batches. Additional results are presented in Section 3.5 for the above mentioned mixes that were more difficult to blend.

The temperature rise associated with mixing the solution and dry materials is provided in Table 3-2. This temperature increase does not take into consideration the specific heats of the solution, dry materials, and grout and it does not consider the temperature of the mixing system components and environment. These data must be used with caution.

Table 3-2 Temperature Increase In Grout During Mixing

\begin{tabular}{|c|c|c|c|c|c|c|c|}
\hline HAW \# & $\Delta \mathrm{T}\left({ }^{\circ} \mathrm{C}\right)$ & $\mathrm{HAW} \#$ & $\Delta \mathrm{T}\left({ }^{\circ} \mathrm{C}\right)$ & $\mathrm{HAW} \#$ & $\Delta \mathrm{T}\left({ }^{\circ} \mathrm{C}\right)$ & $\mathrm{HAW} \#$ & $\Delta \mathrm{T}\left({ }^{\circ} \mathrm{C}\right)$ \\
\hline 0 & 0.0 & 11 & 2.6 & 22 & 3.5 & 33 & 1.1 \\
\hline 1 & 1.7 & 12 & 1.3 & 23 & 3.9 & 34 & 1.1 \\
\hline 2 & 4.5 & 13 & 0.0 & 24 & 1.8 & 35 & 2.8 \\
\hline 3 & 1.3 & 14 & 0.7 & 25 & 2.0 & 36 & 2.0 \\
\hline 4 & 0.5 & 15 & 4.5 & 26 & 1.5 & 37 & 4.9 \\
\hline 5 & 2.5 & 16 & 2.3 & 27 & 1.7 & 38 & 1.9 \\
\hline 6 & 2.5 & 17 & 5.2 & 28 & 0.6 & 39 & 1.9 \\
\hline 7 & 0.2 & 18 & 1.7 & 29 & 4.0 & 40 & 1.9 \\
\hline 8 & 0.0 & 19 & 1.0 & 30 & 0.3 & 41 & 2.0 \\
\hline 9 & 2.2 & 20 & 1.2 & 31 & 0.0 & & \\
\cline { 1 - 4 } & 0.8 & 21 & 2.6 & 32 & 4.2 & & \\
\hline
\end{tabular}

The cured grout samples did not contained any bleed water, and they satisfied the set requirements in every case. These data are not in any table in this report.

The vane measurements performed on the HAW grout simulants are provided in Appendix D, Figure D - 1 through Figure D - 14. This information is provided in full, since this measurement is the response to mixability. Appendix $\mathrm{D}$ also contains the repeated tests for specific HAW blends which are shown in Figure D - 15 and Figure D - 16.

The results for all the HAW tests are included in Table 3-3 through Table 3-7. In these tables, the response function, yield stress, is provided as a reference. Table 3-3 contains the as batched acidified molarity, density and wt\% total solids. Table 3-4 contains all the physical data for the neutralized/pH adjusted solutions. Table 3-5 contains all the physical grout properties, including both the measured and calculated densities. Table 3-6 contains the molarity of individual elements and a few compounds in the final grout product. Table 3-7 contains the molarity of individual elements $(\mathrm{Ga}, \mathrm{Al}, \mathrm{Ag}, \mathrm{Cu})$ used to determine the batching of the acidic solutions, while keeping the "others" molarity separate.

The data from this testing which include design points, measured and calculated variables are presented in Table 3-3 through Table 3-7. In each of these tables, an identifying HAW test number is provided for each of the experimental runs as well as the response variables (yield stress). The response variable is provided for convenience, so as to easily compare test input 
and response variables. HAW-0 and HAW-41 were not selected as part of the variability study (see section 2.2.2), but are included in all the tables except for Table 3-7. Table 3-3 provides the design points (i.e., the acid batch sheet targeted molarities of $\mathrm{HNO}_{3}, \mathrm{Ga}, \mathrm{Al}, \mathrm{Ag}$, $\mathrm{Cu}$ and Others along with the calculated $\mathrm{NO}_{3}$ molarity) as determined by Hansen and Edwards ${ }^{9}$ along with measurements of the density and total solids of the acid solutions. Table 3-4 contains the measured $\mathrm{pH}$, density, wt\% TS in the fluid, and wt\% DSS, and the calculated wt\% UDS of the neutralized/pH adjusted fluids. Table 3-4 also contains the rheology data of the neutralized/pH adjusted fluids. These data were not included in the variability study due to the fact that some of fluids were Newtonian in behavior, while others were non-Newtonian; hence a comparison was not practical. SRNL did not have any detailed process knowledge (agitator design, mixing speed, feed rates) to determine some nominal shear rate either via mixing or transport, were an apparent viscosity could have been used as an input variable. Table 3-5 provides the physical properties of the final grout; the calculated mass fractions of cement, zircon, simulant, and water as well as the calculated and measured grout densities. Table 3-6 provides the calculated chemical composition (molarity) for each of the chemicals or compounds ( $\mathrm{Ga}, \mathrm{Al}, \mathrm{Ag}, \mathrm{Cu}, \mathrm{Er}, \mathrm{Ba}, \mathrm{Ca}, \mathrm{Cd}, \mathrm{K}, \mathrm{Mg}, \mathrm{Na}$, and $\mathrm{NO}_{3}{ }^{-}$) in the final grout product. Note that there are differences in the Na concentration between batches that are the same, which is due to how much $\mathrm{NaOH}$ solution was added to each to obtain a final $\mathrm{pH}$ of $12 \pm 0.3$. Table 3-7 also provides the concentration of the design points (acid batch sheet components) in the final grout, while maintaining the "Others" as one group. 
SRNL-STI-2009-00101, REVISION 0

Table 3-3 Results - Acidified Fluids and Grout Yield Stress

\begin{tabular}{|c|c|c|c|c|c|c|c|c|c|c|c|c|}
\hline \multirow{3}{*}{$\begin{array}{c}\text { HAW } \\
\text { Test } \\
\#\end{array}$} & \multicolumn{9}{|c|}{ Acidified HAW Properties } & \multirow{2}{*}{\multicolumn{3}{|c|}{$\begin{array}{l}\text { Grout Yield Stress } \\
(\mathrm{Pa})\end{array}$}} \\
\hline & \multicolumn{7}{|c|}{ Molarity } & \multirow{2}{*}{$\begin{array}{l}\text { Density } \\
(\mathrm{g} / \mathrm{mL})\end{array}$} & \multirow{2}{*}{$\begin{array}{c}\text { wt\% } \\
\text { Total } \\
\text { Solids } \\
\end{array}$} & & & \\
\hline & $\mathrm{HNO}_{3}$ & $\mathrm{Ga}$ & $\mathrm{Al}$ & Ag & $\mathrm{Cu}$ & Others & $\mathrm{NO}_{3}$ & & & $\mathrm{t}=0$ & $\begin{array}{l}\mathrm{t}=3 \\
\min \end{array}$ & $\begin{array}{c}\mathrm{t}=6 \\
\min \end{array}$ \\
\hline 0 & $\mathrm{n} / \mathrm{c}$ & $n / c$ & $\mathrm{n} / \mathrm{c}$ & $n / c$ & $\mathrm{n} / \mathrm{c}$ & $\mathrm{n} / \mathrm{c}$ & 7.86 & 1.268 & $4.66 \%$ & 146 & 207 & 276 \\
\hline 1 & 0 & 0 & 0 & 0 & 0 & 0 & 0.00 & 0.997 & $0.00 \%$ & 467 & 540 & 562 \\
\hline 2 & 0 & 0 & 0 & 0.5423 & 0 & 0 & 0.54 & 1.073 & $8.65 \%$ & 452 & 528 & 642 \\
\hline 3 & 3.695 & 0 & 0.05809 & 0.27115 & 0 & 0.5516 & 4.62 & 1.194 & $7.55 \%$ & 338 & 360 & 444 \\
\hline 4 & 7.39 & 0 & 0 & 0 & 0 & 1.1032 & 8.34 & 1.278 & $\mathrm{n} / \mathrm{m}$ & 227 & 290 & 330 \\
\hline 5 & 0 & 0 & 0 & 0 & 0 & 0 & 0.00 & 0.997 & $0.00 \%$ & 493 & 559 & 596 \\
\hline 6 & 7.39 & 0 & 0 & 0.5423 & 0 & 0 & 7.93 & 1.300 & $7.08 \%$ & 99 & 130 & 173 \\
\hline 7 & 3.695 & 0.05809 & 0 & 0 & 0.27115 & 0.5516 & 4.89 & 1.197 & $6.41 \%$ & 199 & 279 & 386 \\
\hline 8 & 7.39 & 0 & 0 & 0 & 0.5423 & 1.1032 & 9.43 & 1.359 & $\mathrm{n} / \mathrm{m}$ & 102 & 110 & 137 \\
\hline 9 & 0 & 0.11618 & 0 & 0 & 0 & 1.1032 & 1.30 & 1.083 & $8.46 \%$ & 1389 & 1544 & 1502 \\
\hline 10 & 0 & 0 & 0 & 0 & 0.5423 & 0 & 1.08 & 1.080 & $6.28 \%$ & 544 & 703 & 915 \\
\hline 11 & 0 & 0.11618 & 0 & 0 & 0 & 0 & 0.35 & 1.018 & $1.54 \%$ & 934 & 971 & 1093 \\
\hline 12 & 3.695 & 0.05809 & 0 & 0.27115 & 0 & 0.5516 & 4.62 & 1.195 & $7.72 \%$ & 346 & 381 & 387 \\
\hline 13 & 7.39 & 0 & 0.11618 & 0 & 0 & 1.1032 & 8.69 & 1.288 & $\mathrm{n} / \mathrm{m}$ & 111 & 130 & 169 \\
\hline 14 & 7.39 & 0.11618 & 0 & 0 & 0 & 1.1032 & 8.69 & 1.305 & $\mathrm{n} / \mathrm{m}$ & 265 & 307 & 358 \\
\hline 15 & 0 & 0 & 0.11618 & 0 & 0 & 0 & 0.35 & 1.016 & $1.46 \%$ & 1495 & 1627 & 1642 \\
\hline 16 & 7.39 & 0.11618 & 0 & 0 & 0 & 0 & 7.74 & 1.247 & $1.19 \%$ & 256 & 289 & 358 \\
\hline 17 & 3.695 & 0.05809 & 0 & 0.27115 & 0 & 0.5516 & 4.62 & 1.195 & $7.50 \%$ & 256 & 301 & 300 \\
\hline 18 & 7.39 & 0 & 0.11618 & 0 & 0.5423 & 1.1032 & 9.77 & 1.355 & $\mathrm{n} / \mathrm{m}$ & 131 & 135 & 154 \\
\hline 19 & 7.39 & 0.11618 & 0 & 0 & 0.5423 & 1.1032 & 9.77 & 1.367 & $\mathrm{n} / \mathrm{m}$ & 132 & 147 & 161 \\
\hline 20 & 0 & 0 & 0.11618 & 0 & 0.5423 & 0 & 1.43 & 1.098 & $7.53 \%$ & 565 & 687 & 753 \\
\hline 21 & 0 & 0.11618 & 0 & 0.5423 & 0 & 0 & 0.89 & 1.094 & $9.81 \%$ & 536 & 638 & 764 \\
\hline 22 & 0 & 0 & 0 & 0 & 0 & 1.1032 & 0.95 & 1.062 & $6.92 \%$ & 1225 & 1085 & 1188 \\
\hline 23 & 0 & 0 & 0 & 0.5423 & 0 & 1.1032 & 1.49 & 1.137 & $14.60 \%$ & 1267 & 1321 & 1329 \\
\hline 24 & 7.39 & 0.11618 & 0 & 0 & 0.5423 & 1.1032 & 9.77 & 1.364 & $\mathrm{n} / \mathrm{m}$ & 119 & 120 & 126 \\
\hline 25 & 7.39 & 0 & 0 & 0 & 0 & 0 & 7.39 & 1.230 & $0.00 \%$ & 116 & 155 & 187 \\
\hline 26 & 7.39 & 0.11618 & 0 & 0.5423 & 0 & 0 & 8.28 & 1.319 & $8.20 \%$ & 132 & 187 & 230 \\
\hline 27 & 0 & 0 & 0 & 0 & 0.5423 & 1.1032 & 2.04 & 1.142 & $12.25 \%$ & 534 & 766 & 1003 \\
\hline 28 & 7.39 & 0 & 0 & 0.5423 & 0 & 1.1032 & 8.88 & 1.351 & $\mathrm{n} / \mathrm{m}$ & 210 & 260 & 292 \\
\hline 29 & 0 & 0.11618 & 0 & 0.5423 & 0 & 1.1032 & 1.84 & 1.157 & $15.68 \%$ & 1413 & 1573 & 1558 \\
\hline 30 & 7.39 & 0 & 0 & 0 & 0.5423 & 0 & 8.47 & 1.301 & $5.31 \%$ & 150 & 245 & 300 \\
\hline 31 & 3.695 & 0 & 0.05809 & 0 & 0.27115 & 0.5516 & 4.89 & 1.197 & $6.76 \%$ & 198 & 205 & 280 \\
\hline 32 & 0 & 0 & 0.11618 & 0 & 0 & 1.1032 & 1.30 & 1.080 & $8.12 \%$ & 1098 & 1341 & 1291 \\
\hline 33 & 7.39 & 0 & 0.11618 & 0.5423 & 0 & 1.1032 & 9.23 & 1.336 & $\mathrm{n} / \mathrm{m}$ & 140 & 177 & 216 \\
\hline 34 & 7.39 & 0.11618 & 0 & 0.5423 & 0 & 1.1032 & 9.23 & 1.373 & $\mathrm{n} / \mathrm{m}$ & 279 & 332 & 392 \\
\hline 35 & 7.39 & 0 & 0.11618 & 0 & 0 & 0 & 7.74 & 1.244 & $0.00 \%$ & 227 & 286 & 330 \\
\hline 36 & 3.695 & 0 & 0.05809 & 0 & 0.27115 & 0.5516 & 4.89 & 1.196 & $6.43 \%$ & 173 & 214 & 287 \\
\hline 37 & 0 & 0 & 0.11618 & 0 & 0.5423 & 1.1032 & 2.38 & 1.160 & $13.08 \%$ & 790 & 1007 & 1124 \\
\hline 38 & 7.39 & 0 & 0.11618 & 0.5423 & 0 & 1.1032 & 9.23 & 1.363 & $\mathrm{n} / \mathrm{m}$ & 178 & 212 & 243 \\
\hline 39 & 7.39 & 0.11618 & 0 & 0.5423 & 0 & 1.1032 & 9.23 & 1.368 & $\mathrm{n} / \mathrm{m}$ & 286 & 329 & 406 \\
\hline 40 & 7.39 & 0 & 0.11618 & 0 & 0.5423 & 0 & 8.82 & 1.315 & $6.28 \%$ & 107 & 114 & 129 \\
\hline 41 & $\mathrm{n} / \mathrm{c}$ & $\mathrm{n} / \mathrm{c}$ & $\mathrm{n} / \mathrm{c}$ & $\mathrm{n} / \mathrm{c}$ & $\mathrm{n} / \mathrm{c}$ & $\mathrm{n} / \mathrm{c}$ & 7.61 & 1.264 & $4.63 \%$ & 164 & 261 & 301 \\
\hline
\end{tabular}

$\mathrm{n} / \mathrm{c}=$ not calculated, $\mathrm{n} / \mathrm{m}=$ not measured 
SRNL-STI-2009-00101, REVISION 0

Table 3-4 Results - Neutralized/pH Adjusted Fluids and Grout Yield Stress

\begin{tabular}{|c|c|c|c|c|c|c|c|c|c|c|c|c|c|}
\hline \multirow{4}{*}{$\begin{array}{c}\text { HAW } \\
\text { Test } \\
\#\end{array}$} & \multicolumn{10}{|c|}{ Neutralized pH Adjusted Simulants } & \multirow{3}{*}{\multicolumn{3}{|c|}{$\begin{array}{l}\text { Grout Yield Stress } \\
\qquad(\mathrm{Pa})\end{array}$}} \\
\hline & \multirow[b]{3}{*}{$\begin{array}{l}\text { Density } \\
\text { g/mL }\end{array}$} & \multirow{2}{*}{\multicolumn{3}{|c|}{ Weight Percent Solids Analysis }} & \multirow[b]{3}{*}{$\mathrm{pH}$} & \multicolumn{5}{|c|}{ Rheology } & & & \\
\hline & & & & & & \multicolumn{2}{|c|}{ Newtonian } & \multicolumn{3}{|c|}{ Bingham Plastic } & & & \\
\hline & & $\begin{array}{l}\text { Total } \\
\text { solids }\end{array}$ & $\begin{array}{l}\text { Solids In } \\
\text { Supernate }\end{array}$ & $\begin{array}{l}\text { Undissolved } \\
\text { solids in } \\
\text { fluid }\end{array}$ & & $\begin{array}{l}\text { Viscosity } \\
\text { (cP) }\end{array}$ & $\mathrm{R}^{2}$ & $\begin{array}{l}\text { Plastic } \\
\text { Viscosity } \\
\text { (cP) }\end{array}$ & $\begin{array}{l}\text { Yields } \\
\text { Stress } \\
(\mathrm{Pa})\end{array}$ & $\mathrm{R}^{2}$ & $\mathrm{t}=0$ & $\begin{array}{l}\mathrm{t}=3 \\
\min \end{array}$ & $\begin{array}{l}\mathrm{t}=6 \\
\min \end{array}$ \\
\hline 0 & 1.294 & 37.72 & 37.28 & 0.71 & 12.0 & 3.31 & 0.995 & $\mathrm{n} / \mathrm{c}$ & $\mathrm{n} / \mathrm{c}$ & $\mathrm{n} / \mathrm{c}$ & 146 & 207 & 276 \\
\hline 1 & 0.998 & 0.00 & 0.00 & 0.00 & 12.0 & 1.07 & 0.843 & $\mathrm{n} / \mathrm{c}$ & $\mathrm{n} / \mathrm{c}$ & $\mathrm{n} / \mathrm{c}$ & 467 & 540 & 562 \\
\hline 2 & 1.085 & 10.33 & 4.46 & 6.15 & 11.8 & $\mathrm{n} / \mathrm{c}$ & $\mathrm{n} / \mathrm{c}$ & 3.99 & 0.52 & 0.993 & 452 & 528 & 642 \\
\hline 3 & 1.234 & 29.57 & 26.67 & 3.95 & 11.9 & $\mathrm{n} / \mathrm{c}$ & $n / c$ & $\mathrm{n} / \mathrm{c}$ & $\mathrm{n} / \mathrm{c}$ & $n / c$ & 338 & 360 & 444 \\
\hline 4 & 1.296 & 42.64 & 38.14 & 7.27 & 11.7 & $\mathrm{n} / \mathrm{c}$ & $\mathrm{n} / \mathrm{c}$ & 7.02 & 1.77 & 0.991 & 227 & 290 & 330 \\
\hline 5 & 0.998 & 0.00 & 0.00 & 0.00 & 12.0 & 1.11 & 0.864 & $\mathrm{n} / \mathrm{c}$ & $\mathrm{n} / \mathrm{c}$ & $\mathrm{n} / \mathrm{c}$ & 493 & 559 & 596 \\
\hline 6 & 1.321 & 38.57 & 36.27 & 7.16 & 11.9 & $\mathrm{n} / \mathrm{c}$ & $\mathrm{n} / \mathrm{c}$ & 4.69 & 0.80 & 0.988 & 99 & 130 & 173 \\
\hline 7 & 1.220 & 31.34 & 27.40 & 5.43 & 11.9 & $\mathrm{n} / \mathrm{c}$ & $\mathrm{n} / \mathrm{c}$ & $\mathrm{n} / \mathrm{c}$ & $\mathrm{n} / \mathrm{c}$ & $\mathrm{n} / \mathrm{c}$ & 199 & 279 & 386 \\
\hline 8 & 1.338 & 45.14 & 40.69 & 7.49 & 11.7 & $\mathrm{n} / \mathrm{c}$ & $n / c$ & 6.28 & 1.18 & 0.996 & 102 & 110 & 137 \\
\hline 9 & 1.091 & 14.15 & 11.05 & 3.48 & 11.9 & $\mathrm{n} / \mathrm{c}$ & $\mathrm{n} / \mathrm{c}$ & 4.76 & 1.19 & 0.987 & 1389 & 1544 & 1502 \\
\hline 10 & 1.071 & 12.44 & 8.09 & 4.73 & 11.9 & $\mathrm{n} / \mathrm{c}$ & $\mathrm{n} / \mathrm{c}$ & $\mathrm{n} / \mathrm{c}$ & $\mathrm{n} / \mathrm{c}$ & $\mathrm{n} / \mathrm{c}$ & 544 & 703 & 915 \\
\hline 11 & 1.026 & 3.63 & 3.34 & 0.29 & 11.8 & 1.25 & 0.883 & $\mathrm{n} / \mathrm{c}$ & $\mathrm{n} / \mathrm{c}$ & $\mathrm{n} / \mathrm{c}$ & 934 & 971 & 1093 \\
\hline 12 & 1.222 & 29.91 & 26.59 & 4.52 & 11.9 & $\mathrm{n} / \mathrm{c}$ & $\mathrm{n} / \mathrm{c}$ & 3.98 & 0.63 & 0.989 & 346 & 381 & 387 \\
\hline 13 & 1.329 & 43.51 & 39.15 & 7.17 & 12.0 & $\mathrm{n} / \mathrm{c}$ & $\mathrm{n} / \mathrm{c}$ & 6.12 & 1.10 & 0.993 & 111 & 130 & 169 \\
\hline 14 & 1.311 & 42.34 & 39.07 & 5.37 & 11.8 & $\mathrm{n} / \mathrm{c}$ & $\mathrm{n} / \mathrm{c}$ & 7.35 & 1.98 & 0.989 & 265 & 307 & 358 \\
\hline 15 & 1.026 & 4.01 & 4.02 & -0.01 & 12.2 & 1.19 & 0.870 & $\mathrm{n} / \mathrm{c}$ & $\mathrm{n} / \mathrm{c}$ & $\mathrm{n} / \mathrm{c}$ & 1495 & 1627 & 1642 \\
\hline 16 & 1.279 & 35.95 & 35.95 & 0.00 & 11.7 & 1.96 & 0.977 & $n / c$ & $\mathrm{n} / \mathrm{c}$ & $n / c$ & 256 & 289 & 358 \\
\hline 17 & 1.223 & 29.74 & 26.60 & 4.28 & 12.0 & 3.84 & 0.988 & $\mathrm{n} / \mathrm{c}$ & $\mathrm{n} / \mathrm{c}$ & $\mathrm{n} / \mathrm{c}$ & 256 & 301 & 300 \\
\hline 18 & 1.360 & 47.28 & 41.92 & 9.24 & 11.9 & $\mathrm{n} / \mathrm{c}$ & $\mathrm{n} / \mathrm{c}$ & 7.42 & 1.59 & 0.994 & 131 & 135 & 154 \\
\hline 19 & 1.359 & 46.32 & 42.14 & 7.22 & 12.0 & $\mathrm{n} / \mathrm{c}$ & $\mathrm{n} / \mathrm{c}$ & 6.92 & 1.34 & 0.994 & 132 & 147 & 161 \\
\hline 20 & 1.107 & 14.84 & 10.48 & 4.88 & 11.8 & $\mathrm{n} / \mathrm{c}$ & $\mathrm{n} / \mathrm{c}$ & 3.85 & 1.16 & 0.965 & 565 & 687 & 753 \\
\hline 21 & 1.126 & 12.65 & 7.04 & 6.04 & 11.9 & 1.54 & 0.894 & $\mathrm{n} / \mathrm{c}$ & $\mathrm{n} / \mathrm{c}$ & $\mathrm{n} / \mathrm{c}$ & 536 & 638 & 764 \\
\hline 22 & 1.072 & 11.38 & 9.14 & 2.47 & 11.7 & $\mathrm{n} / \mathrm{c}$ & $\mathrm{n} / \mathrm{c}$ & 4.23 & 1.13 & 0.973 & 1225 & 1085 & 1188 \\
\hline 23 & 1.136 & 19.01 & 12.41 & 7.53 & 11.9 & $\mathrm{n} / \mathrm{c}$ & $\mathrm{n} / \mathrm{c}$ & 5.43 & 2.44 & 0.969 & 1267 & 1321 & 1329 \\
\hline 24 & 1.359 & 47.04 & 41.88 & 8.88 & 11.9 & $\mathrm{n} / \mathrm{c}$ & $\mathrm{n} / \mathrm{c}$ & 7.17 & 1.22 & 0.996 & 119 & 120 & 126 \\
\hline 25 & 1.266 & 34.89 & 34.86 & 0.04 & 11.8 & 1.99 & 0.951 & $\mathrm{n} / \mathrm{c}$ & $\mathrm{n} / \mathrm{c}$ & $\mathrm{n} / \mathrm{c}$ & 116 & 155 & 187 \\
\hline 26 & 1.365 & 40.67 & 37.35 & 5.30 & 12.1 & $\mathrm{n} / \mathrm{c}$ & $\mathrm{n} / \mathrm{c}$ & $\mathrm{n} / \mathrm{c}$ & $\mathrm{n} / \mathrm{c}$ & $\mathrm{n} / \mathrm{c}$ & 132 & 187 & 230 \\
\hline 27 & 1.166 & 20.35 & 14.93 & 6.37 & 11.9 & $\mathrm{n} / \mathrm{c}$ & $\mathrm{n} / \mathrm{c}$ & 4.20 & 1.24 & 0.960 & 534 & 766 & 1003 \\
\hline 28 & 1.338 & 44.08 & 39.47 & 7.62 & 12.0 & $\mathrm{n} / \mathrm{c}$ & $\mathrm{n} / \mathrm{c}$ & 7.04 & 3.29 & 0.965 & 210 & 260 & 292 \\
\hline 29 & 1.164 & 21.66 & 14.86 & 7.99 & 11.7 & $\mathrm{n} / \mathrm{c}$ & $\mathrm{n} / \mathrm{c}$ & 5.53 & 2.24 & 0.949 & 1413 & 1573 & 1558 \\
\hline 30 & 1.312 & 39.02 & 36.94 & 3.30 & 11.8 & $\mathrm{n} / \mathrm{c}$ & $\mathrm{n} / \mathrm{c}$ & 5.92 & 1.20 & 0.983 & 150 & 245 & 300 \\
\hline 31 & 1.222 & 31.18 & 27.47 & 5.12 & 11.8 & $\mathrm{n} / \mathrm{c}$ & $\mathrm{n} / \mathrm{c}$ & 4.55 & 0.52 & 0.994 & 198 & 205 & 280 \\
\hline 32 & 1.108 & 13.80 & 10.86 & 3.29 & 11.9 & $\mathrm{n} / \mathrm{c}$ & $\mathrm{n} / \mathrm{c}$ & 4.54 & 0.54 & 0.973 & 1098 & 1341 & 1291 \\
\hline 33 & 1.351 & 46.11 & 40.80 & 8.97 & 12.0 & $\mathrm{n} / \mathrm{c}$ & $\mathrm{n} / \mathrm{c}$ & 6.46 & 1.53 & 0.992 & 140 & 177 & 216 \\
\hline 34 & 1.353 & 46.02 & 40.61 & 9.10 & 11.9 & $\mathrm{n} / \mathrm{c}$ & $\mathrm{n} / \mathrm{c}$ & 6.82 & 1.23 & 0.992 & 279 & 332 & 392 \\
\hline 35 & 1.276 & 35.83 & 35.86 & -0.05 & 11.8 & 2.06 & 0.955 & $\mathrm{n} / \mathrm{c}$ & $\mathrm{n} / \mathrm{c}$ & $\mathrm{n} / \mathrm{c}$ & 227 & 286 & 330 \\
\hline 36 & 1.215 & 31.29 & 27.42 & 5.33 & 11.9 & $\mathrm{n} / \mathrm{c}$ & $\mathrm{n} / \mathrm{c}$ & $\mathrm{n} / \mathrm{c}$ & $\mathrm{n} / \mathrm{c}$ & $\mathrm{n} / \mathrm{c}$ & 173 & 214 & 287 \\
\hline 37 & 1.186 & 22.76 & 17.48 & 6.40 & 11.9 & $\mathrm{n} / \mathrm{c}$ & $\mathrm{n} / \mathrm{c}$ & 4.45 & 1.33 & 0.959 & 790 & 1007 & 1124 \\
\hline 38 & 1.356 & 45.41 & 40.69 & 7.96 & 11.9 & $\mathrm{n} / \mathrm{c}$ & $\mathrm{n} / \mathrm{c}$ & 6.60 & 1.58 & 0.989 & 178 & 212 & 243 \\
\hline 39 & 1.358 & 46.10 & 40.61 & 9.24 & 11.9 & $n / c$ & $n / c$ & 7.28 & 1.56 & 0.993 & 286 & 329 & 406 \\
\hline 40 & 1.323 & 41.26 & 38.71 & 4.15 & 11.8 & $\mathrm{n} / \mathrm{c}$ & $\mathrm{n} / \mathrm{c}$ & 5.66 & 0.51 & 0.997 & 107 & 114 & 129 \\
\hline 41 & 1.288 & 37.39 & 36.99 & 0.63 & 11.7 & $\mathrm{n} / \mathrm{c}$ & $\mathrm{n} / \mathrm{c}$ & $\mathrm{n} / \mathrm{c}$ & $\mathrm{n} / \mathrm{c}$ & $\mathrm{n} / \mathrm{c}$ & 164 & 261 & 301 \\
\hline
\end{tabular}


SRNL-STI-2009-00101, REVISION 0

Table 3-5 Results - Grout Physical Properties and Yield Stress Measurements

\begin{tabular}{|c|c|c|c|c|c|c|c|c|c|}
\hline \multirow{3}{*}{$\begin{array}{c}\text { HAW } \\
\text { Test } \\
\#\end{array}$} & \multicolumn{6}{|c|}{ Grout } & \multirow{2}{*}{\multicolumn{3}{|c|}{$\begin{array}{l}\text { Grout Yield Stress } \\
(\mathrm{Pa})\end{array}$}} \\
\hline & \multicolumn{4}{|c|}{ Mass Fraction of Materials } & \multicolumn{2}{|c|}{ Density $(\mathrm{g} / \mathrm{mL})$} & & & \\
\hline & Cement & Zircon & Simulant & content & Calculated & Measured & $\mathrm{t}=0$ & $\begin{array}{l}\mathrm{t}=3 \\
\min \end{array}$ & $\begin{array}{l}\mathrm{t}=6 \\
\mathrm{~min}\end{array}$ \\
\hline 0 & 0.6390 & 0.0532 & 0.3078 & 0.1917 & 2.21 & 2.18 & 146 & 207 & 276 \\
\hline 1 & 0.7229 & 0.0602 & 0.2169 & 0.2169 & 2.17 & 2.16 & 467 & 540 & 562 \\
\hline 2 & 0.7053 & 0.0588 & 0.2360 & 0.2116 & 2.20 & 2.18 & 452 & 528 & 642 \\
\hline 3 & 0.6626 & 0.0552 & 0.2822 & 0.1988 & 2.22 & 2.21 & 338 & 360 & 444 \\
\hline 4 & 0.6225 & 0.0519 & 0.3256 & 0.1868 & 2.17 & 2.15 & 227 & 290 & 330 \\
\hline 5 & 0.7229 & 0.0602 & 0.2169 & 0.2169 & 2.17 & 2.14 & 493 & 559 & 596 \\
\hline 6 & 0.6363 & 0.0530 & 0.3107 & 0.1909 & 2.23 & 2.19 & 99 & 130 & 173 \\
\hline 7 & 0.6578 & 0.0548 & 0.2874 & 0.1973 & 2.19 & 2.16 & 199 & 279 & 386 \\
\hline 8 & 0.6134 & 0.0511 & 0.3354 & 0.1840 & 2.19 & 2.15 & 102 & 110 & 137 \\
\hline 9 & 0.6980 & 0.0582 & 0.2439 & 0.2094 & 2.18 & 2.16 & 1389 & 1544 & 1502 \\
\hline 10 & 0.7013 & 0.0584 & 0.2403 & 0.2104 & 2.17 & 2.15 & 544 & 703 & 915 \\
\hline 11 & 0.7170 & 0.0598 & 0.2232 & 0.2151 & 2.18 & 2.14 & 934 & 971 & 1093 \\
\hline 12 & 0.6617 & 0.0551 & 0.2832 & 0.1985 & 2.20 & 2.17 & 346 & 381 & 387 \\
\hline 13 & 0.6194 & 0.0516 & 0.3290 & 0.1858 & 2.19 & 2.15 & 111 & 130 & 169 \\
\hline 14 & 0.6236 & 0.0520 & 0.3244 & 0.1871 & 2.19 & 2.19 & 265 & 307 & 358 \\
\hline 15 & 0.7164 & 0.0597 & 0.2239 & 0.2149 & 2.18 & 2.16 & 1495 & 1627 & 1642 \\
\hline 16 & 0.6445 & 0.0537 & 0.3018 & 0.1933 & 2.21 & 2.20 & 256 & 289 & 358 \\
\hline 17 & 0.6621 & 0.0552 & 0.2827 & 0.1986 & 2.21 & 2.25 & 256 & 301 & 300 \\
\hline 18 & 0.6052 & 0.0504 & 0.3444 & 0.1816 & 2.19 & 2.16 & 131 & 135 & 154 \\
\hline 19 & 0.6090 & 0.0507 & 0.3403 & 0.1827 & 2.20 & 2.21 & 132 & 147 & 161 \\
\hline 20 & 0.6966 & 0.0580 & 0.2454 & 0.2090 & 2.19 & 2.22 & 565 & 687 & 753 \\
\hline 21 & 0.7009 & 0.0584 & 0.2407 & 0.2103 & 2.23 & 2.20 & 536 & 638 & 764 \\
\hline 22 & 0.7033 & 0.0586 & 0.2381 & 0.2110 & 2.18 & 2.15 & 1225 & 1085 & 1188 \\
\hline 23 & 0.6879 & 0.0573 & 0.2548 & 0.2064 & 2.20 & 2.19 & 1267 & 1321 & 1329 \\
\hline 24 & 0.6061 & 0.0505 & 0.3434 & 0.1818 & 2.19 & 2.16 & 119 & 120 & 126 \\
\hline 25 & 0.6476 & 0.0540 & 0.2984 & 0.1943 & 2.21 & 2.19 & 116 & 155 & 187 \\
\hline 26 & 0.6294 & 0.0524 & 0.3182 & 0.1888 & 2.25 & 2.19 & 132 & 187 & 230 \\
\hline 27 & 0.6849 & 0.0571 & 0.2580 & 0.2055 & 2.22 & 2.21 & 534 & 766 & 1003 \\
\hline 28 & 0.6175 & 0.0515 & 0.3310 & 0.1853 & 2.20 & 2.18 & 210 & 260 & 292 \\
\hline 29 & 0.6820 & 0.0568 & 0.2612 & 0.2046 & 2.21 & 2.20 & 1413 & 1573 & 1558 \\
\hline 30 & 0.6348 & 0.0529 & 0.3123 & 0.1904 & 2.22 & 2.20 & 150 & 245 & 300 \\
\hline 31 & 0.6582 & 0.0549 & 0.2869 & 0.1975 & 2.19 & 2.18 & 198 & 205 & 280 \\
\hline 32 & 0.6986 & 0.0582 & 0.2431 & 0.2096 & 2.20 & 2.19 & 1098 & 1341 & 1291 \\
\hline 33 & 0.6097 & 0.0508 & 0.3394 & 0.1829 & 2.19 & 2.21 & 140 & 177 & 216 \\
\hline 34 & 0.6101 & 0.0508 & 0.3390 & 0.1830 & 2.20 & 2.19 & 279 & 332 & 392 \\
\hline 35 & 0.6448 & 0.0537 & 0.3015 & 0.1934 & 2.21 & 2.19 & 227 & 286 & 330 \\
\hline 36 & 0.6579 & 0.0548 & 0.2873 & 0.1974 & 2.19 & 2.16 & 173 & 214 & 287 \\
\hline 37 & 0.6795 & 0.0566 & 0.2639 & 0.2038 & 2.22 & 2.18 & 790 & 1007 & 1124 \\
\hline 38 & 0.6124 & 0.0510 & 0.3366 & 0.1837 & 2.20 & 2.19 & 178 & 212 & 243 \\
\hline 39 & 0.6098 & 0.0508 & 0.3394 & 0.1829 & 2.20 & 2.19 & 286 & 329 & 406 \\
\hline 40 & 0.6273 & 0.0523 & 0.3204 & 0.1882 & 2.21 & 2.19 & 107 & 114 & 129 \\
\hline 41 & 0.6400 & 0.0533 & 0.3067 & 0.1920 & 2.21 & 2.21 & 164 & 261 & 301 \\
\hline
\end{tabular}


SRNL-STI-2009-00101, REVISION 0

Table 3-6 Results - Grout Element and Compound Concentrations and Yield Stress

\begin{tabular}{|c|c|c|c|c|c|c|c|c|c|c|c|c|c|c|c|}
\hline \multirow{2}{*}{$\begin{array}{c}\text { HAW } \\
\text { Test } \\
\#\end{array}$} & \multicolumn{12}{|c|}{ Molarity of Elements and Compounds in Grout } & \multicolumn{3}{|c|}{$\begin{array}{l}\text { Grout Yield Stress } \\
(\mathrm{Pa})\end{array}$} \\
\hline & Ga & $\mathrm{Al}$ & Ag & $\mathrm{Cu}$ & Er & $\mathrm{Ba}$ & $\mathrm{Ca}$ & $\mathrm{Cd}$ & K & $\mathrm{Mg}$ & $\mathrm{Na}$ & $\mathrm{NO}_{3}$ & $t=0$ & $\begin{array}{l}\mathrm{t}=3 \\
\min \end{array}$ & $\begin{array}{l}\mathrm{t}=6 \\
\min \end{array}$ \\
\hline 0 & 0.000 & 0.005 & 0.000 & 0.012 & 0.000 & 0.000 & 0.035 & 0.000 & 0.055 & 0.033 & 2.853 & 2.884 & 146 & 207 & 276 \\
\hline 1 & 0.000 & 0.000 & 0.000 & 0.000 & 0.000 & 0.000 & 0.000 & 0.000 & 0.000 & 0.000 & 0.007 & 0.000 & 467 & 540 & 562 \\
\hline 2 & 0.000 & 0.000 & 0.257 & 0.000 & 0.000 & 0.000 & 0.000 & & 0.000 & 0.000 & 0.281 & 0.257 & 452 & 528 & 642 \\
\hline 3 & 0.000 & 0.062 & 0.123 & 0.003 & 0.000 & 0.007 & 0.021 & 0.001 & 0.034 & 0.021 & 2.107 & 2.127 & 338 & 360 & 444 \\
\hline 4 & 0.000 & 0.070 & 0.000 & 0.005 & 0.001 & 0.013 & 0.041 & 0.003 & 0.067 & 0.040 & 3.643 & 3.732 & 227 & 290 & 330 \\
\hline 5 & 0.000 & 0.000 & 0.000 & 0.000 & 0.000 & 0.000 & 0.000 & 0.000 & 0.000 & 0.000 & 0.006 & 0.000 & 493 & 559 & 596 \\
\hline 6 & 0.000 & 0.000 & 0.232 & 0.000 & 0.000 & 0.000 & 0.000 & 0.000 & 0.000 & 0.000 & 3.408 & 3.393 & 99 & 130 & 173 \\
\hline 7 & 0.026 & 0.036 & 0.000 & 0.126 & 0.000 & 0.007 & 0.021 & 0.001 & 0.035 & 0.021 & 2.150 & 2.254 & 199 & 279 & 386 \\
\hline 8 & 0.000 & 0.068 & 0.000 & 0.235 & 0.001 & 0.012 & 0.040 & 0.002 & 0.064 & 0.039 & 3.969 & 4.057 & 102 & 110 & 137 \\
\hline 9 & 0.055 & 0.075 & 0.000 & 0.006 & 0.001 & 0.014 & 0.045 & 0.003 & 0.072 & 0.043 & 0.506 & 0.687 & 1389 & 1544 & 1502 \\
\hline 10 & 0.000 & 0.000 & 0.000 & 0.252 & 0.000 & 0.000 & 0.000 & 0.000 & 0.000 & 0.000 & 0.610 & 0.681 & 544 & 703 & 915 \\
\hline 11 & 0.055 & 0.000 & 0.000 & 0.000 & 0.000 & 0.000 & 0.000 & 0.000 & 0.000 & 0.000 & 0.195 & 0.164 & 934 & 971 & 1093 \\
\hline 12 & 0.026 & 0.036 & 0.123 & & & & & & 0.034 & 0.02 & 2.071 & 2.123 & 346 & 381 & 387 \\
\hline 13 & 0.000 & 0.122 & 0.000 & 0.0 & 0.001 & 0.0 & 0.042 & & 0.067 & 0.040 & 818 & 3.908 & 111 & 130 & 169 \\
\hline 14 & 0.050 & 0.069 & 0.000 & 0.005 & 0.001 & 0.013 & 0.041 & 0.002 & 0.065 & 0.039 & 3.717 & 3.805 & 265 & 307 & 358 \\
\hline 15 & 0.000 & 0.055 & 0.000 & 0.000 & 0.000 & 0.000 & 0.000 & 0.000 & 0.000 & 0.000 & 0.236 & 0.164 & 1495 & 1627 & 1642 \\
\hline 16 & 050 & 0.000 & 0.000 & 0.000 & 0.000 & 0.0 & .000 & & 0.000 & 0.000 & 3.377 & 3.303 & 256 & 289 & 358 \\
\hline 17 & 0.026 & 0.036 & 0.123 & 0.003 & 0.000 & 0.007 & 0.021 & 0.001 & 0.034 & 0.021 & 2.075 & 2.121 & 256 & 301 & 300 \\
\hline 18 & 0.000 & 0.119 & 0.000 & 0.240 & 0.001 & 0.013 & 0.041 & 0.003 & 0.066 & 0.039 & 4.203 & 4.294 & 131 & 135 & 154 \\
\hline 19 & 0.049 & 0.068 & 0.000 & & & & 0.040 & 0.002 & & & 4.139 & 4.228 & 132 & 147 & 161 \\
\hline 20 & 0.000 & 0.054 & 0.000 & 0.251 & 0.000 & 0.000 & 0.000 & 0.000 & 0.000 & 0.000 & 0.744 & 0.664 & 565 & 687 & 753 \\
\hline 21 & 0.055 & 0.000 & 0.257 & 0.000 & 0.000 & 0.000 & 0.000 & 0.000 & 0.000 & 0.000 & 0.441 & 0.422 & 536 & 638 & 764 \\
\hline 22 & 0.000 & 0.075 & 0.000 & & & & & & & & 0.471 & 0.520 & 1225 & 1085 & 1188 \\
\hline 23 & 0.000 & 0.075 & 0.254 & 0.006 & 0.001 & 0.014 & 0.044 & 0.003 & 0.071 & 0.043 & 0.673 & 0.771 & 1267 & 1321 & 1329 \\
\hline 24 & 0.050 & 0.068 & 0.000 & 0.238 & 0.001 & 0.013 & 0.040 & 0.002 & 0.065 & 0.039 & 4.172 & 4.262 & 119 & 120 & 126 \\
\hline 25 & 0.000 & 0.000 & 0.000 & & & & & & 0.000 & 0.000 & 3.226 & 3.181 & 116 & 155 & 187 \\
\hline 26 & 0.050 & 0.000 & 0.235 & 0.000 & 0.000 & 0.000 & 0.000 & 0.000 & 0.000 & 0.000 & 3.611 & 3.588 & 132 & 187 & 230 \\
\hline 27 & 0.000 & 0.075 & 0.000 & 0.260 & 0.001 & 0.014 & 0.044 & 0.003 & 0.072 & 0.043 & 0.868 & 1.028 & 534 & 766 & 1003 \\
\hline 28 & 0.000 & 0.068 & 0.232 & 0.005 & 0.001 & 0.012 & 0.040 & 0.002 & 0.065 & 0.039 & 3.771 & 3.858 & 210 & 260 & 292 \\
\hline 29 & 0.054 & 0.075 & 0.254 & 0.006 & 0.001 & 0.014 & 0.044 & 0.003 & 0.071 & 0.043 & 0.857 & 0.934 & 1413 & 1573 & 1558 \\
\hline 30 & 0.000 & 0.000 & 0.000 & 0.229 & 0.000 & 0.000 & 0.000 & 0.000 & 0.000 & 0.000 & 3.583 & 3.576 & 150 & 245 & 300 \\
\hline 31 & 0.000 & 0.062 & 0.000 & 0.125 & 0.000 & 0.007 & 0.021 & 0.001 & 0.034 & 0.021 & 2.206 & 2.245 & 198 & 205 & 280 \\
\hline 32 & 0.000 & 0.131 & 0.000 & 0.006 & 0.001 & 0.014 & 0.045 & 0.003 & 0.072 & 0.043 & 0.568 & 0.689 & 1098 & 1341 & 1291 \\
\hline 33 & 0.000 & 0.120 & 0.237 & 0.005 & 0.001 & 0.013 & 0.041 & 0.003 & 0.067 & 0.040 & 4.012 & 4.103 & 140 & 177 & 216 \\
\hline 34 & 0.050 & 0.068 & 0.232 & 0.005 & 0.001 & 0.012 & 0.040 & 0.002 & 0.065 & 0.039 & 3.899 & 4.022 & 279 & 332 & 392 \\
\hline 35 & 0.000 & 0.050 & 0.000 & 0.000 & 0.000 & 0.000 & 0.000 & 0.000 & 0.000 & 0.000 & 3.358 & 3.305 & 227 & 286 & 330 \\
\hline 36 & 0.000 & 0.062 & 0.000 & 0.125 & 0.000 & 0.007 & 0.021 & 0.001 & 0.034 & 0.021 & 2.173 & 2.246 & 173 & 214 & 287 \\
\hline 37 & 0.000 & 0.129 & 0.000 & 0.259 & 0.001 & 0.014 & 0.044 & 0.003 & 0.071 & 0.043 & 1.061 & 1.187 & 790 & 1007 & 1124 \\
\hline 38 & 0.000 & 0.118 & 0.232 & 0.005 & 0.001 & 0.012 & 0.040 & 0.002 & 0.065 & 0.039 & 3.933 & 4.021 & 178 & 212 & 243 \\
\hline 39 & 0.050 & 0.069 & 0.233 & 0.005 & 0.001 & 0.013 & 0.041 & 0.002 & 0.065 & 0.039 & 3.949 & 4.038 & 286 & 329 & 406 \\
\hline 40 & 0.000 & 0.049 & 0.000 & 0.230 & 0.000 & 0.000 & 0.000 & 0.000 & 0.000 & 0.000 & 3.751 & 3.741 & 107 & 114 & 129 \\
\hline 41 & 0.000 & 0.005 & 0.000 & 0.012 & 0.000 & 0.000 & 0.035 & 0.000 & 0.055 & 0.033 & 2.774 & 2.805 & 164 & 261 & 301 \\
\hline
\end{tabular}


Table 3-7 Results - Grout Element and "Others" Concentration and Yield Stress

\begin{tabular}{|c|c|c|c|c|c|c|c|c|}
\hline \multirow{2}{*}{$\begin{array}{c}\text { HAW } \\
\text { Test } \\
\#\end{array}$} & \multicolumn{5}{|c|}{$\begin{array}{l}\text { Chemical and "Others" Molarity when } \\
\text { "Others" are Grouped }\end{array}$} & \multicolumn{3}{|c|}{$\begin{array}{l}\text { Grout Yield Stress } \\
\qquad(\mathrm{Pa})\end{array}$} \\
\hline & $\mathrm{Ga}$ & $\mathrm{Al}$ & $\mathrm{Ag}$ & $\mathrm{Cu}$ & $\begin{array}{l}\text { Other } \\
\text { Total }\end{array}$ & $\mathrm{t}=0$ & $\begin{array}{l}\mathrm{t}=3 \\
\min \end{array}$ & $\begin{array}{l}\mathrm{t}=6 \\
\min \end{array}$ \\
\hline 1 & 0.000 & 0.000 & 0.000 & 0.000 & 0.000 & 467 & 540 & 562 \\
\hline 2 & 0.000 & 0.000 & 0.257 & 0.000 & 0.000 & 452 & 528 & 642 \\
\hline 3 & 0.000 & 0.026 & 0.123 & 0.000 & 0.124 & 338 & 360 & 444 \\
\hline 4 & 0.000 & 0.000 & 0.000 & 0.000 & 0.240 & 227 & 290 & 330 \\
\hline 5 & 0.000 & 0.000 & 0.000 & 0.000 & 0.000 & 493 & 559 & 596 \\
\hline 6 & 0.000 & 0.000 & 0.232 & 0.000 & 0.000 & 99 & 130 & 173 \\
\hline 7 & 0.026 & 0.000 & 0.000 & 0.123 & 0.124 & 199 & 279 & 386 \\
\hline 8 & 0.000 & 0.000 & 0.000 & 0.230 & 0.231 & 102 & 110 & 137 \\
\hline 9 & 0.055 & 0.000 & 0.000 & 0.000 & 0.258 & 1389 & 1544 & 1502 \\
\hline 10 & 0.000 & 0.000 & 0.000 & 0.252 & 0.000 & 544 & 703 & 915 \\
\hline 11 & 0.055 & 0.000 & 0.000 & 0.000 & 0.000 & 934 & 971 & 1093 \\
\hline 12 & 0.026 & 0.000 & 0.123 & 0.000 & 0.123 & 346 & 381 & 387 \\
\hline 13 & 0.000 & 0.051 & 0.000 & 0.000 & 0.241 & 111 & 130 & 169 \\
\hline 14 & 0.050 & 0.000 & 0.000 & 0.000 & 0.235 & 265 & 307 & 358 \\
\hline 15 & 0.000 & 0.055 & 0.000 & 0.000 & 0.000 & 1495 & 1627 & 1642 \\
\hline 16 & 0.050 & 0.000 & 0.000 & 0.000 & 0.000 & 256 & 289 & 358 \\
\hline 17 & 0.026 & 0.000 & 0.123 & 0.000 & 0.123 & 256 & 301 & 300 \\
\hline 18 & 0.000 & 0.050 & 0.000 & 0.235 & 0.236 & 131 & 135 & 154 \\
\hline 19 & 0.049 & 0.000 & 0.000 & 0.231 & 0.232 & 132 & 147 & 161 \\
\hline 20 & 0.000 & 0.054 & 0.000 & 0.251 & 0.000 & 565 & 687 & 753 \\
\hline 21 & 0.055 & 0.000 & 0.257 & 0.000 & 0.000 & 536 & 638 & 764 \\
\hline 22 & 0.000 & 0.000 & 0.000 & 0.000 & 0.257 & 1225 & 1085 & 1188 \\
\hline 23 & 0.000 & 0.000 & 0.254 & 0.000 & 0.256 & 1267 & 1321 & 1329 \\
\hline 24 & 0.050 & 0.000 & 0.000 & 0.233 & 0.234 & 119 & 120 & 126 \\
\hline 25 & 0.000 & 0.000 & 0.000 & 0.000 & 0.000 & 116 & 155 & 187 \\
\hline 26 & 0.050 & 0.000 & 0.235 & 0.000 & 0.000 & 132 & 187 & 230 \\
\hline 27 & 0.000 & 0.000 & 0.000 & 0.255 & 0.256 & 534 & 766 & 1003 \\
\hline 28 & 0.000 & 0.000 & 0.232 & 0.000 & 0.233 & 210 & 260 & 292 \\
\hline 29 & 0.054 & 0.000 & 0.254 & 0.000 & 0.255 & 1413 & 1573 & 1558 \\
\hline 30 & 0.000 & 0.000 & 0.000 & 0.229 & 0.000 & 150 & 245 & 300 \\
\hline 31 & 0.000 & 0.026 & 0.000 & 0.123 & 0.123 & 198 & 205 & 280 \\
\hline 32 & 0.000 & 0.055 & 0.000 & 0.000 & 0.259 & 1098 & 1341 & 1291 \\
\hline 33 & 0.000 & 0.051 & 0.237 & 0.000 & 0.239 & 140 & 177 & 216 \\
\hline 34 & 0.050 & 0.000 & 0.232 & 0.000 & 0.234 & 279 & 332 & 392 \\
\hline 35 & 0.000 & 0.050 & 0.000 & 0.000 & 0.000 & 227 & 286 & 330 \\
\hline 36 & 0.000 & 0.026 & 0.000 & 0.123 & 0.123 & 173 & 214 & 287 \\
\hline 37 & 0.000 & 0.053 & 0.000 & 0.250 & 0.251 & 790 & 1007 & 1124 \\
\hline 38 & 0.000 & 0.050 & 0.232 & 0.000 & 0.234 & 178 & 212 & 243 \\
\hline 39 & 0.050 & 0.000 & 0.233 & 0.000 & 0.235 & 286 & 329 & 406 \\
\hline 40 & 0.000 & 0.049 & 0.000 & 0.230 & 0.000 & 107 & 114 & 129 \\
\hline
\end{tabular}




\subsection{INITIAL REVIEW OF THE TEST MEASUREMENTS}

Several plots were prepared as part of the review of the measurements from these tests. Figure 3-1 provides a plot of the yield stress measurements by test number (\#). The yield stress measurements are identified by a time indicator, which is set at values of 1,4 , and 6 reflecting the initial measurement, $2^{\text {nd }}$ measurement $\left(3\right.$ minutes later), and the $3^{\text {rd }}$ measurement ( 3 minutes after the $2^{\text {nd }}$ ). The plot indicates that the yield stress measurements for a test run were increasing over the course of the measurements for most of the test runs, indicating the cementitious reactions may be occurring during the measurement. The yield stress for each measurement time was plotted against each other using a scatterplot, see Figure E - 1 in Appendix E, showing a strong linear correlation. Therefore, the data also indicate that any of the three yield stress data sets could have been used as the response variable. This data also reflects that if only a single yield stress measurement is obtained from multiple grout samples, the timing of the measurement is critical.

Figure 3-2 provides a plot of the first yield stress measurement for each test by test number with the acid batching information indicated on the $x$-axis. The six repeated tests are identified in this plot: HAW-1 and -5, HAW-12 and -17, HAW-31 and -36, HAW-33 and 38, HAW-19 and -24 and HAW-34 and -39. It should be noted that the results for HAW-17 presented in this report are the results from a rerun of that test. The initial response values for HAW-17 were 854, 1017, and $1029 \mathrm{~Pa}$ while the rerun values were 256, 301, and $300 \mathrm{~Pa}$ as shown in Figure 3-2. Comparisons between these results and those from the repeat run and HAW-12, led to the conclusion that the earlier yield stress measurements for HAW-17 were deemed to be an anomaly and were excluded from the analysis presented in this report.

Figure E - 1 through Figure E - 8 in Appendix E are plots of the natural logarithms of the first yield stress measurements (response variable) from these tests versus the input variables presented in Table 3-3 through Table 3-7. A review of these plots can be used to indicate the variables that have a more significant influence of the values of this response variable. Table 3-8 summarizes the effect on the response variable as the input variable increases. As the concentration of input variables on the left side of Table 3-8 increase, the yield stress tends to decrease. The opposite is true for the variables on the right side of Table 3-8. Note the variables maybe interrelated, hence yielding the same type of response. For instance, the $\mathrm{Na}$ and $\mathrm{NO}_{3}$ molarity in the final grout show essential the same type of decreasing trend in yield stress as these variables increase. This is because the vast majority (close to 100\%) of the $\mathrm{Na}$ and $\mathrm{NO}_{3}$ in the neutralized/pH adjusted solution is $\mathrm{NaNO}_{3}$. The variables not listed in Table 3-8 did not show any linear trend, such as the concentration of undissolved solids in the neutralized/pH adjusted fluid. 
SRNL-STI-2009-00101, REVISION 0

Table 3-8 Effect on Yield Stress as Input Variable Increases

\begin{tabular}{|c|c|c|c|}
\hline \multicolumn{2}{|c|}{ Decrease in Yield Stress } & \multicolumn{2}{|c|}{ Increase in Yield Stress } \\
\hline Input Variable & Appendix E & Input Variable & Appendix E \\
\hline Batch Sheet Input Data $-\mathrm{HNO}_{3}$ & Figure E - 2 & Final Grout - Cement Fraction & Figure E - 5 \\
\hline Acid Solution - density & Figure E - 3 & Final Grout - Zircon Fraction & Figure E - 5 \\
\hline $\begin{array}{l}\text { Neutralized-pH adjusted fluid - } \\
\text { density }\end{array}$ & Figure E - 4 & Final Grout - Water Fraction & Figure E - 5 \\
\hline $\begin{array}{c}\text { Neutralized-pH adjusted fluid - } \\
\text { wt } \% \text { TS }\end{array}$ & Figure E - 4 & & \\
\hline $\begin{array}{c}\text { Neutralized-pH adjusted fluid - } \\
\text { wt } \% \text { SSS }\end{array}$ & Figure E - 4 & & \\
\hline Final Grout - Simulant Fraction & Figure E - 5 & & \\
\hline Final Grout - Na Molarity & Figure E - 7 & & \\
\hline Final Grout $-\mathrm{NO}_{3}$ Molarity & Figure E - 7 & & \\
\hline
\end{tabular}




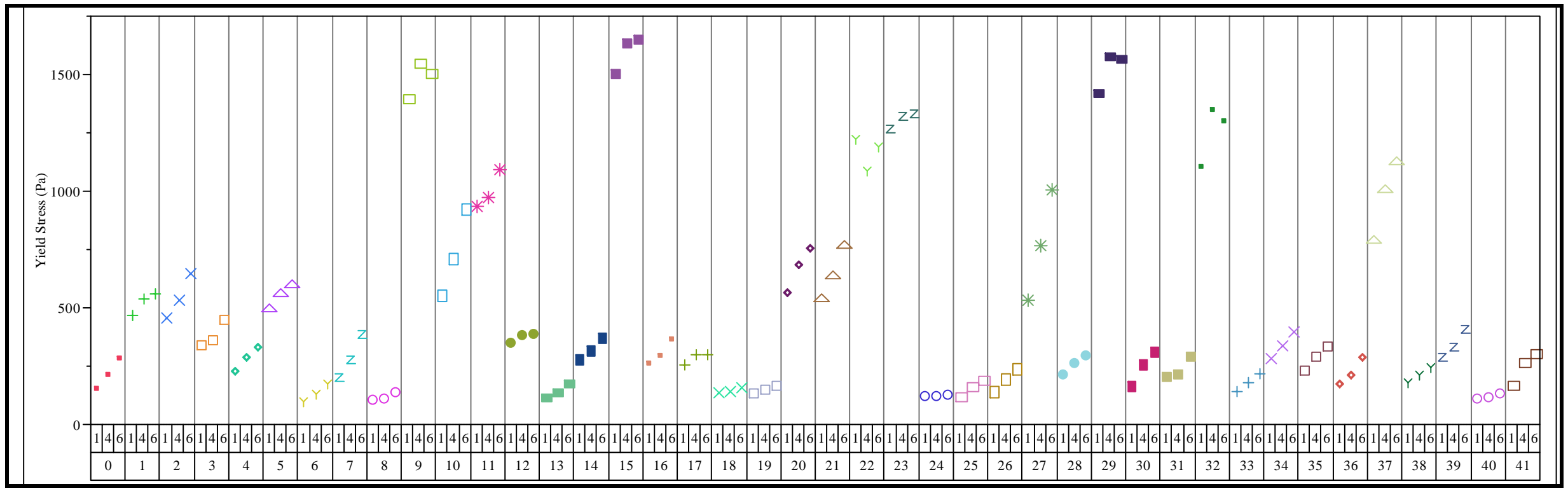

Figure 3-1 Set of Yield Stress Measurements by Test Run, HAW-0 Through HAW-41 


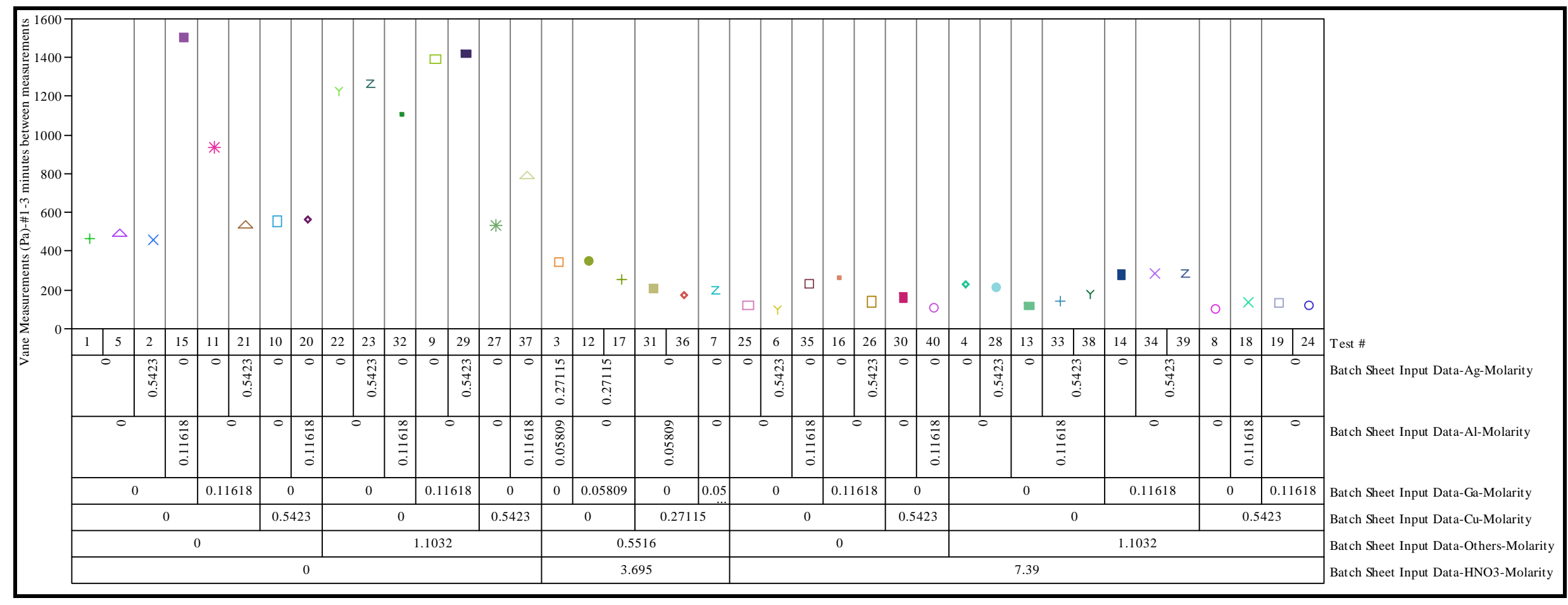

Figure 3-2 First Yield Stress Measurement by Batching Variables, HAW-1 Through HAW-40 


\subsection{STATISTICAL ANALYSIS}

The natural logarithm of the first yield stress measurement is utilized as the response variable in the statistical analyses explored in this report. The objective of the statistical analyses is to identify significant relationships between this response variable and various batching, experimental, or grout-related variables from the information in Table 3-3 through Table 3-7. In addition to the general objective, the statistical analyses must address the specific question of whether substitution of components (i.e., substituting $\mathrm{Al}$ for $\mathrm{Ga}$ and/or substituting $\mathrm{Cu}$ for $\mathrm{Ag}$ ) is a viable approach for use in future full scale testing.

The initial statistical analysis is provided in Figure 3-3 and Figure 3-4, and it explored the relationship between the natural logarithm of the first yield stress measurement and the acid batching variables defined in the variability study. There are 40 experimental runs making up these results. The intent of the analysis is to get an initial impression of those variables that are seen to have a statistically significant impact on the response variable. For these tests, the estimated coefficients (from "Parameter Estimates" Figure 3-3), from this analysis suggest the relationship between the input variable and the variables $\mathrm{HNO}_{3}, \mathrm{Ga}, \mathrm{Cu}$, and "Others" have a statistically significant influence on the response variable. Increases in the concentrations of $\mathrm{HNO}_{3}$ and $\mathrm{Cu}$ lead to decreases in yield stress while increases in $\mathrm{Ga}$ and "Others" lead to increases in yield stress. The effects of the other two batching variables, Al and Ag, are not statistically significant. These relationships can be observed in the leverage plots shown in Figure 3-4.

As a consequence, if one were to substitute $\mathrm{Al}$ for $\mathrm{Ga}$ in future testing, it is likely that the yield stress would be less for the testing with $\mathrm{Al}$ as compared to the yield stress of corresponding tests containing $\mathrm{Ga}$. The same general trend in results would be expected if $\mathrm{Cu}$ were used in place of Ag (i.e., lower yield stress values for tests with $\mathrm{Cu}$ versus the values for yield stress for corresponding Ag tests).

An additional aspect of the results from Figure 3-3 is that while the $\mathrm{R}^{2}$ value for the model is $86 \%$, there is an indication of a lack of fit for this simple main-effects model.

Excluding tests that involved $\mathrm{Al}$ and $\mathrm{Cu}$ from the data used to explore models for the yield stress response resulted in 20 remaining data points. Figure 3-5 provides the JMP results from modeling the natural logarithms of the first yield stress measurements versus a maineffects model for $\mathrm{HNO}_{3}$, Ga, Ag, and "Others" in the acid batches. All of these candidate, explanatory variables are statistically significant except for Ag. Once again, increases in the concentrations of $\mathrm{HNO}_{3}$ lead to decreases in yield stress while increases in Ga and "Others" lead to increases in yield stress. There is no indication of lack of fit for this modeling effort. Note that in the Parameter Estimates section of Figure 3-5, for every molar increase in $\mathrm{HNO}_{3}$ results in a log yield stress decrease of -0.209479 and covers a large range of molarity. For Ga and "Others", this estimated parameter is larger that than for $\mathrm{HNO}_{3}$, but their molarity range is much smaller.

Figure 3-6 provides the results from a similar modeling effort for tests that did not include $\mathrm{Ag}$ and $\mathrm{Ga}$. In this case, the candidate explanatory variables are $\mathrm{HNO}_{3}, \mathrm{Al}, \mathrm{Cu}$, and "Others." 
From the exhibit, only the main effect for $\mathrm{HNO}_{3}$ is statistically significant. There is also a slight indication of a lack of fit for this model which could be addressed by adding a squaredterm for $\mathrm{HNO}_{3}$, as indicated in Figure 3-6. Since the variability study was not designed to investigate for such curvilinear effects, this influence on the yield stress by the level of $\mathrm{HNO}_{3}$ should be considered preliminary. In fact, the curvilinear effect could be attributed to $\mathrm{Cu}$ instead of $\mathrm{HNO}_{3}$, and additional testing designed to specifically answer this question would be needed to address this issue. The variability study was not intended to fully investigate for such non-linear effects.

\subsection{ELEMENTAL SUBSTITIONS}

As previously discussed, substituting copper for silver and aluminum for gallium was statistically shown to result in a lower yield stress, provided all other parameters are maintained. This can also be observed in Figure 3-7 for the $\mathrm{Cu}$ for Ag substitution and Figure 3-8 for the Al for Ga substitution. The arrows shown in these figures indicate the effect of substituting, given all other parameters are held constant. The consequence of this finding is that the simulants compositions provided to the mixer vendor were nonconservative for yield stress. 


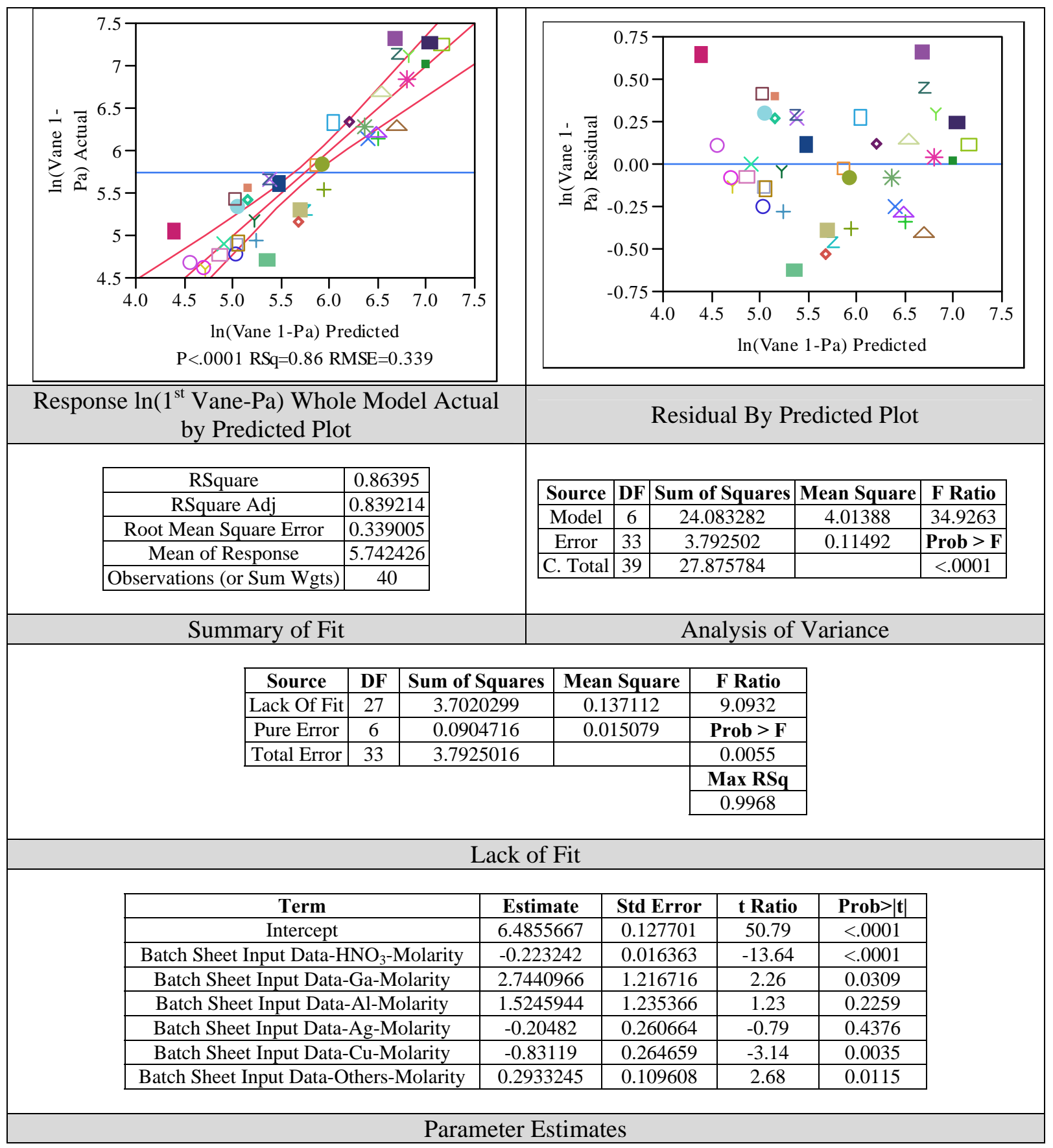

Figure 3-3 Modeling of Natural Logarithm of First Yield Stress Measurements (all acid batching variables) 


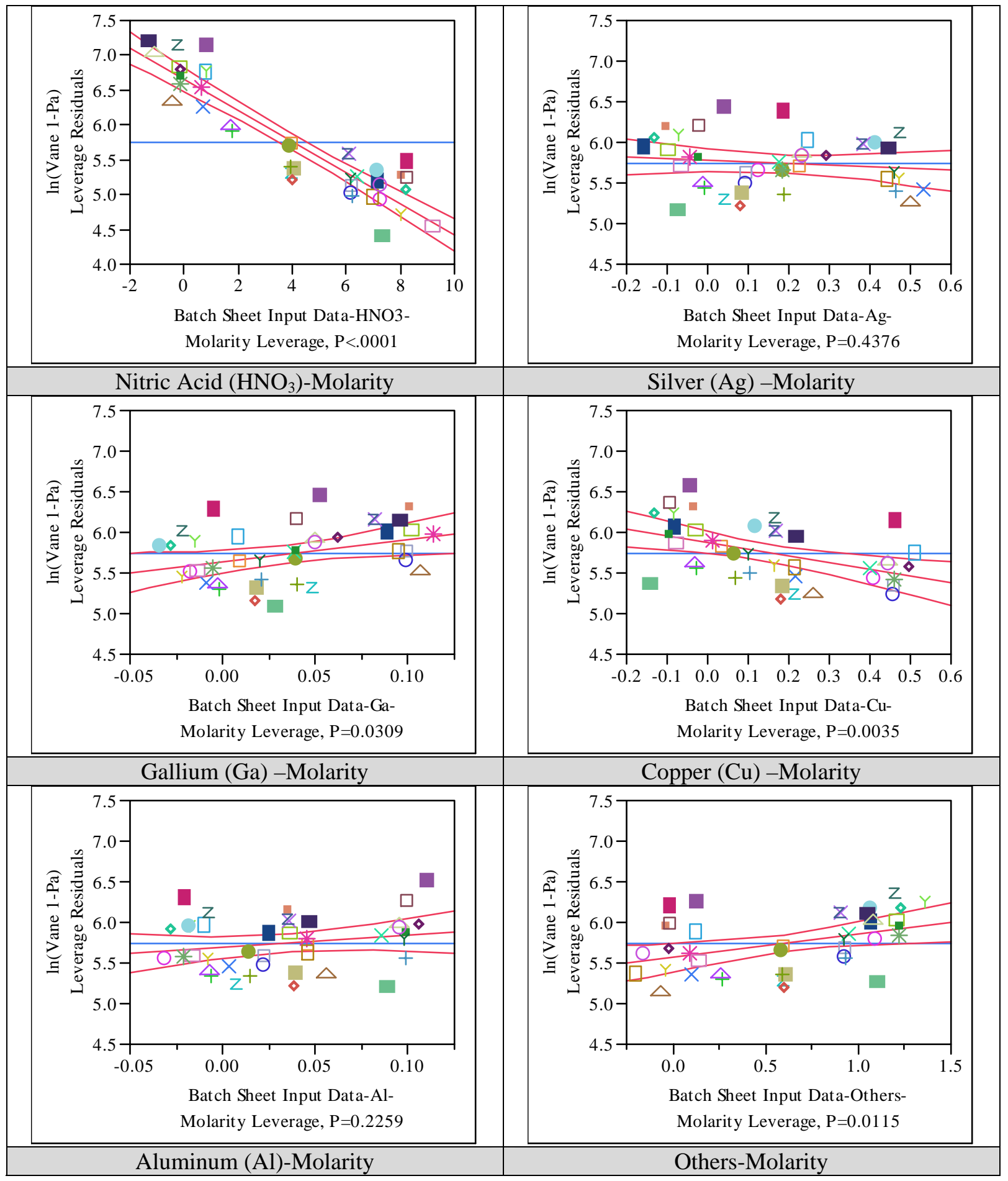

Figure 3-4 Leverage Plots of Natural Logarithm of First Yield Stress Measurements Against Acid Batch Sheet Input Data 
SRNL-STI-2009-00101, REVISION 0

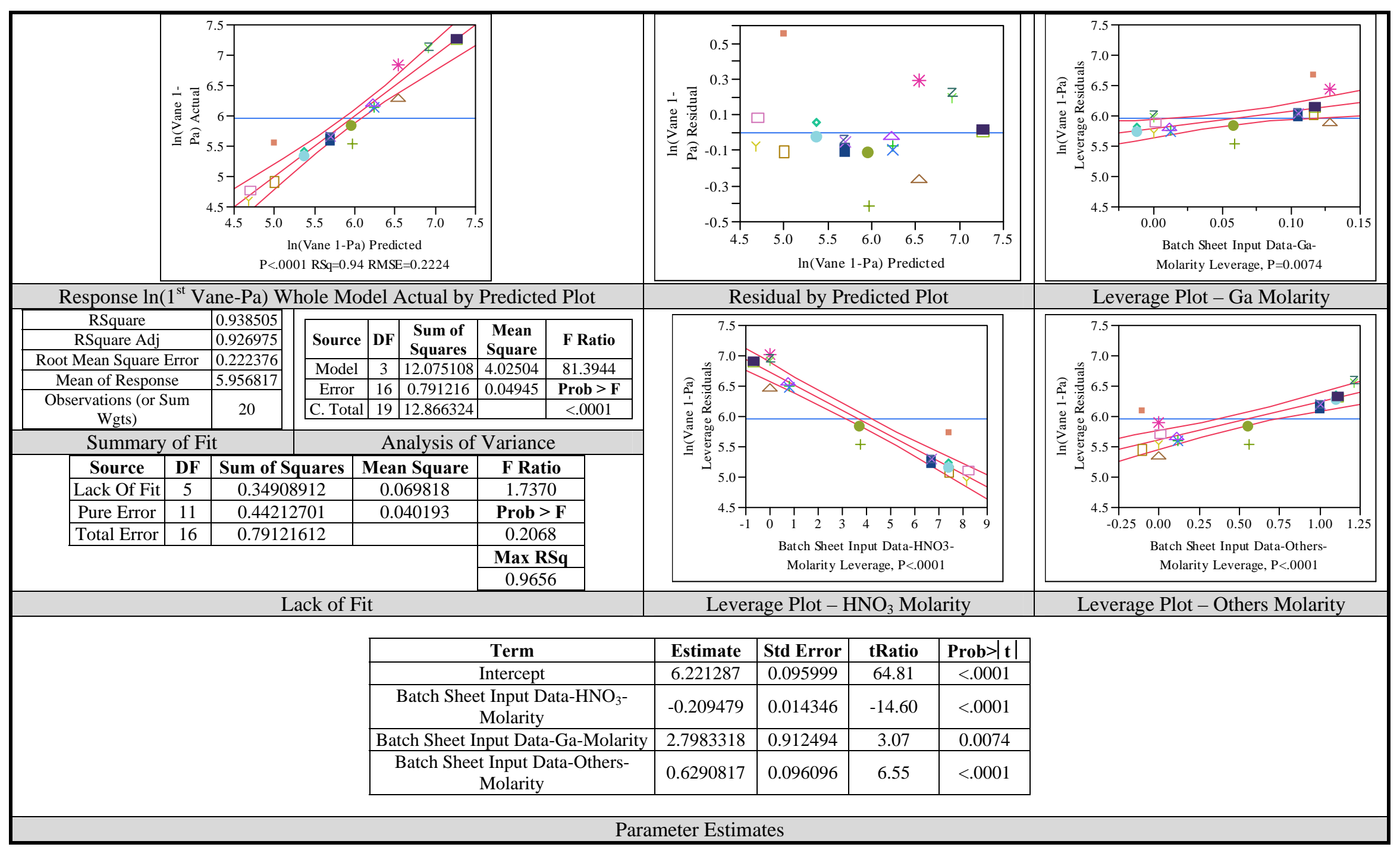

Figure 3-5 Modeling of Natural Logarithm of First Yield Stress Measurements (excluding runs with substitution variables) 


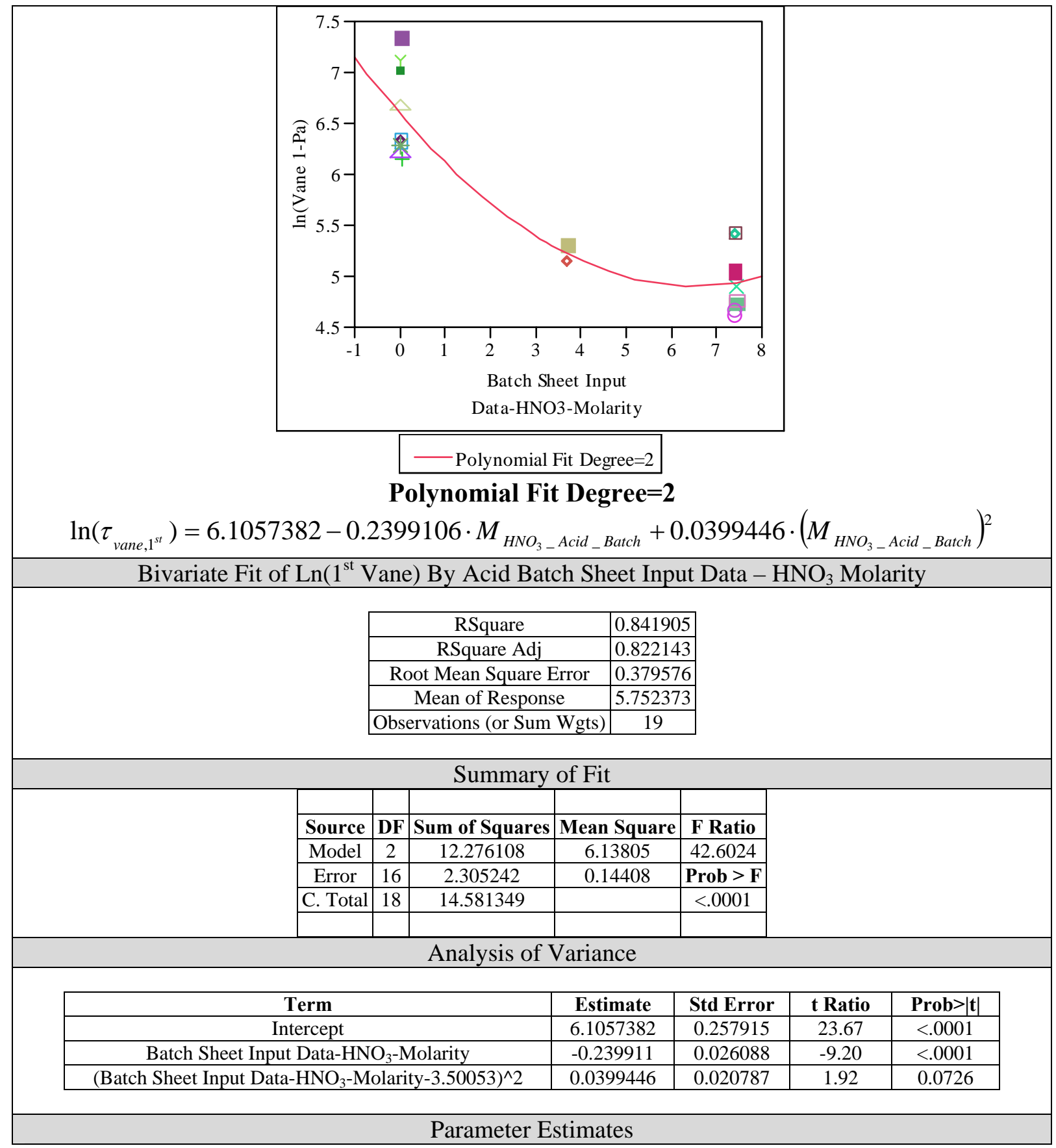

Figure 3-6 Modeling of Natural Logarithm of First Yield Stress Measurements (excluding runs with Ag and Ga) 


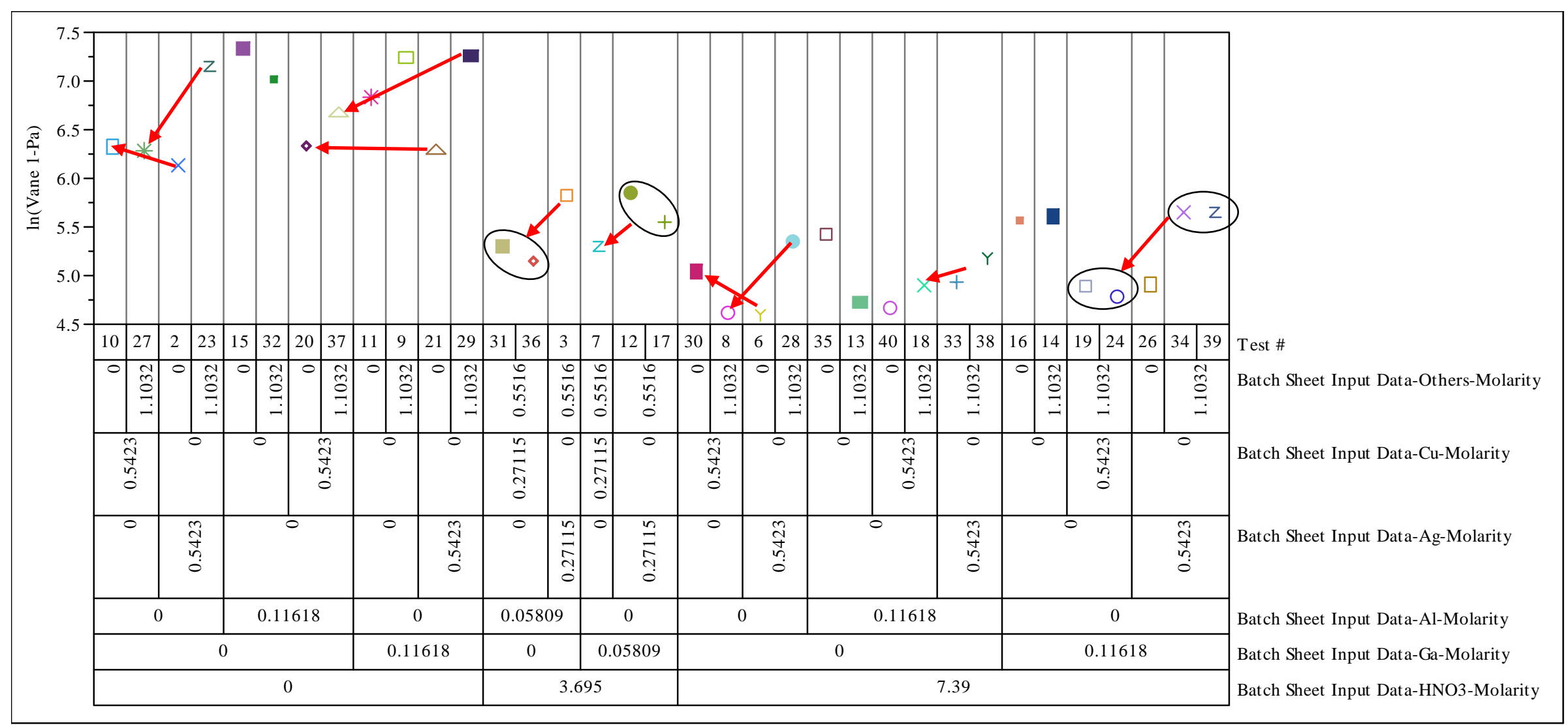

Figure 3-7 Plot of natural logarithm of first yield stress measurement (Pa) for trials investigating substitutability grouped as indicated by the information provided on the $\mathrm{x}$-axis. This plot is arranged to help investigate the viability of substituting $\mathrm{Cu}$ for Ag. Arrows show direction of yield stress change during substitution. 


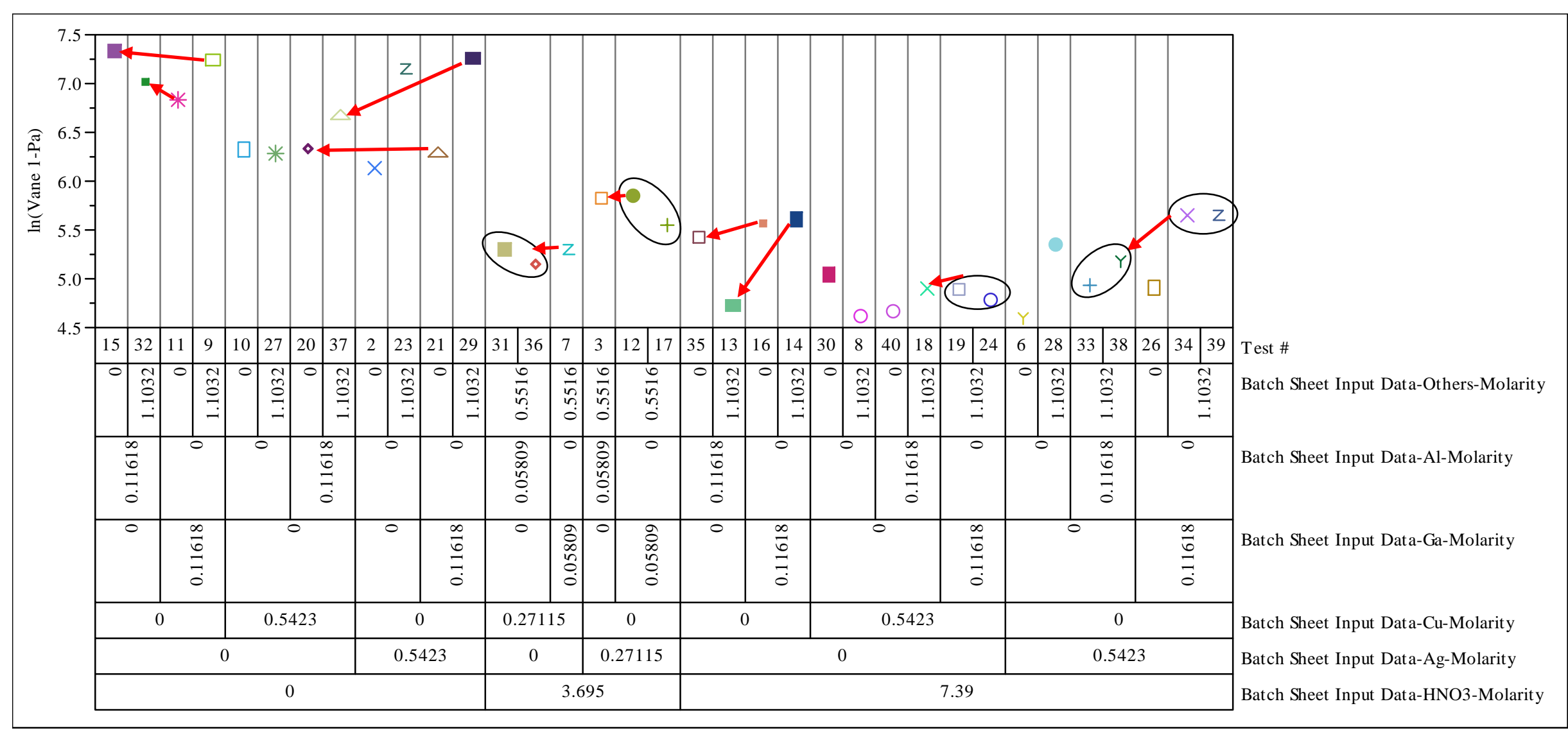

Figure 3-8 Plot of natural logarithm of first yield stress measurement (Pa) for trials investigating substitutability grouped as indicated by the information provided on the $\mathbf{x}$-axis. This plot is arranged to help investigate the viability of substituting Al for Ga. Arrows show direction of yield stress change during substitution. 


\subsection{GROUT BLENDS WITH INITIAL WETTING ISSUES}

The following grout mixtures, HAW-9, -20, -29 and -37 had difficulties initially wetting the solution with the dry materials using the Hobart mixer at its lowest speed (\#1), which is also the highest torque position. The mixing difficulty was to the extent that the Hobart mixer electrically overloaded and stopped mixing. At this point, some of the batched materials (partially wetted) was removed and then, when the material in the Hobart mixer was mixing effectively at mixing speed (\#1), the removed material was added back in portions. For HAW-9, -20, -29, and -37, the total mixing times at speed \#1 were 9, 6-1/2, 4 and 4 minutes respectively. Figure 3-9 show the natural logarithm of the first yield stress and mixes that had high yield stresses. It was noted in the mixing log that these other high yield stress grouts were hard to mix at the lower speed, but it was not necessary to remove material to assist in the mixing. The cause for the initial wetting problem could not be discerned. HAW-9, -20 , and -37 grouts were processed again in a different manner. In the modified method the liquid and solids were added batch wise to the mixer at its lowest speed so as not to cause the mixer to seize. When all the materials were added, the mixing sequence followed the same protocol used for the other mixes. The results from the two different mixing methods are provided in Table 3-9, where the HAW-\#A refers to the second method of mixing and the mixing methods show little differences in the yield stress. This result may indicate that the method used for initially wetting of the materials does not impact the yield stress measurements.

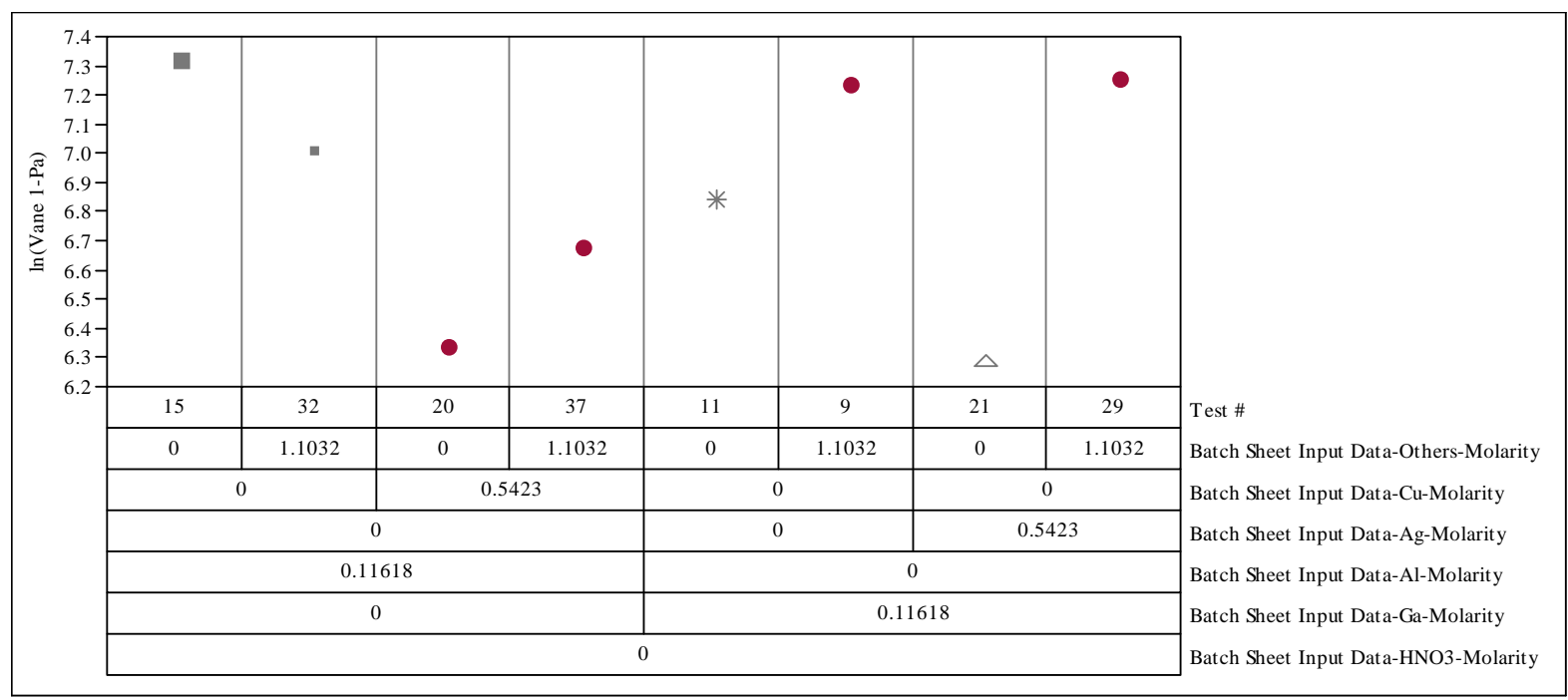

Figure 3-9 Initial Wetting Mix Batches and Other High Yield Stress Results

Table 3-9 Result Using Two Different Mixing Method for the Initial Mixes that Provided Wetting Issues

\begin{tabular}{|c|c|c|c|c|c|c|}
\hline Yield Stress & \multicolumn{7}{|c|}{ Yield Stress (Pa) } \\
\cline { 2 - 7 } Measurement & HAW-9 & HAW-9A & HAW-20 & HAW-20A & HAW-37 & HAW-37A \\
\hline First & 1389 & 1575 & 565 & 576 & 790 & 650 \\
\hline Second & 1544 & 1645 & 687 & 681 & 1007 & 786 \\
\hline Third & 1502 & 1653 & 753 & 750 & 1124 & 907 \\
\hline
\end{tabular}




\subsection{FULL SCALE SIMULANT COMPARISON TO VARIABILITY HAW BATCHES}

HAW-0 and HAW-41 were simulants used in the full scale mixing tests that were performed in Hanford and SRNL to support the initial design and handling processing issues. These simulants were tested to determine how they compare to the simulants developed to support the variability test. The results for the full scale simulant, HAW-0 and HAW-41 are provided in Table 3-3 through Table 3-6. The yield stress measurements for both batches are very similar and the average of the first yield stress measurement is shown in Figure 3-10, which includes all the first yield stress measurements. These data clearly shows that this simulant is not very difficult to mix. The first yield stress measurement versus increased sodium molarity concentration in the final grout is provided in Figure 3-11, showing that the sodium concentration in HAW-0/HAW-41 is in the region where mixing was not an issue, as supported by the variability studies.

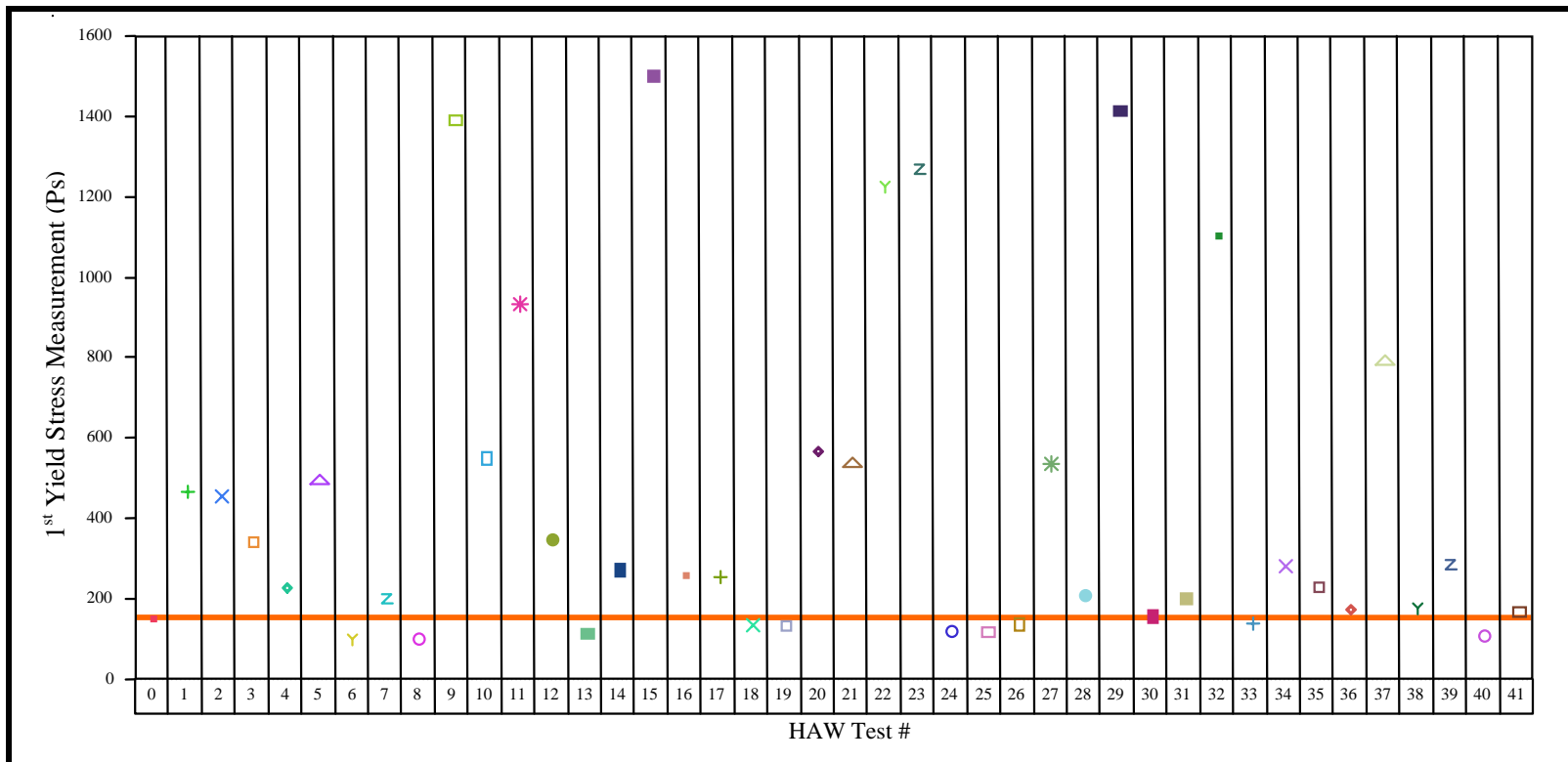

Figure 3-10 First Yield Stress Measurement Versus HAW Tests with Averaged Yield Stress HAW-0/HAW-41 Line Reference

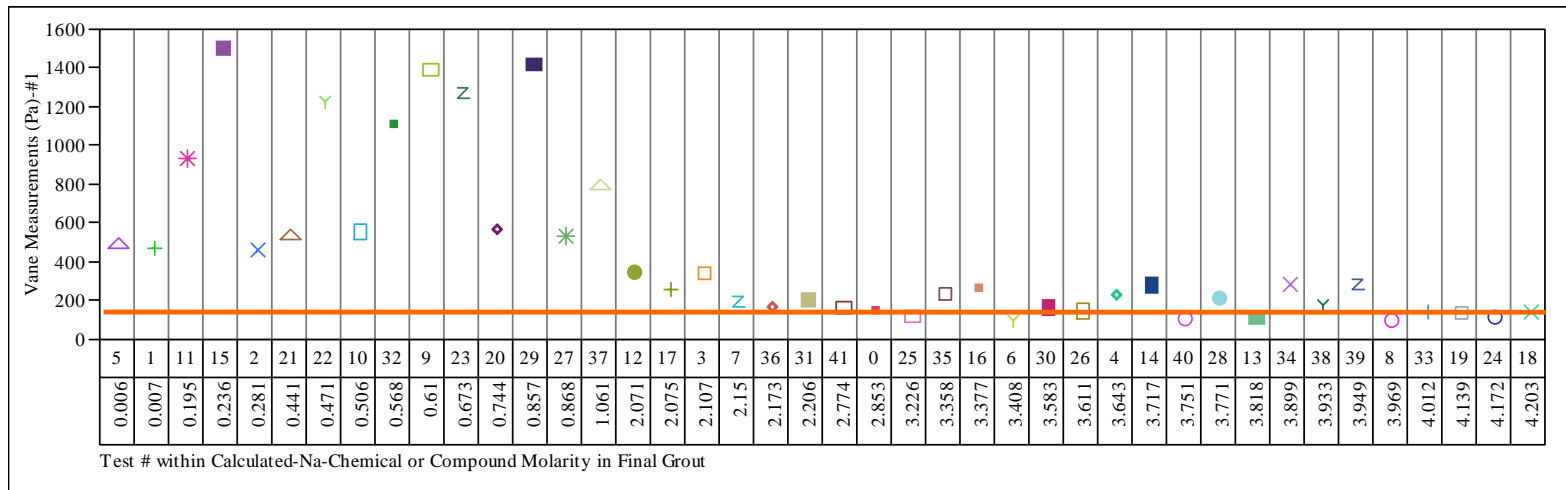

Figure 3-11 First Yield Stress Versus Sodium Molarity in Final Grout for All HAW with Averaged Yield Stress HAW-0/HAW-41 Line Reference 


\subsection{WATER ONLY GROUT BATCHES}

Grout batches using just water and made with the same composition of dry mix $\left(1 / 12^{\text {th }}\right.$ zircon flour and $11 / 12^{\text {th }}$ Portland cement, by mass) used for the HAW mixes were utilized to develop the method for HAW grout mixing. This would provide an indication of when the Hobart mixer would have issues with mixing (initial wetting). Water to cement ratios of 0.28 - 0.35 were evaluated to identify a mixture that could be used on a daily basis. Based on this evaluation, a W/C of 0.30 was selected. This W/C of 0.30 was batched on a daily basis to verify that the mixing method and measurement were consistent when HAW grout measurements were being performed. The Hobart mixer did not seize during mixing of any of the water-only batches. The individual results are provided in Table 3-10 and the averaged values and standard deviations are provided in Figure 3-12.

Table 3-10 Water Grout Batches - 1400 mL Total Volume

\begin{tabular}{|c|c|c|c|c|c|}
\hline Date & W/C & $\begin{array}{c}1^{\text {st }} \text { Vane } \\
\text { Measurement } \\
\text { (Pascal) }\end{array}$ & Date & W/C & $\begin{array}{c}1^{\text {st }} \text { Vane } \\
\text { Measurement } \\
\text { (Pascal) }\end{array}$ \\
\hline $11 / 25 / 2008$ & 0.28 & 1182 & $12 / 5 / 2008$ & 0.3 & 502.5 \\
\hline $11 / 25 / 2008$ & 0.28 & 1017 & $12 / 8 / 2008$ & 0.3 & 503.1 \\
\hline $11 / 26 / 2008$ & 0.28 & 1080 & $12 / 9 / 2008$ & 0.3 & 489.7 \\
\hline $12 / 1 / 2008$ & 0.29 & 896.3 & $1 / 6 / 2009$ & 0.3 & 458.4 \\
\hline $11 / 24 / 2008$ & 0.3 & 487.9 & $1 / 12 / 2009$ & 0.3 & 426.8 \\
\hline $11 / 25 / 2008$ & 0.3 & 533.3 & $12 / 2 / 2008$ & 0.31 & 406.6 \\
\hline $11 / 25 / 2008$ & 0.3 & 435.2 & $11 / 25 / 2008$ & 0.32 & 294.1 \\
\hline $12 / 1 / 2008$ & 0.3 & 483.4 & $12 / 1 / 2008$ & 0.32 & 293.3 \\
\hline $12 / 2 / 2008$ & 0.3 & 472.5 & $12 / 2 / 2008$ & 0.35 & 148.3 \\
\hline $12 / 4 / 2008$ & 0.3 & 515.6 & & & \\
\hline
\end{tabular}

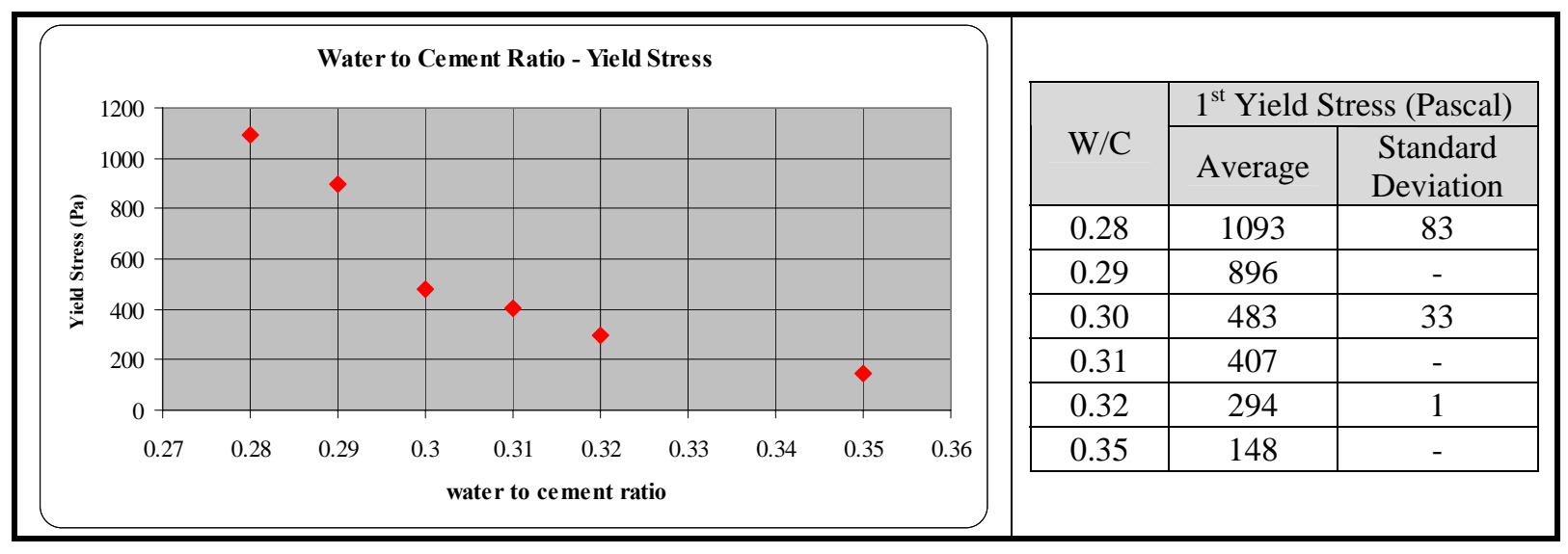

Figure 3-12 Averaged Water to Cement Mass Ratio Batches for First Yield Stress Measurements 


\subsection{WSB FLOWSHEET - SRNL WSB SIMULANT COMPARISION}

The present flowsheet WSB flowsheet is provided in Reference 23. The composition of the acidic feed from MFFF has changed since this document has been issued. ${ }^{\text {vii }}$ It is expected that this flowsheet will be revised to incorporate changes that have occurred in the composition of the acidic waste stream, similar to those tested in this task. In the existing WSB flowsheet there a two additional items that differ in what SRNL has consistently provided WSB-DA in support of the HAW full scale tests and in this task; (1) SRNL has targeted a pH of 12 for a neutralized/pH adjusted acidic feed, the WSB flowsheet calls out an additional $10 \%$ caustic volume (or mass) addition required to destroy all the nitric acid $\left(\mathrm{HNO}_{3}\right)$, and (2) WSB-DA provided guidance for a zircon flour to Portland cement mass ratio of $1 / 12$ and the WSB flowsheet calls out an $\mathrm{Z} / \mathrm{C}$ mass ratio of $1 / 4$.

The impact of these differences, on salt solution, cement and zircon flour contribution to a fixed volume the final product (for example 65\% full condition) in a 55 gallon drum can be represented by the following equations [13] and [14];

$$
\begin{aligned}
V_{\text {grout }} & =V_{\text {Portland_Cement }_{-}}+V_{\text {Zircon_Flour }_{\text {grout }}}+V_{\text {Salt_Solution }} \\
M_{\text {grout }} & =\left(\frac{V}{\rho}\right)_{\text {Portland_Cement }}+\left(\frac{V}{\rho}\right)_{\text {Zircon_Flour }}+\left(\frac{V}{\rho}\right)_{\text {Salt_Solution }} \\
& =M_{\text {Portland_Cement }}+M_{\text {Zircon_Flour }_{\text {Grolt_Solution }}}+M_{\text {Salt }}
\end{aligned}
$$

where $\mathrm{V}_{\text {grout }}=$ volume of grout

$\mathrm{M}_{\text {grout }}=$ mass of grout

$\mathrm{V}_{\mathrm{i}}=$ volume of the $\mathrm{i}^{\text {th }}$ component in grout

$\mathrm{M}_{\mathrm{i}}=$ mass of the $\mathrm{i}^{\text {th }}$ component in grout

$\rho i=$ density of the $i^{\text {th }}$ component in grout

A change in any of the components will cause a change to the others, given a fixed volume or mass of material. For example, if more salt solution is required (due to higher solids content) then to maintain a specific water to cement mass ratio, there must be a reduction in the contributions in both Portland cement and zircon flour.

For item (1), SRNL performed calculations to compare the volume of 51 wt\% $\mathrm{NaOH}$ solution required to obtain a $\mathrm{pH}$ of 12 and for $10 \%$ extra $\mathrm{NaOH}$ solution. The density of $51 \mathrm{wt} \% \mathrm{NaOH}$ solution is approximately $1.528 \mathrm{~g} / \mathrm{mL}$ at $20{ }^{\circ} \mathrm{C}$ as compared to $1.521 \mathrm{~g} / \mathrm{mL}$ for $50 \mathrm{wt} \% \mathrm{NaOH}$ solution. ${ }^{24}$ For the $10 \%$ extra NaOH solution in the SRNL calculation, SRNL determined the amount of $\mathrm{NaOH}$ that reacted with the $\mathrm{HNO}_{3}$ and metals that contained $\mathrm{NO}_{3}{ }^{-}$ that would react to produce $\mathrm{NaNO}_{3}$ to form a neutral solution. A starting volume of 1-L of acidic solution was used to calculate the quantity of $\mathrm{NO}_{3}{ }^{-}$required to react with the nitric acid and nitrates from the metals. It is assumed that the additional $\mathrm{NaOH}$ will only increase the $\mathrm{pH}$ and will not interact with the metals to create hydroxide or oxide metals. The

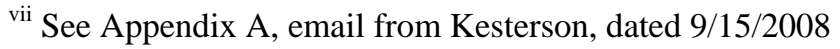


available nitrates for reaction in the one liter of acidic solution, the mass of $51 \mathrm{wt} \% \mathrm{NaOH}$ solution to obtain a neutral $\mathrm{pH}$, from a $\mathrm{pH}$ of 7 to a $\mathrm{pH}$ of 12 , and from a $\mathrm{pH}$ of 7 to $+10 \%$ $\mathrm{NaOH}$ solution, the volume of neutralized acidic solution, and the difference in volume between the $+10 \% \mathrm{NaOH}$ solution over that of a $\mathrm{pH} 12$ solution are provided in Table 3-11. The results from this table show that the $+10 \% \mathrm{NaOH}$ solution will increase the $\mathrm{NaOH}$ requirements for all cases, other than for water only. This is due to water having a $\mathrm{pH}$ of 7 and no $\mathrm{NO}_{3}{ }^{-}$. Since the $\mathrm{NaOH}$ solution contains $51 \mathrm{wt} \%$ solids, the total solids fraction of the $+10 \% \mathrm{NaOH}$ solutions will increase on a mass basis as compared to the $\mathrm{pH} 12$ adjusted solutions. The calculated densities of the salt solutions are provided in Table 3-12, which shows that indeed the $+10 \% \mathrm{NaOH}$ solutions are slightly more dense. These densities were determined using volume additivity.

The impact of items (1) and (2) on the grout density and mass contribution of the various components in the grout are proved in Table 3-12 through Table 3-14 for Z/C ratios of 1/12 and $1 / 4$. The grout densities were determined using volume additivity. The W/C mass ratio for all the grout densities in these tables is 0.30 . The density of the Portland cement and zircon flour used in these calculations are those stated in section 2.3.3. The densities of the salt solution were those provided in Table 3-12. The grout density differences between the $\mathrm{pH}$ of 12 and $+10 \% \mathrm{NaOH}$ for a given $\mathrm{Z} / \mathrm{C}$ mass ratio are very slight, with the $+10 \% \mathrm{NaOH}$ slightly more dense. As the $\mathrm{Z} / \mathrm{C}$ ratio increases, so does the grout density.

The calculated masses of the various components for one liter of grout for Z/C mass ratio of 1/12 and 1/4 are provided in Table 3-13 and Table 3-14 respectively. The mass contributions for the $\mathrm{pH}$ of 12 and $+10 \% \mathrm{NaOH}$ for a given a $\mathrm{Z} / \mathrm{C}$ mass ratio are similar, with the mass contribution from the salt solution be slightly greater and the contributions of the dry materials be slightly less for the $+10 \% \mathrm{NaOH}$ solution as compared to the $\mathrm{pH}$ of 12 solution. The mass contribution of zircon flour increases drastically for a Z/C mass ratio of $1 / 4$ as compared to the $\mathrm{Z} / \mathrm{C}$ mass ratio of $1 / 12$, when comparing the same salt concentrations. 
SRNL-STI-2009-00101, REVISION 0

Table 3-11 Impact of Increased NaOH Addition to Neutralized HAW Solution

\begin{tabular}{|c|c|c|c|c|c|c|c|}
\hline \multirow[b]{2}{*}{$\begin{array}{l}\text { HAW } \\
\text { Test \# }\end{array}$} & \multirow{2}{*}{$\begin{array}{c}\text { Free } \\
\text { nitrates in } \\
1 \mathrm{~L} \text { of } \\
\text { acidic } \\
\text { solution }\end{array}$} & \multicolumn{3}{|c|}{$\begin{array}{c}\text { Mass of } 51 \mathrm{wt} \% \mathrm{NaOH} \text { solution } \\
\text { addition (grams) }\end{array}$} & \multirow{2}{*}{$\begin{array}{c}\mathrm{pH} \\
\text { of } \\
+10 \% \\
\mathrm{NaOH}\end{array}$} & \multicolumn{2}{|c|}{ Volume of solution (mL) } \\
\hline & & $\mathrm{pH}=7$ & $\begin{array}{l}\mathrm{pH} 7 \text { to } \\
12\end{array}$ & $\begin{array}{l}\mathrm{pH} 7 \text { to } \\
+10 \% \\
\mathrm{NaOH}\end{array}$ & & $\begin{array}{l}\mathrm{pH}=7 \\
\text { solution }\end{array}$ & $\begin{array}{c}\text { volume } \\
\text { increase - } \\
\text { pH } 12 \text { to } \\
+10 \% \mathrm{NaOH} \\
\end{array}$ \\
\hline $0 / 41$ & 7.88 & 617.8 & 1.2 & 61.8 & 13.7 & 1457.1 & 39.7 \\
\hline 1 & 0.00 & 0.0 & 0.8 & 0.0 & 12.0 & 999.3 & -0.5 \\
\hline 2 & 0.54 & 42.5 & 0.8 & 4.3 & 12.7 & $\begin{array}{ll}1027.8 \\
\end{array}$ & 2.3 \\
\hline 3 & 4.62 & 362.0 & 1.0 & 36.2 & 13.6 & 1260.5 & 23.0 \\
\hline 4 & 8.34 & 654.2 & 1.2 & 65.4 & 13.7 & 1491.4 & 42.0 \\
\hline 5 & 0.00 & 0.0 & 0.8 & 0.0 & 12.0 & 999.5 & -0.5 \\
\hline 6 & 7.93 & 622.1 & 1.1 & 62.2 & 13.7 & 1454.6 & 40.0 \\
\hline 7 & 4.89 & 383.3 & 1.0 & 38.3 & 13.6 & 1295.1 & 24.4 \\
\hline 8 & 9.43 & 739.2 & 1.2 & 73.9 & 13.8 & 1567.9 & 47.6 \\
\hline 9 & 1.30 & 101.9 & 0.8 & 10.2 & 13.1 & 1083.2 & 6.1 \\
\hline 10 & 1.08 & 85.1 & 0.9 & 8.5 & 13.0 & 1087.3 & 5.0 \\
\hline 11 & 0.35 & 27.3 & 0.8 & 2.7 & 12.5 & 1019.8 & 1.3 \\
\hline 12 & 4.62 & 362.0 & 1.0 & 36.2 & 13.6 & 1273.2 & 23.0 \\
\hline 13 & 8.69 & 681.5 & 1.2 & 68.2 & 13.8 & 1488.3 & 43.8 \\
\hline 14 & 8.69 & 681.5 & 1.2 & 68.2 & 13.7 & 1514.8 & 43.8 \\
\hline 15 & 0.35 & 27.3 & 0.8 & 2.7 & 12.5 & 1017.4 & 1.3 \\
\hline 16 & 7.74 & 606.9 & 1.1 & 60.7 & 13.7 & 1449.1 & 39.0 \\
\hline 17 & 4.62 & 362.0 & 1.0 & 36.2 & 13.6 & 1273.1 & 23.0 \\
\hline 18 & 9.77 & 766.6 & 1.2 & 76.7 & 13.8 & 1561.4 & 49.4 \\
\hline 19 & 9.77 & 766.6 & 1.2 & 76.7 & 13.8 & 1571.7 & 49.4 \\
\hline 20 & 1.43 & 112.4 & 0.9 & 11.2 & 13.1 & 1099.6 & 6.8 \\
\hline 21 & 0.89 & 69.9 & 0.8 & 7.0 & 12.9 & 1033.1 & 4.0 \\
\hline 22 & 0.95 & 74.6 & 0.8 & 7.5 & 13.0 & 1060.7 & 4.3 \\
\hline 23 & 1.49 & 117.1 & 0.9 & 11.7 & 13.1 & 1104.1 & 7.1 \\
\hline 24 & 9.77 & 766.6 & 1.2 & 76.7 & 13.8 & 1568.4 & 49.4 \\
\hline 25 & 7.39 & 579.6 & 1.1 & 58.0 & 13.7 & 1428.9 & 37.2 \\
\hline 26 & 8.28 & 649.4 & 1.1 & 64.9 & 13.7 & 1441.9 & 41.8 \\
\hline 27 & 2.04 & 159.7 & 0.9 & 16.0 & 13.3 & 1116.8 & 9.9 \\
\hline 28 & 8.88 & 696.7 & 1.2 & 69.7 & 13.8 & 1531.6 & 44.8 \\
\hline 29 & 1.84 & 144.5 & 0.9 & 14.4 & 13.2 & 1118.1 & 8.9 \\
\hline 30 & 8.47 & 664.6 & 1.2 & 66.5 & 13.7 & 1497.7 & 42.7 \\
\hline 31 & 4.89 & 383.3 & 1.0 & 38.3 & 13.6 & 1292.5 & 24.4 \\
\hline 32 & 1.30 & 101.9 & 0.8 & 10.2 & 13.1 & 1066.7 & 6.1 \\
\hline 33 & 9.23 & 724.0 & 1.2 & 72.4 & 13.8 & 1529.7 & 46.6 \\
\hline 34 & 9.23 & 724.0 & 1.2 & 72.4 & 13.8 & 1549.7 & 46.6 \\
\hline 35 & 7.74 & 606.9 & 1.1 & 60.7 & 13.7 & 1451.0 & 39.0 \\
\hline 36 & 4.89 & 383.3 & 1.0 & 38.3 & 13.6 & 1304.4 & 24.4 \\
\hline 37 & 2.38 & 187.0 & 0.9 & 18.7 & 13.3 & 1136.0 & 11.7 \\
\hline 38 & 9.23 & 724.0 & 1.2 & 72.4 & 13.8 & 1541.8 & 46.6 \\
\hline 39 & 9.23 & 724.0 & 1.2 & 72.4 & 13.8 & 1540.9 & 46.6 \\
\hline 40 & 8.82 & 692.0 & 1.2 & 69.2 & 13.8 & 1516.5 & 44.5 \\
\hline
\end{tabular}


SRNL-STI-2009-00101, REVISION 0

Table 3-12 Impact on Density Due to Increases in $\mathrm{NaOH}$ and Zircon Flour

\begin{tabular}{|c|c|c|c|c|c|c|}
\hline \multirow{3}{*}{$\begin{array}{l}\text { HAW } \\
\text { Test \# }\end{array}$} & \multirow{2}{*}{\multicolumn{2}{|c|}{$\begin{array}{l}\text { Density Salt Solution } \\
\qquad(\mathrm{g} / \mathrm{mL})\end{array}$}} & \multicolumn{4}{|c|}{ Grout Density (g/mL) } \\
\hline & & & \multicolumn{2}{|c|}{$\mathrm{Z} / \mathrm{C}=1 / 12$} & \multicolumn{2}{|c|}{$\mathrm{Z} / \mathrm{C}=1 / 4$} \\
\hline & $\mathrm{pH}=12$ & $\begin{array}{l}+10 \% \\
\mathrm{NaOH}\end{array}$ & $\mathrm{pH}=12$ & $\begin{array}{l}+10 \% \\
\mathrm{NaOH}\end{array}$ & $\mathrm{pH}=12$ & $\begin{array}{l}+10 \% \\
\mathrm{NaOH}\end{array}$ \\
\hline $0 / 41$ & 1.288 & 1.295 & 2.208 & 2.210 & 2.329 & 2.331 \\
\hline 1 & 0.998 & 0.998 & 2.174 & 2.174 & 2.309 & 2.309 \\
\hline 2 & 1.086 & 1.087 & 2.201 & 2.201 & 2.334 & 2.334 \\
\hline 3 & 1.235 & 1.240 & 2.217 & 2.218 & 2.342 & 2.343 \\
\hline 4 & 1.296 & 1.303 & 2.170 & 2.174 & 2.287 & 2.291 \\
\hline 5 & 0.998 & 0.998 & 2.174 & 2.173 & 2.309 & 2.309 \\
\hline 6 & 1.322 & 1.327 & 2.228 & 2.230 & 2.348 & 2.350 \\
\hline 7 & 1.220 & 1.226 & 2.191 & 2.193 & 2.315 & 2.317 \\
\hline 8 & 1.338 & 1.344 & 2.191 & 2.194 & 2.307 & 2.310 \\
\hline 9 & 1.092 & 1.095 & 2.185 & 2.185 & 2.316 & 2.316 \\
\hline 10 & 1.071 & 1.074 & 2.175 & 2.175 & 2.307 & 2.307 \\
\hline 11 & 1.026 & 1.026 & 2.181 & 2.181 & 2.316 & 2.316 \\
\hline 12 & 1.223 & 1.228 & 2.197 & 2.199 & 2.321 & 2.323 \\
\hline 13 & 1.324 & 1.330 & 2.191 & 2.195 & 2.309 & 2.312 \\
\hline 14 & 1.311 & 1.317 & 2.187 & 2.190 & 2.305 & 2.308 \\
\hline 15 & 1.026 & 1.027 & 2.179 & 2.179 & 2.314 & 2.314 \\
\hline 16 & 1.279 & 1.286 & 2.210 & 2.213 & 2.332 & 2.334 \\
\hline 17 & 1.223 & 1.229 & 2.205 & 2.207 & 2.330 & 2.331 \\
\hline 18 & 1.360 & 1.365 & 2.190 & 2.194 & 2.305 & 2.308 \\
\hline 19 & 1.359 & 1.364 & 2.197 & 2.201 & 2.313 & 2.316 \\
\hline 20 & 1.100 & 1.103 & 2.187 & 2.187 & 2.318 & 2.318 \\
\hline 21 & 1.127 & 1.128 & 2.227 & 2.227 & 2.359 & 2.359 \\
\hline 22 & 1.072 & 1.074 & 2.182 & 2.182 & 2.314 & 2.314 \\
\hline 23 & 1.136 & 1.138 & 2.196 & 2.197 & 2.326 & 2.326 \\
\hline 24 & 1.359 & 1.365 & 2.193 & 2.196 & 2.307 & 2.311 \\
\hline 25 & 1.267 & 1.273 & 2.207 & 2.209 & 2.329 & 2.331 \\
\hline 26 & 1.365 & 1.370 & 2.250 & 2.251 & 2.369 & 2.370 \\
\hline 27 & 1.166 & 1.169 & 2.216 & 2.216 & 2.345 & 2.345 \\
\hline 28 & 1.338 & 1.343 & 2.198 & 2.201 & 2.315 & 2.318 \\
\hline 29 & 1.164 & 1.167 & 2.205 & 2.206 & 2.334 & 2.335 \\
\hline 30 & 1.312 & 1.318 & 2.216 & 2.219 & 2.337 & 2.339 \\
\hline 31 & 1.223 & 1.228 & 2.194 & 2.196 & 2.318 & 2.320 \\
\hline 32 & 1.108 & 1.111 & 2.202 & 2.203 & 2.334 & 2.334 \\
\hline 33 & 1.351 & 1.357 & 2.193 & 2.196 & 2.308 & 2.311 \\
\hline 34 & 1.353 & 1.358 & 2.196 & 2.199 & 2.311 & 2.314 \\
\hline 35 & 1.276 & 1.282 & 2.208 & 2.210 & 2.330 & 2.332 \\
\hline 36 & 1.211 & 1.216 & 2.183 & 2.185 & 2.307 & 2.309 \\
\hline 37 & 1.186 & 1.190 & 2.219 & 2.219 & 2.347 & 2.347 \\
\hline 38 & 1.356 & 1.361 & 2.204 & 2.207 & 2.320 & 2.323 \\
\hline 39 & 1.358 & 1.363 & 2.201 & 2.204 & 2.317 & 2.319 \\
\hline 40 & 1.324 & 1.329 & 2.209 & 2.211 & 2.327 & 2.330 \\
\hline
\end{tabular}


SRNL-STI-2009-00101, REVISION 0

Table 3-13 Cement, Zicron Flour and Salt Solution Mass Contribution for 1-Liter of Grout for Z/C Mass Ratio of $1 / 12$ for $\mathrm{pH} 12$ and $+10 \% \mathrm{NaOH}$ Salt Solutions

\begin{tabular}{|c|c|c|c|c|c|c|}
\hline \multirow{3}{*}{$\begin{array}{l}\text { HAW } \\
\text { Test \# }\end{array}$} & \multicolumn{6}{|c|}{ Grams of material in one liter of grout } \\
\hline & \multicolumn{2}{|c|}{ Portland Cement } & \multicolumn{2}{|c|}{ Zircon Flour } & \multicolumn{2}{|c|}{ Salt Solution } \\
\hline & $\mathrm{pH}=12$ & $\begin{array}{l}+10 \% \\
\mathrm{NaOH}\end{array}$ & $\mathrm{pH}=12$ & $\begin{array}{l}+10 \% \\
\mathrm{NaOH}\end{array}$ & $\mathrm{pH}=12$ & $\begin{array}{l}+10 \% \\
\mathrm{NaOH}\end{array}$ \\
\hline $0 / 41$ & 1413.4 & 1412.0 & 117.8 & 117.7 & 676.7 & 680.6 \\
\hline 1 & 1571.2 & 1571.3 & 130.9 & 130.9 & 471.5 & 471.4 \\
\hline 2 & 1552.4 & 1552.0 & 129.4 & 129.3 & 519.6 & 520.2 \\
\hline 3 & 1468.6 & 1466.7 & 122.4 & 122.2 & 625.6 & 629.1 \\
\hline 4 & 1348.5 & 1348.7 & 112.4 & 112.4 & 709.2 & 712.5 \\
\hline 5 & 1571.1 & 1571.2 & 130.9 & 130.9 & 471.5 & 471.4 \\
\hline 6 & 1417.5 & 1416.0 & 118.1 & 118.0 & 692.3 & 695.9 \\
\hline 7 & 1440.9 & 1439.4 & 120.1 & 120.0 & 629.7 & 633.2 \\
\hline 8 & 1344.9 & 1345.3 & 112.1 & 112.1 & 733.6 & 736.5 \\
\hline 9 & 1524.8 & 1524.0 & 127.1 & 127.0 & 532.8 & 534.3 \\
\hline 10 & 1525.0 & 1524.3 & 127.1 & 127.0 & 522.6 & 523.9 \\
\hline 11 & 1563.9 & 1563.7 & 130.3 & 130.3 & 487.0 & 487.4 \\
\hline 12 & 1448.0 & 1446.4 & 120.7 & 120.5 & 628.1 & 631.5 \\
\hline 13 & 1358.5 & 1358.5 & 113.2 & 113.2 & 719.7 & 722.9 \\
\hline 14 & 1362.4 & 1362.3 & 113.5 & 113.5 & 711.3 & 714.6 \\
\hline 15 & 1561.1 & 1560.9 & 130.1 & 130.1 & 488.1 & 488.4 \\
\hline 16 & 1424.4 & 1422.7 & 118.7 & 118.6 & 667.2 & 671.3 \\
\hline 17 & 1460.0 & 1458.3 & 121.7 & 121.5 & 623.5 & 626.9 \\
\hline 18 & 1325.2 & 1326.2 & 110.4 & 110.5 & 754.4 & $\begin{array}{l}756.8 \\
\end{array}$ \\
\hline 19 & 1337.4 & 1338.1 & 111.5 & 111.5 & 748.5 & 751.0 \\
\hline 20 & 1522.2 & 1521.3 & 126.8 & 126.8 & 537.8 & 539.4 \\
\hline 21 & 1560.5 & 1559.8 & 130.0 & 130.0 & 536.1 & 537.1 \\
\hline 22 & 1534.4 & 1533.8 & 127.9 & 127.8 & 519.6 & 520.7 \\
\hline 23 & 1510.5 & 1509.7 & 125.9 & 125.8 & 559.6 & 561.2 \\
\hline 24 & 1329.3 & 1330.2 & 110.8 & 110.8 & 752.5 & 754.9 \\
\hline 25 & 1429.2 & 1427.5 & 119.1 & 119.0 & 658.6 & 662.8 \\
\hline 26 & 1415.8 & 1414.3 & 118.0 & 117.9 & 715.9 & 719.1 \\
\hline 27 & 1517.4 & 1516.2 & 126.5 & 126.3 & 571.7 & 573.7 \\
\hline 28 & 1357.1 & 1357.1 & 113.1 & 113.1 & 728.1 & 731.1 \\
\hline 29 & 1504.0 & 1503.0 & 125.3 & 125.2 & 576.1 & 577.9 \\
\hline 30 & 1407.0 & 1405.6 & 117.2 & 117.1 & 692.2 & 695.9 \\
\hline 31 & 1444.0 & 1442.5 & 120.3 & 120.2 & 629.6 & 633.1 \\
\hline 32 & 1538.6 & 1537.7 & 128.2 & 128.1 & 535.6 & 537.1 \\
\hline 33 & 1336.5 & 1337.1 & 111.4 & 111.4 & 744.7 & 747.3 \\
\hline 34 & 1339.5 & 1340.1 & 111.6 & 111.7 & 744.4 & 747.0 \\
\hline 35 & 1423.7 & 1422.0 & 118.6 & 118.5 & 665.7 & 669.8 \\
\hline 36 & 1437.4 & 1436.0 & 119.8 & 119.7 & 626.1 & 629.7 \\
\hline 37 & 1507.4 & 1506.1 & 125.6 & 125.5 & 585.6 & 587.9 \\
\hline 38 & 1351.0 & 1351.2 & 112.6 & 112.6 & 740.6 & 743.3 \\
\hline 39 & 1343.7 & 1344.1 & 112.0 & 112.0 & 745.2 & 747.7 \\
\hline 40 & 1385.5 & 1384.7 & 115.5 & 115.4 & 707.6 & 711.1 \\
\hline
\end{tabular}


SRNL-STI-2009-00101, REVISION 0

Table 3-14 Cement, Zicron Flour and Salt Solution Mass Contribution for 1-Liter of Grout for Z/C Mass Ratio of 1/4 for pH 12 and + 10\% NaOH Salt Solutions

\begin{tabular}{|c|c|c|c|c|c|c|}
\hline \multirow{3}{*}{$\begin{array}{l}\text { HAW } \\
\text { Test \# }\end{array}$} & \multicolumn{6}{|c|}{ Grams of material in one liter of grout } \\
\hline & \multicolumn{2}{|c|}{ Portland Cement } & \multicolumn{2}{|c|}{ Zircon Flour } & \multicolumn{2}{|c|}{ Salt Solution } \\
\hline & $\mathrm{pH}=12$ & $\begin{array}{c}+10 \% \\
\mathrm{NaOH}\end{array}$ & $\mathrm{pH}=12$ & $\begin{array}{c}+10 \% \\
\mathrm{NaOH}\end{array}$ & $\mathrm{pH}=12$ & $\begin{array}{l}+10 \% \\
\mathrm{NaOH}\end{array}$ \\
\hline $0 / 41$ & 1347.1 & 1345.9 & 336.8 & 336.5 & 645.0 & 648.8 \\
\hline 1 & 1489.7 & 1489.8 & 372.4 & 372.5 & 447.1 & 446.9 \\
\hline 2 & 1472.8 & 1472.5 & 368.2 & 368.1 & 492.9 & 493.5 \\
\hline 3 & 1397.2 & 1395.5 & 349.3 & 348.9 & 595.2 & 598.5 \\
\hline 4 & 1288.0 & 1288.3 & 322.0 & 322.1 & 677.4 & 680.6 \\
\hline 5 & 1489.6 & 1489.7 & 372.4 & 372.4 & 447.1 & 446.9 \\
\hline 6 & 1350.9 & 1349.5 & 337.7 & 337.4 & 659.8 & 663.2 \\
\hline 7 & 1372.1 & 1370.8 & 343.0 & 342.7 & 599.6 & 603.0 \\
\hline 8 & 1284.8 & 1285.2 & 321.2 & 321.3 & 700.9 & 703.6 \\
\hline 9 & 1448.0 & 1447.2 & 362.0 & 361.8 & 505.9 & 507.4 \\
\hline 10 & 1448.2 & 1447.5 & 362.0 & 361.9 & 496.3 & 497.5 \\
\hline 11 & 1483.2 & 1483.0 & 370.8 & 370.7 & 461.9 & 462.2 \\
\hline 12 & 1378.5 & 1377.1 & 344.6 & 344.3 & 598.0 & 601.3 \\
\hline 13 & 1297.2 & 1297.2 & 324.3 & 324.3 & 687.3 & 690.3 \\
\hline 14 & 1300.8 & 1300.6 & 325.2 & 325.2 & 679.1 & 682.3 \\
\hline 15 & 1480.7 & 1480.5 & 370.2 & 370.1 & 462.9 & 463.3 \\
\hline 16 & 1357.1 & 1355.6 & 339.3 & 338.9 & 635.7 & 639.7 \\
\hline 17 & 1389.4 & 1387.8 & 347.3 & 347.0 & 593.3 & 596.6 \\
\hline 18 & 1266.8 & 1267.7 & 316.7 & 316.9 & 721.2 & 723.4 \\
\hline 19 & 1278.0 & 1278.5 & 319.5 & 319.6 & 715.2 & 717.6 \\
\hline 20 & 1445.6 & 1444.8 & 361.4 & 361.2 & 510.8 & 512.3 \\
\hline 21 & 1480.1 & 1479.5 & 370.0 & 369.9 & 508.5 & 509.5 \\
\hline 22 & 1456.6 & 1456.1 & 364.2 & 364.0 & 493.3 & 494.4 \\
\hline 23 & 1435.1 & 1434.3 & 358.8 & 358.6 & 531.7 & 533.2 \\
\hline 24 & 1270.5 & 1271.3 & 317.6 & 317.8 & 719.2 & 721.5 \\
\hline 25 & 1361.5 & 1359.9 & 340.4 & 340.0 & 627.4 & 631.4 \\
\hline 26 & 1349.4 & 1347.9 & 337.3 & 337.0 & 682.3 & 685.3 \\
\hline 27 & 1441.3 & 1440.2 & 360.3 & 360.0 & 543.0 & 545.0 \\
\hline 28 & 1295.9 & 1295.9 & 324.0 & 324.0 & 695.3 & 698.1 \\
\hline 29 & 1429.2 & 1428.3 & 357.3 & 357.1 & 547.5 & 549.2 \\
\hline 30 & 1341.3 & 1340.1 & 335.3 & 335.0 & 659.9 & 663.5 \\
\hline 31 & 1374.9 & 1373.6 & 343.7 & 343.4 & 599.5 & 602.9 \\
\hline 32 & 1460.5 & 1459.6 & 365.1 & 364.9 & 508.4 & 509.8 \\
\hline 33 & 1277.1 & 1277.7 & 319.3 & 319.4 & 711.6 & 714.1 \\
\hline 34 & 1279.9 & 1280.4 & 320.0 & 320.1 & 711.3 & 713.7 \\
\hline 35 & 1356.5 & 1355.0 & 339.1 & 338.7 & 634.3 & 638.2 \\
\hline 36 & 1368.9 & 1367.6 & 342.2 & 341.9 & 596.3 & 599.8 \\
\hline 37 & 1432.3 & 1431.1 & 358.1 & 357.8 & 556.4 & 558.6 \\
\hline 38 & 1290.4 & 1290.5 & 322.6 & 322.6 & 707.4 & 709.9 \\
\hline 39 & 1283.7 & 1284.1 & 320.9 & 321.0 & 711.9 & 714.3 \\
\hline 40 & 1321.8 & 1321.1 & 330.4 & 330.3 & 675.1 & 678.4 \\
\hline
\end{tabular}


SRNL-STI-2009-00101, REVISION 0

\subsection{CONCLUSIONS}

Given the conditions of preparing the grout in this task, all of the grouts were visually well mixed prior to preparing the grouts for measurements. All of the cured grouts were measured for bleed and set. All of the cured grouts satisfied the bleed and set requirements, where no bleed water was observed on any of the grout samples after one day and all had set within 3 days of curing. This data indicates, for a well mixed product, bleed and set requirement are satisfied for the range of acidic feeds tested in this task.

The conclusions from this testing that impact the mixability/yield stress are:

- The grout yield stress of the simulant that has been used in full scale tests is bounded in the region where the acid molarity is between 3.695 to $7.39 \mathrm{HNO}_{3}$. Its value is closer to the lower range of yield stress in this acid concentration range.

- Statistically the yield stress decreases with increasing $\mathrm{HNO}_{3}$ concentration and increases with increasing gallium and "Other" metals concentration.

- Statistically, silver had no impact on the yield stress.

- Increasing the sodium nitrate concentration causes a decrease in the yield stress.

- As the water content in the neutralized/pH adjusted solution increases, the yield stress increases.

- The undissolved solids fraction, $\mathrm{pH}$, and density of the neutralized/pH adjusted solution do not cause the yield stress to trend.

- The simulant used in the full scale tests resulted in yield stresses that are bounded by the testing performed in this task and the results were toward the lower bounds of HAW simulant used in the variability study.

- Table 3-8 lists the variables that show a linear trend to either increase or decrease the yield stress as the variable in the grout increases in concentration. Many of the variables which show the same type of trending are inter-related, such as $\mathrm{Na}$ and $\mathrm{NO}_{3}$. Other notables are;

0 As the water content increases in the neutralized salt solution, the yield stress increases. This is due to the fraction cement (and/or zircon flour) increasing to maintain a constant water to cement ratio.

o As the total solids concentration increased in the neutralized/pH adjusted solution, the yield stresses decreased. This is consistent with the above statement, since the quantity of water in the grout decreases as the total solids content increases in the neutralized/pH adjusted solution for a given grout volume.

o The undissolved solids fraction, $\mathrm{pH}$ and density of the neutralized/pH adjusted solutions do not cause the yield stress to trend.

o Many of the individual chemicals do not cause the yield stress to trend.

- Figure 3-7 clearly shows that increasing the $\mathrm{HNO}_{3}$ molarity in the acid solutions results in a lower yield stress in the grout. An increase in $\mathrm{HNO}_{3}$ molarity results in an increase in the $\mathrm{NaNO}_{3}$ concentration in the grout after the neutralization/pH adjustment process. 
- The neutralized/pH adjusted solutions were either Newtonian or non-Newtonian. Cursory review of Table 3-4 shows that there is no relationship between rheology and grout yield stress.

These tests showed that the substitution elements, aluminum for gallium and copper for silver are not good substitutes. Statistically, as the concentration of aluminum and copper increased the yield stress decreased This is contrary to the gallium, where the yield stress increased with increasing gallium concentration. Silver was shown not to impact yield stress. The following observations were made:

- HAW acid feeds containing silver nitrate as the only metal resulted in undissolved solids that had a tendency to settle quickly, when neutralized/pH adjusted.

- The substitution of $\mathrm{Cu}$ for $\mathrm{Ag}$ and $\mathrm{Al}$ for $\mathrm{Ga}$ was shown, statistically not to be adequate elemental substitutes. Substitution of these elements resulted in a lower response variable, resulting in a non-conservative condition of testing.

- Excluding tests involving $\mathrm{Al}$ and $\mathrm{Cu}$ from the "acid solution" data set resulted in $\mathrm{HNO}_{3}, \mathrm{Ga}$ and "others" becoming statistically significant. The response function decreased with increasing $\mathrm{HNO}_{3}$ concentration and increased with increasing $\mathrm{Ga}$ and "Others" concentration in the acid solution.

During the processing of HAW simulant solutions, from making of the acidic solution and processing the acidic solution through the neutralization/pH adjustment, and making the final product, the following conclusions were observed;

- Mixing during the neutralization/pH adjustment process of the different acidic solutions required different agitator speeds to incorporate and disperse the $\mathrm{NaOH}$ solution. The resulting solutions were either Newtonian or non-Newtonian.

- Active cooling was required during the $\mathrm{NaOH}$ addition in the neutralization/pH adjustment process when the $\mathrm{HNO}_{3}$ concentration was greater than or equal to 3.695M in the acid solution.

- Undissolved batch materials in the acidic feeds dissolved when the acidic fluid is neutralized and $\mathrm{pH}$ adjusted. In the WSB, these solids may cause mixing and transport problems due to settling. These undissolved solids were included as feed for making the acids solutions. These solids may not necessarily exist in the actual WSB HAW process.

- During the neutralization/pH adjustment phase, final mixing speeds ranged between 200 to 475 RPM.

- During the neutralization/pH adjustment phase, where the concentrated $\mathrm{NaOH}$ solution was added to the surface of the agitated fluid and between a $\mathrm{pH}$ of 3 to 10, cavern mixing was observed on some of the solutions that contained high acids and metals. To overcome cavern mixing, the agitator speed was increased to incorporate the $\mathrm{NaOH}$ solution and to provide complete mixing to occur. The rheology during $\mathrm{pH}$ adjustment (between 5 and 10) can vary, going through a viscous region prior to thinning. This phenomenon has been observed in other types of slurries ${ }^{25}$.

- HAW-9, -20, -29 and -37 grout samples initially had difficulties wetting the solution with the dry materials. These HAW samples contained no $\mathrm{HNO}_{3}$ in the acid solution. The cause for the lack of wetting was not determined. Other high shear mixes did challenge the mixer during wetting, but did not cause the mixer to stall. 
- Batches of using only water, Portland cement and zircon flour were made. Different water to cement mass ratios were processed to support this task. There were no wetting issues down to and including a W/C ratio of 0.28 .

- Volume additivity was shown to an effective method in determining the density of the final grout.

Calculations of the physical properties and batching composition for a fixed volume between the SRNL's and WSB's flowsheet was performed. The differences are in the endpoint of $\mathrm{NaOH}$ addition to the acid solution and the zircon/cement mass ratio. SRNL targeted a pH of 12 and WSB states an additional $+10 \% \mathrm{NaOH}$ required to neutralize the $\mathrm{HNO}_{3}$ concentration in the acidified solution. SRNL used a Z/C mass ratio of $1 / 12$ and for WSB it is $1 / 4$. These calculations result in the following conclusions:

- Slightly more $\mathrm{NaOH}$ solution is required for the $+10 \% \mathrm{NaOH}$ solution as compared to the $\mathrm{pH} 12$ cases.

- Salt solution density for the $+10 \% \mathrm{NaOH}$ fluid is slightly greater than the $\mathrm{pH} 12$ fluid, due to the addition of $51 \mathrm{wt} \% \mathrm{NaOH}$ solution.

- The grout densities of the $\mathrm{pH} 12$ and $+10 \% \mathrm{NaOH}$, for a given $\mathrm{Z} / \mathrm{C}$ mass ratio are similar, for a given HAW case. The mass contributions of the Portland cement, zircon flour and salt solution are also very similar, for producing one liter of grout.

- There are significant differences in densities and mass contribution of the components when comparing the $\mathrm{pH} 12$ for $\mathrm{Z} / \mathrm{C}$ mass ratios of $1 / 12$ to that of the $1 / 4$. The large increase in zircon flour in the $\mathrm{Z} / \mathrm{C}$ mass ratio of $1 / 4$ results in a decrease in both the Portland cement and salt solution. 


\subsection{RECOMMENDATIONS}

The following are recommendations based upon the testing performed in this task.

Recommendations related to mixability are:

1. If the WSB expects the acid concentration in the HAW Neutralization/Cement head tanks is equal to or greater than $3.695 \mathrm{M} \mathrm{HNO}_{3}$ prior to neutralization/pH adjustment, perform functional testing of full scale mixing systems using water (rather than salt simulant) at a water to cement ratio of 0.3 . The zircon flour should also be included with the cement.

2. Perform testing for mixability in a full scale mixing system using one of the simulants that had an initial wetting issue or a high yield stress. This will provide engineering/operations additional insight on the capabilities of the mixing equipment and, if necessary, on how to recover from off-normal operations.

3. Perform additional testing with $\mathrm{HNO}_{3}$ ranging from 0 to $3.695 \mathrm{M}$ in the acidic solution. Testing will determine if there are non-linear responses in this range. It is expected that this range of $\mathrm{HNO}_{3}$ will provide a more difficult grout to mix.

4. The current WSB intention to pre-batch the 55 gallon drums with dry materials and operate with a water to cement mass ratio of 0.30 requires that the WSB concentrate to a fixed weight percent solids. Water runs indicate variation in $\mathrm{W} / \mathrm{C}$ ratio can result in significantly different grout yield stress. The water content of the neutralized/pH adjusted solutions, unless controlled by the WSB, will be a variable. Perform additional testing to determine mixability, water content, and set issues.

5. The dry materials, Portland Cement and zircon flour used for future testing, including both bench and full scale, should be those chemicals used in the actual process. Variability in the dry feed material can impact the mixability results.

Recommendations related to using substitution elements are:

1. Perform additional testing to identify more suitable surrogates for gallium. The selected substitution element, aluminum, is not recommended since it provides a nonconservative simulant for testing.

2. Silver was shown to have no impact on the yield stress. Additional testing, without silver may show that no substitute element is required.

The following are recommendations based upon the testing performed in this task.

1. The HAW Neutralization/Cement head tank design should consider the ability to effectively mix a range of solutions that have non-Newtonian fluid properties. The mixer must be able to overcome the changes in the fluid properties, specifically the yield stress of the fluid, as the $\mathrm{NaOH}$ solution is added to change the $\mathrm{pH}$ in the range of 5 to 10 .

2. Functional testing of the WSB neutralization/cementation head tank should be performed using a solution with non-Newtonian properties. This will evaluate the mixing/pumping capabilities of the facility.

3. Perform functional testing of the WSB facility using a solution that has Newtonian properties throughout processing.

4. If undissolved solids are expected in the acidic waste coming from the Mixed Oxide Fuel Fabrication Facility, perform functional testing of the WSB facility using an 
acidic fluid that contains undissolved solids. Undissolved solids in the acidic waste streams may require agitation of the process tanks and flushing of process lines in the WSB facility.

5. The use of sodium nitrate $\left(\mathrm{NaNO}_{3}\right)$ rather than performing the full neutralization/pH adjustment phase will reduce the cost of the HAW simulant. The substitution of $\mathrm{NaNO}_{3}$ would remove the cooling required during the neutralization step. Direct use of $\mathrm{NaNO}_{3}$ may also prove beneficial to control the sodium level in the WSB for mixability. Testing would be required to determine the impact of this substitution.

6. Testing of actual waste should be performed prior to commencement of full operations of the WSB. This will provide an additional level of confidence in the WSB process.

7. Changes to the WSB flowsheet or process influents would require that the changes be evaluated against the testing performed in this study to determine if the current testing bounds the altered process.

8. The impacts of salt solution chemistry and water content on the heat of hydration were not investigated. Chemistry and water content will impact the heat of hydration, resulting in a different heat generation rates, which could cause operational issues during the handling of the 55 gallon drums.

9. The concentrated $\mathrm{NaOH}$ solution should be added subsurface, near the suction to the mechanical agitator to properly entrain and disperse the $\mathrm{NaOH}$ solution during the neutralization/pH adjustment of the acidic solution.

Calculations were performed to determine differences in the $\mathrm{NaOH}$ and zircon flour used by SRNL as compared to the present WSB flowsheet. The following are recommendations from these calculations:

1. Perform tests to determine if the increased hydroxide concentration in the salt solution impacts grout properties and mixability.

2. Perform tests to determine the impact in the variability in the $\mathrm{Z} / \mathrm{C}$ mass ratios on grout properties and mixability, if the $\mathrm{Z} / \mathrm{C}$ mass ratio is different than $1 / 12$. 
SRNL-STI-2009-00101, REVISION 0

\subsection{REFERENCES}

${ }^{1}$ J.R. Schafner, Technical Task Request, X-TTR-F-00001 Revision 0.

2 A.D. Cozzi and E.K. Hansen, "SRNL Support for the Waste Solidification Building," WSRC-TR2008- 00067, Revision 1, October 2008.

${ }^{3}$ Washington Savannah River Company/ Savannah River Site, "Waste Solidification Building - High Activity Waste System - System Design Description”, X-SYD-F-00012, Revision 7, July 12, 2008

${ }^{4}$ Melton, D., Pool, B, Salley, T., “Chemistry for the WSB Cement Mixer Testing”, NNP-WSB-200600009, Revision 2, March 23, 2007

${ }^{5}$ Mid Columbia Engineering, "WSB Cementation Mixing System Project - Proof of Concept Testing - Test Report”, MCE-TR-2963-001, Revision 1, August 8, 2008

${ }^{6}$ Hansen, E., “Mid Columbia Engineering, Inc. (MCE), WSB Field Testing, Trip Report July 2008”, SRNL-PSE-2008-00182, Rev. 1, August 20, 2008

${ }^{7}$ Cozzi, A. D., Hansen, E. K., et. al., "Effect of Heat of Hydration on Drum Temperature And Filter Performance in Full-Scale Waste Solidification Building Simulant High Activity Waste Drums”, WSRC-STI-2008-00367, Revision 0, August 2009

${ }^{8}$ Villarreal, R. and Spall, D., "Selection of Actinide Chemical Analogues for WIPP Tests - Potential Nonradiactive Sorbing and Nonsorbing Tracers for Study of Ion Transport in the Environment" LA13500-MS, Los Alamos National Laboratory, Los Alamos, NM August 1998.

${ }^{9}$ Hansen, E., and Edwards, T., "Revised High Activity Waste Simulant Composition for the HA Waste Variability Study - October 2008”, SRNL-L3100-2008-00078, Revision 0, October 16, 2008

${ }^{10}$ JMP Version 7.0.2, SAS Institute, Inc.; Cary, NC, 1989-2007

${ }^{11}$ Hansen, E. K., “WSB 2008 HAW Variability Study - Data”, SRNL-L3100-2009-00034, February 2009

${ }^{12}$ Hodgman, C. D., et. al., "Handbook of Chemistry and Physics - A ready Reference Book of Chemical and Physical Data”, 42 ${ }^{\text {nd }}$ edition, The Chemical Rubber Publishing Company, 1961

${ }^{13}$ Hobart, Specification F-7533-N50 Mixer

${ }^{14}$ Liddell, P.V. and Boger D.V., "Yield Stress Measurements with the vane”, Journal of NonNewtonian Fluid Mechanics, Vol. 63, pp 235-261, 1996

${ }^{15}$ Nguyen, Q.D. and Boger D.V., "Yield Stress Measurements for Concentrated Suspensions”, Journal of Rheology, Vol. 27, pp 321-349, 1983

${ }^{16}$ Nguyen, Q.D. and Boger D.V., “Direct Yield Stress Measurement with the Vane Method”, Journal of Rheology”, Vol. 29, pp 335-347, 1985

${ }^{17}$ Barnes, H.A. and Nguyen, Q.D., "Review Rotating Vane Rheometry - a Review", Journal of NonNewtonian Fluid Mechanics, Vol. 98, pp 1-14, 2001

${ }^{18}$ Yoshimura, A. S., and Prud'Homme, P.K., “A Comparison of Techniques for Measuring Yield Stresses”, Journal of Rheology, Vol. 31, pp 699-710, 1987

${ }^{19}$ Steffe, J. F., "Rheological Methods in Food Processing Engineering”, Freeman Press, $2^{\text {nd }}$ edition, 1996

${ }^{20}$ Barnes, H. A. and Carnali, J. O., "The vane-in-cup as a novel rheometer geometry for shear thinning and thixotropic materials”, Journal of Rheology, Vol. 34, pp 841-866, 1990

${ }^{21}$ Smith, G.L., and Prindiville, K., "Guidelines for Performing Chemical, Physical, and Rheological Properties Measurements”, 24590-WTP-GPG-RTD-001, Rev. 0, May 20, 2002.

${ }^{22}$ ASTM C807-08, "Standard Test Method for Time of Setting of Hydraulic Cement Mortar by Modified Vicat Needle"

${ }^{23}$ Pool, B., "Flowsheet calculation for the Waste Solidification Building (U)", December 14, 2007

${ }^{24}$ Akerlof, G and Kegeles, G, "The Density of Aqueous Solutions of Sodium Hydroxides”, Chemistry Department of Yale University, 1939 
SRNL-STI-2009-00101, REVISION 0

${ }^{25}$ Barnes, H. A., "Viscosity”, The University of Wales Institute of Non-Newtonian Fluid Mechanics", $1^{\text {st }}$ Edition, 2002 
SRNL-STI-2009-00101, REVISION 0

\section{APPENDIX A. KESTERSON 9/15/2008 Email}


SRNL-STI-2009-00101, REVISION 0

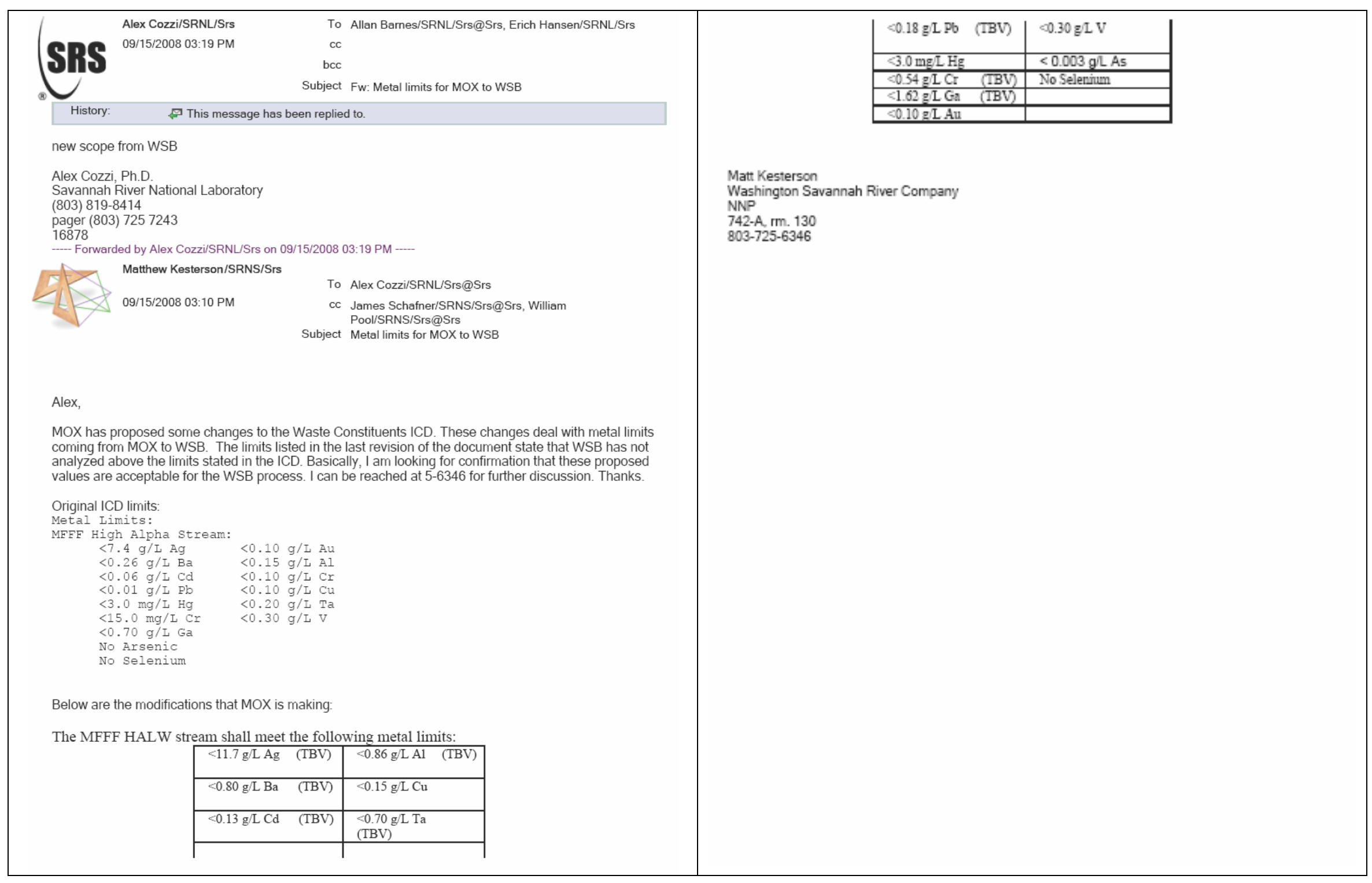


SRNL-STI-2009-00101, REVISION 0

APPENDIX B. SCHAFNER 9/18/2008 EMAIL

Page 68 of 100 
SRNL-STI-2009-00101, REVISION 0

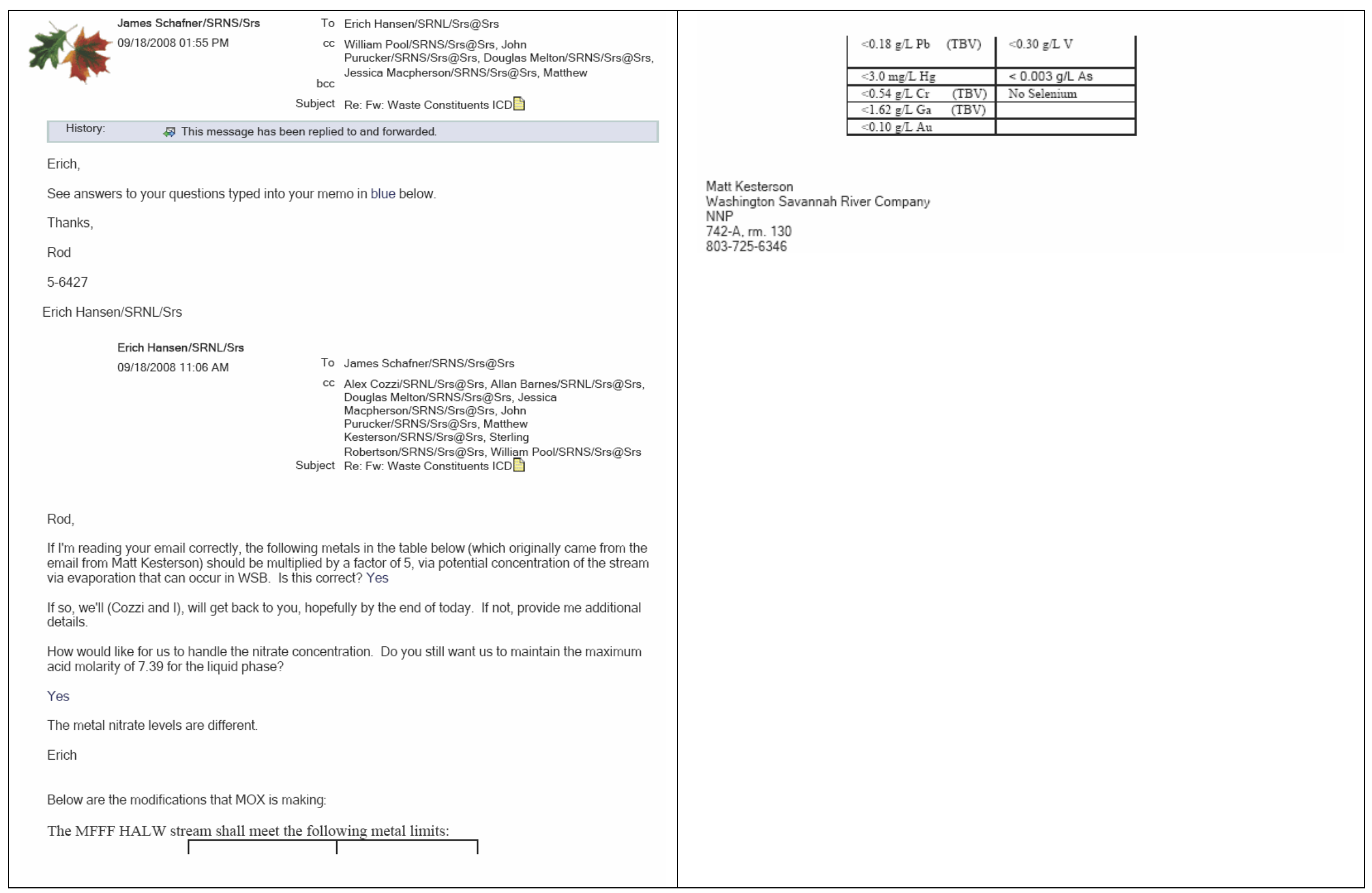


SRNL-STI-2009-00101, REVISION 0

APPENDIX C. EXAMPLES OF BATCH SHEETS

Page 70 of 100 


$\begin{array}{rr}\text { Batch ID: HAWSBA-36A } \\ \text { Instruction for Batching 1L of HA-Simulant } & 1 \\ \text { COST CODE: } & \text { XBWFDSN32 } \\ \text { Date: } & \\ \text { Technician: } & \\ \text { Scales Used: } & \end{array}$

Obtain 1-L flask that can be used with Nitric Acid Solution: Record mass of flask (including top) grams

Add the following Chemicals in the order shown. DI water can be used to flush the chemical into the flash, but do not exceed the 1-L line on the flask

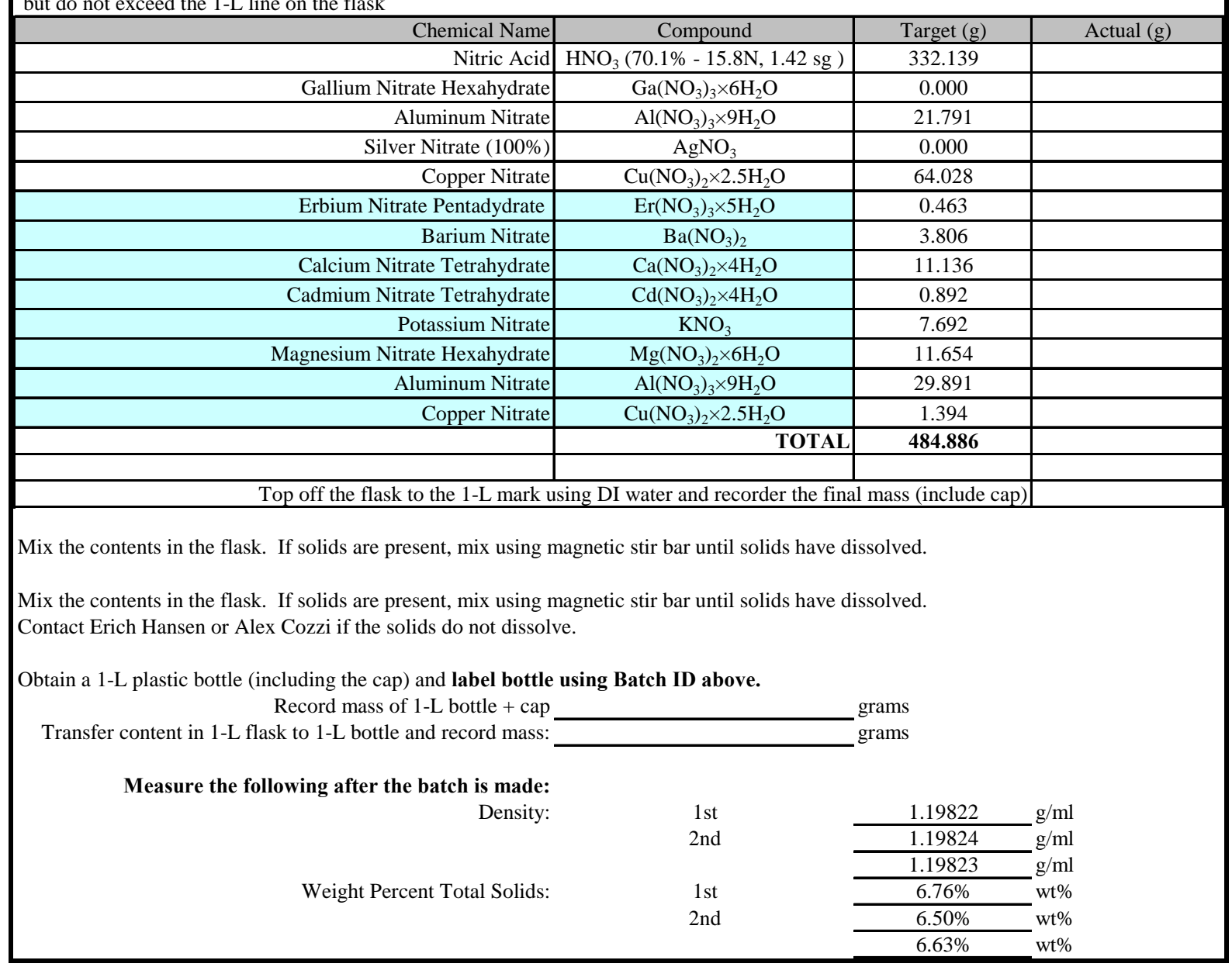

Figure C - 1 Example of HAW Acid Solution: HAW-36A 


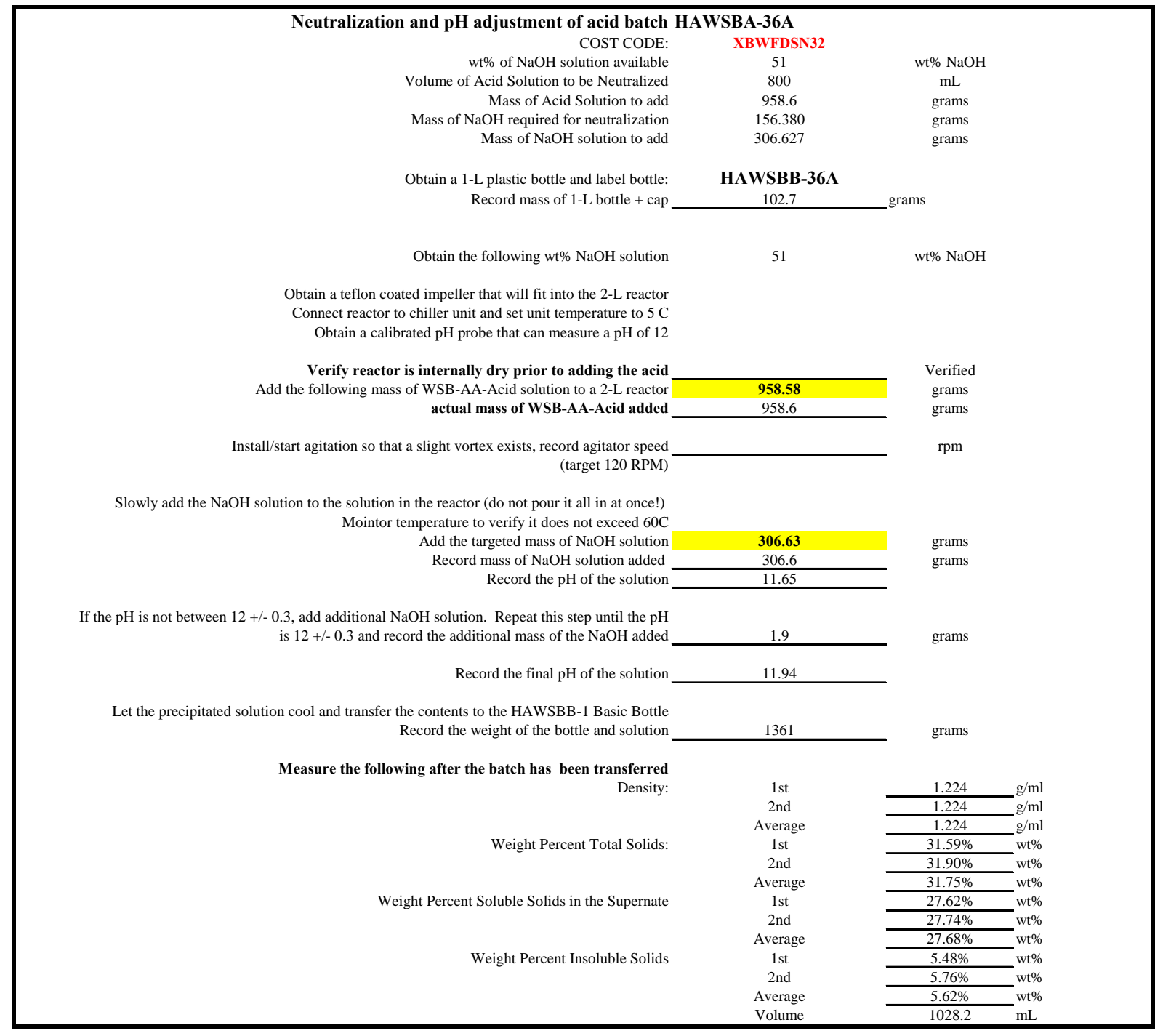

Figure C - 2 Example of HAW Neutralization/pH Adjustment Batch Sheet: HAW-36A 


\section{GROUT BATCHING}

OBTAIN a sealable large plastic bag that can contain 4000 grams of solids

Label plastic bag

Place the following quantity of material into the bag and mix

Verify bag is properly zipper together Portland Cement

Zircon Flour

OBTAIN three $100 \mathrm{~mL}$ gray bottles and caps and one 2" x 2" square Label the bottles the following and record tare values:

Use square for set OBTAIN one $1000 \mathrm{~mL}$ Jar for vane measurements and Label

Verify Hobart Mixer is placed in hood, configured and plugged in Verify Hobart Mixer Speed is set at 1 Start Mixer and verify no binding. If binding, correc

Verify 3 position stop watch is available for use Verify vane is installed and rheometer ready for measurement

Obtain a 1-L plastic beaker, place on scale and tare. Add the following amount of simulant to the beaker $\underline{\text { Target }(\mathbf{g})}$ 885.3

Record the temperature of the simulan Record the temperature of the dry materials

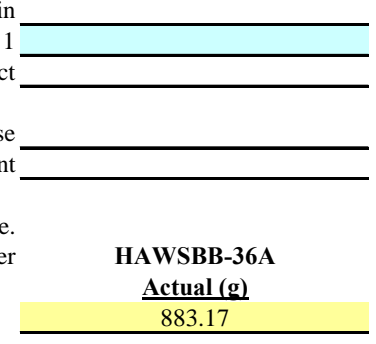

HAWSB-36A-DENSITY 1

HAWSB-36A-DENSITY 2

HAWSB-36A-BLEED

HAWSB-36A-SET

HAWSB-36A-VANE

Place at least 3/4 of the simulant into the Hobart Mixer bowl in the lowered position Add all the dry material to Hobart Mixer in the lowered position and distribute Add the remaining simulant into the Hobart mixer

Raise the bowl into the mixing position

Start mixer at lowest setting (1) for mix for 2 minute, record time of mixing Stop mixer and set setting to (2) and mix for 5 minutes, record time of mixing

$$
\text { Measure temperature of grout in mixing bowl }
$$

After mixing is complete, add between 500 to $750 \mathrm{~mL}$ to Vane Sample Cup Place in rheometer, place vane in $1 / 3$ quadrant to mark position

$$
\begin{array}{r}
\text { and start measurement, record time } \\
\text { Save file as: }
\end{array}
$$

Lower sample and rotate 120 degrees, insert vane to mark and start measurement

$$
\text { Save file as: HAWSB-36A-2 }
$$

Lower sample and rotate 120 degrees, insert vane to mark and start measurement

$$
\text { Save file as: HAWSB-36A-3 }
$$

Fill the following sample bottles to at least 3/4 full and cover:

Fill the 2" x 2" square to at least $3 / 4$ full and cover:

\section{HAWSB-36A-DENSITY HAWSB-36A-DENSITY 2 \\ HAWSB-36A-BLEED HAWSB-36A-SET}

20 to 28 hours later:

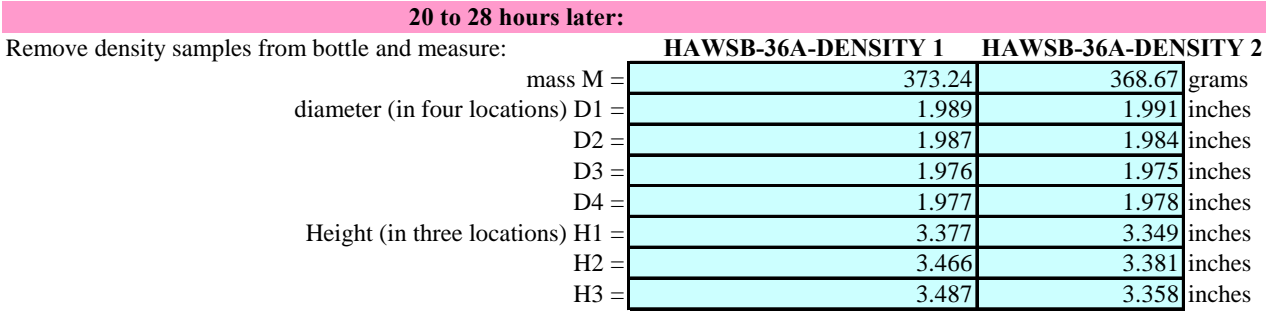

Measure mass of bleed in bleed sample $0 \mathrm{~mL}$ Measure set (penetration) 
SRNL-STI-2009-00101, REVISION 0

\section{APPENDIX D. VANE MEASUREMENTS}




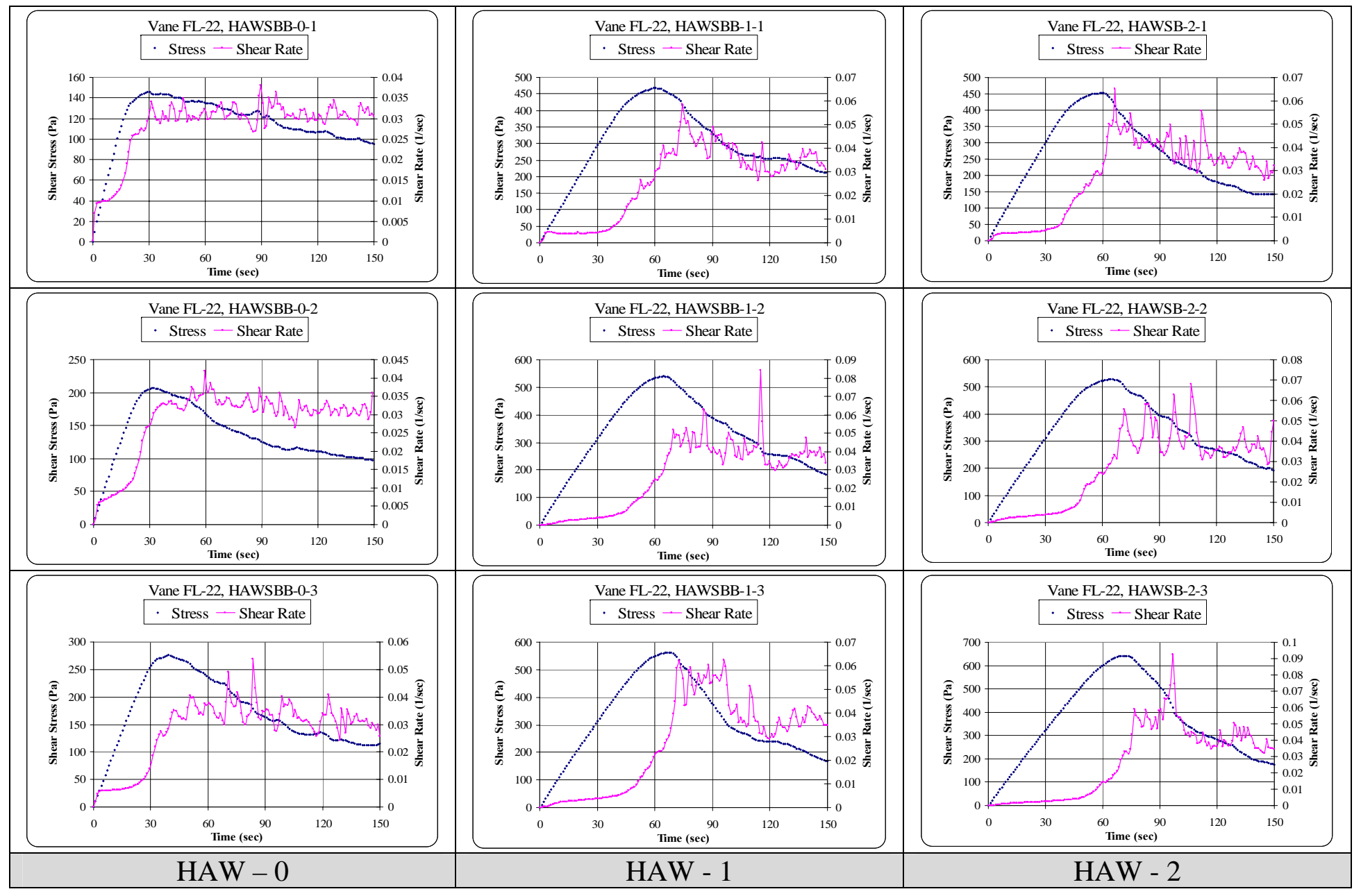

Figure D - 1 Vane Measurements for HAW-0, HAW-1, and HAW-2 


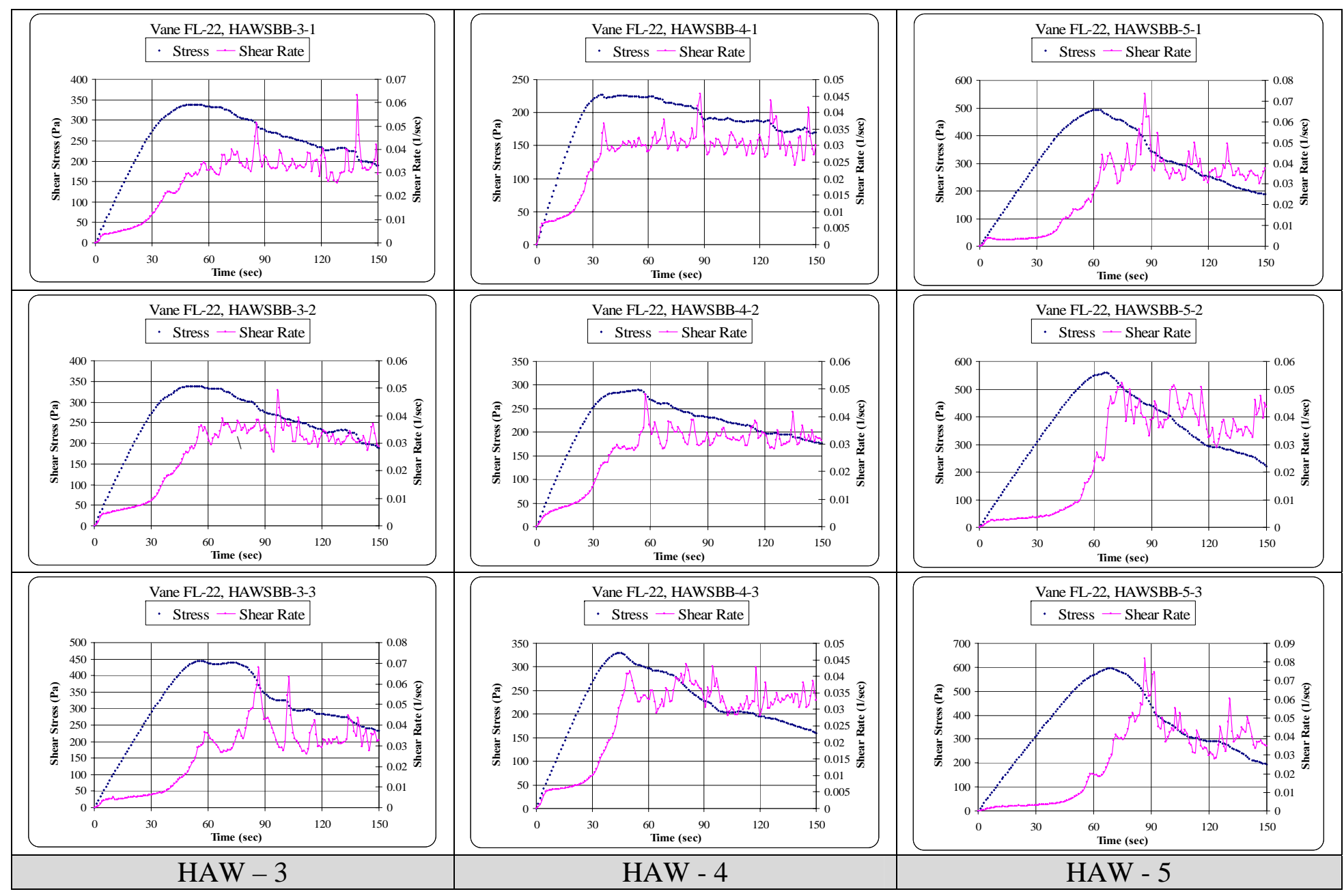

Figure D - 2 Vane Measurements for HAW-3, HAW-4, and HAW-5 


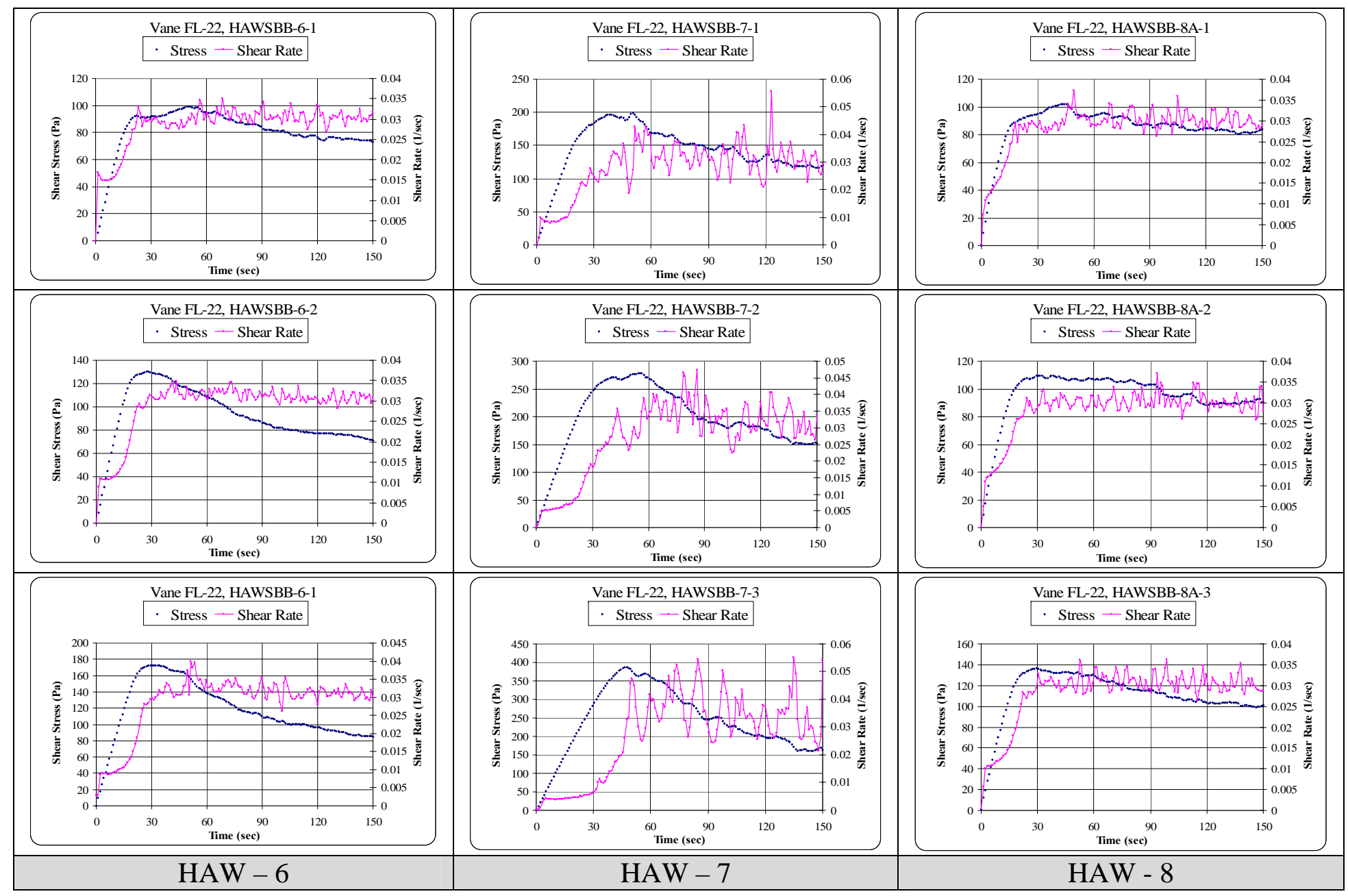

Figure D - 3 Vane Measurements for HAW-6, HAW-7, and HAW-8 


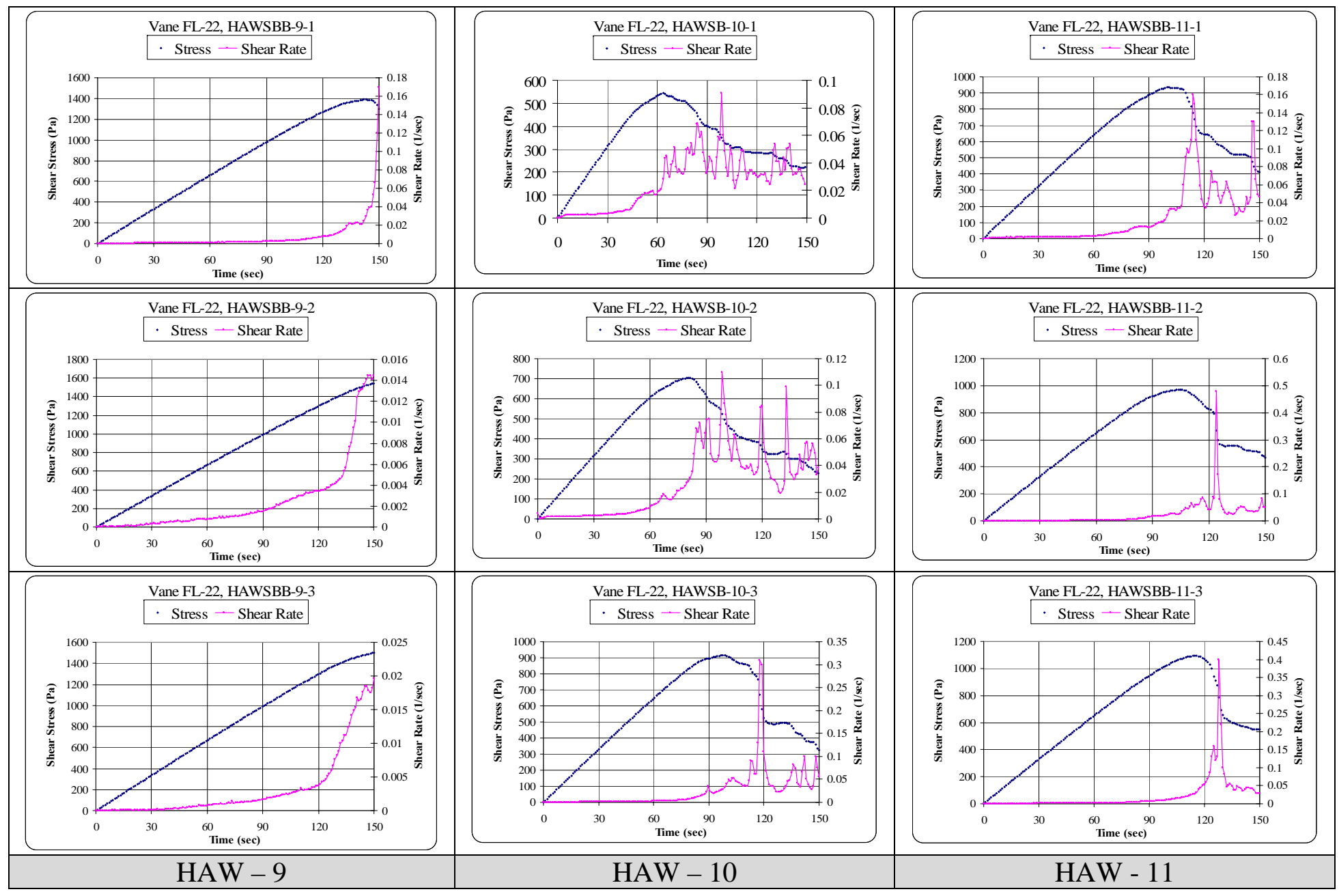

Figure D - 4 Vane Measurements for HAW-9, HAW-10, and HAW-11 


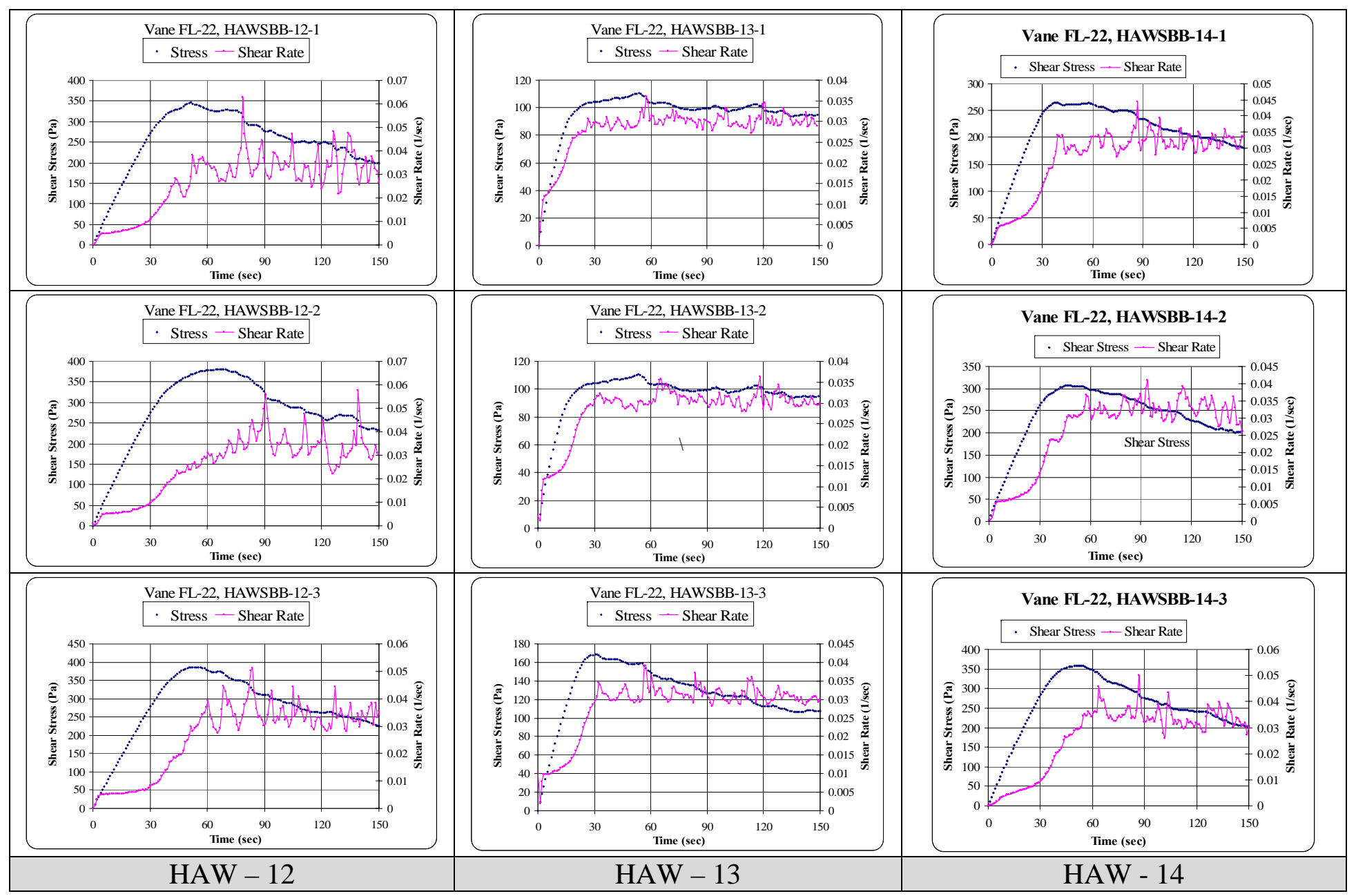

Figure D - 5 Vane Measurements for HAW-12, HAW-13, and HAW-14 


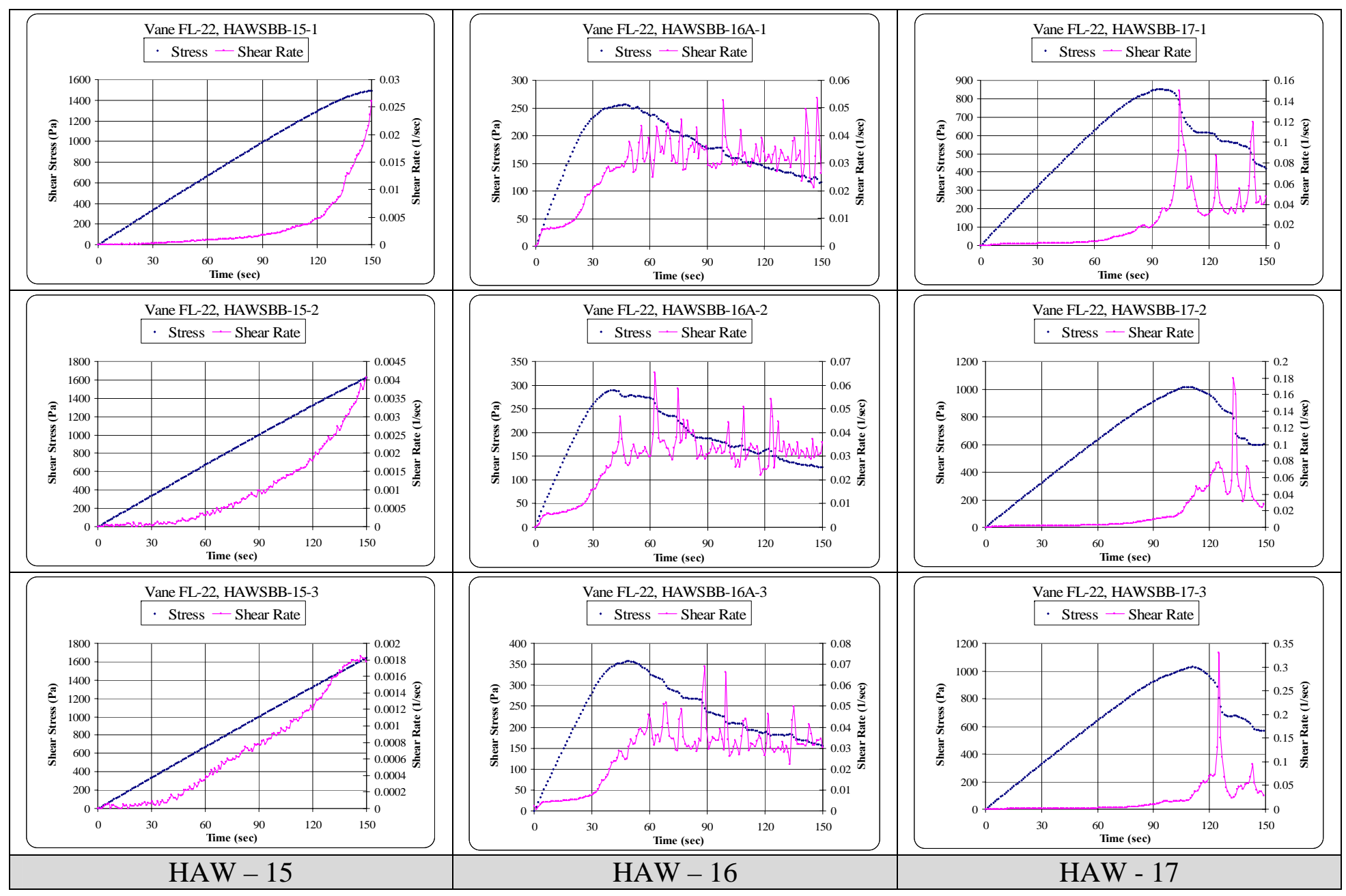

Figure D - 6 Vane Measurements for HAW-15, HAW-16, and HAW-17 


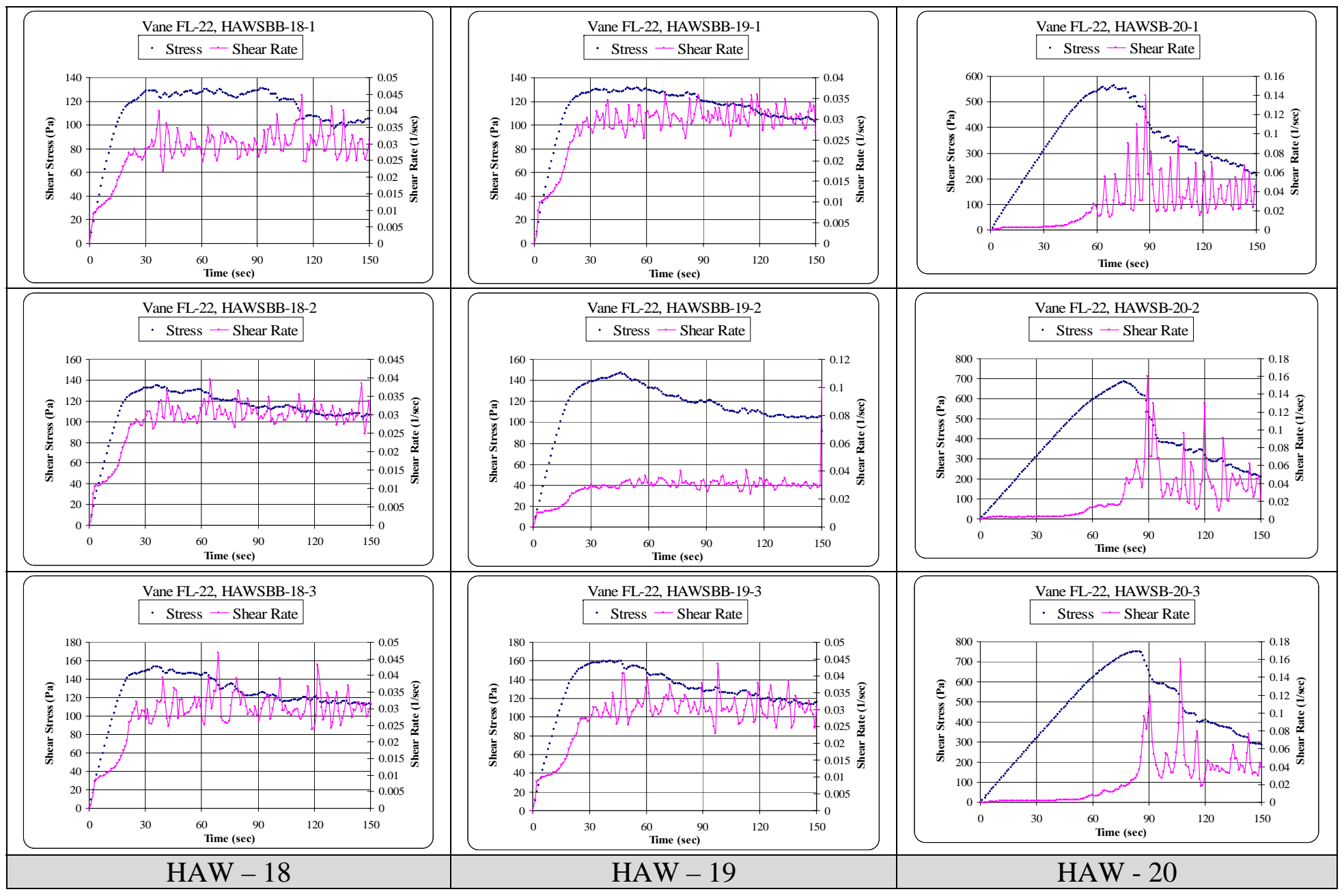

Figure D - 7 Vane Measurements for HAW-18, HAW-19, and HAW-20 


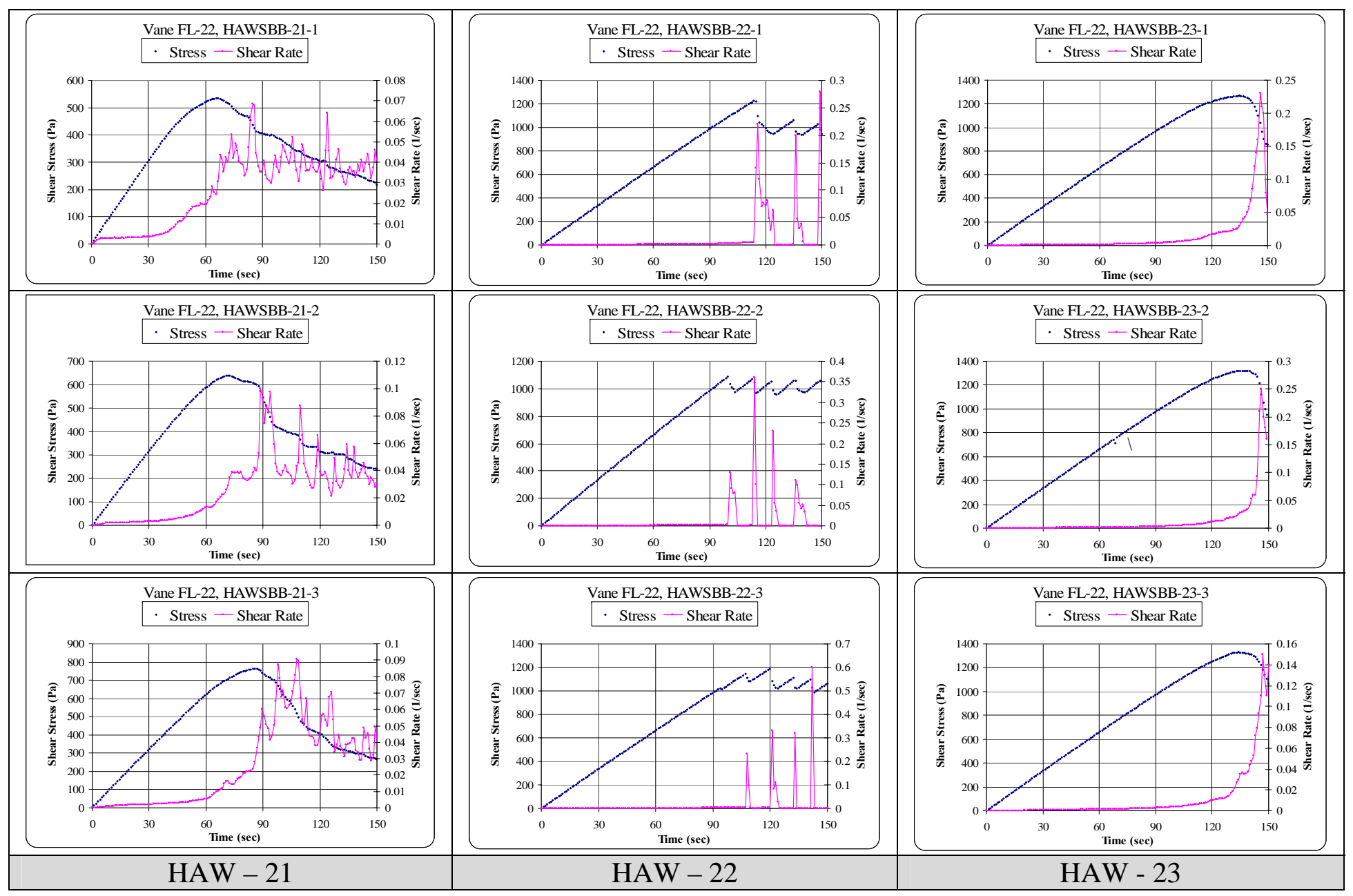

Figure D - 8 Vane Measurements for HAW-21, HAW-22, and HAW-23 


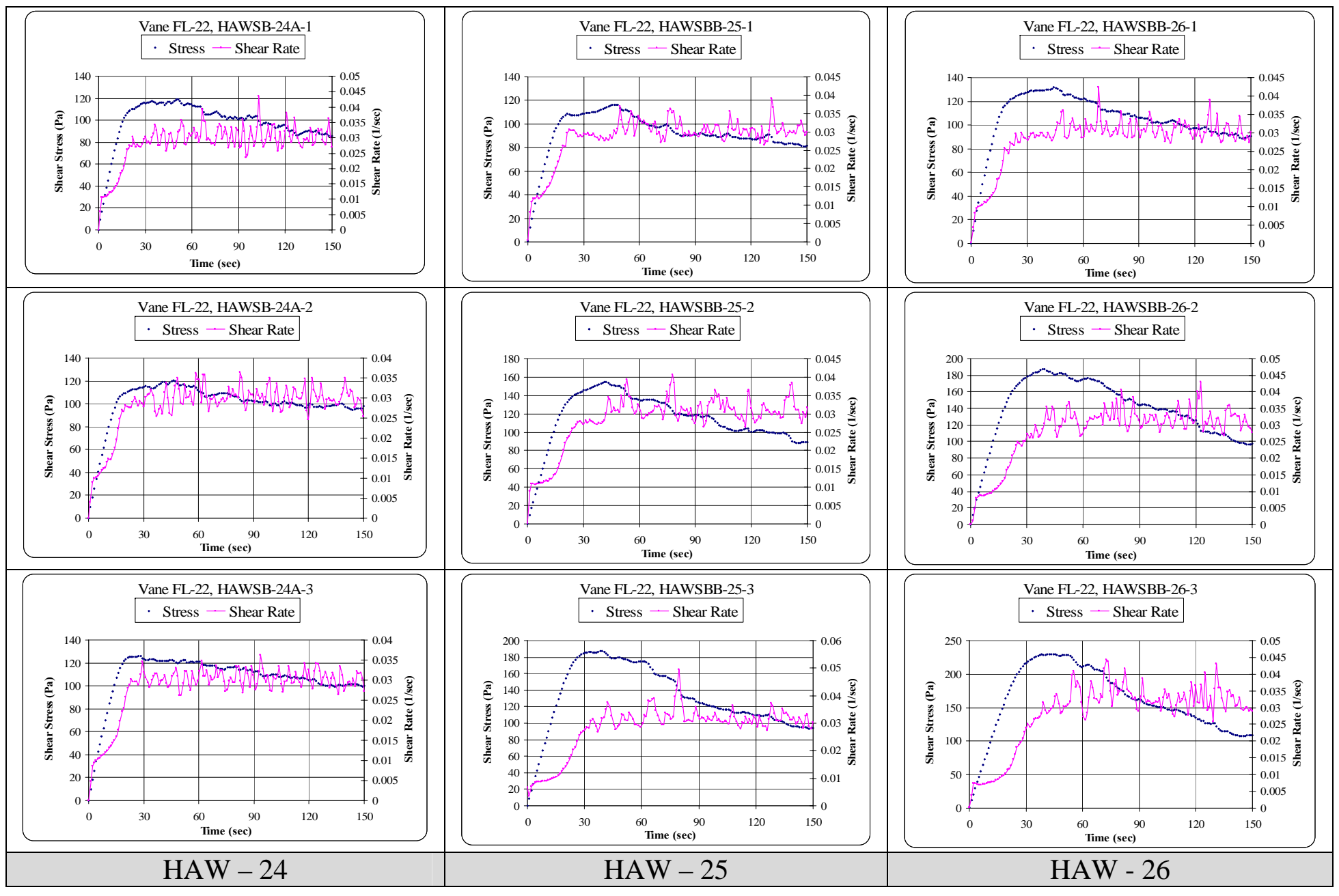

Figure D - 9 Vane Measurements for HAW-24, HAW-25, and HAW-26 


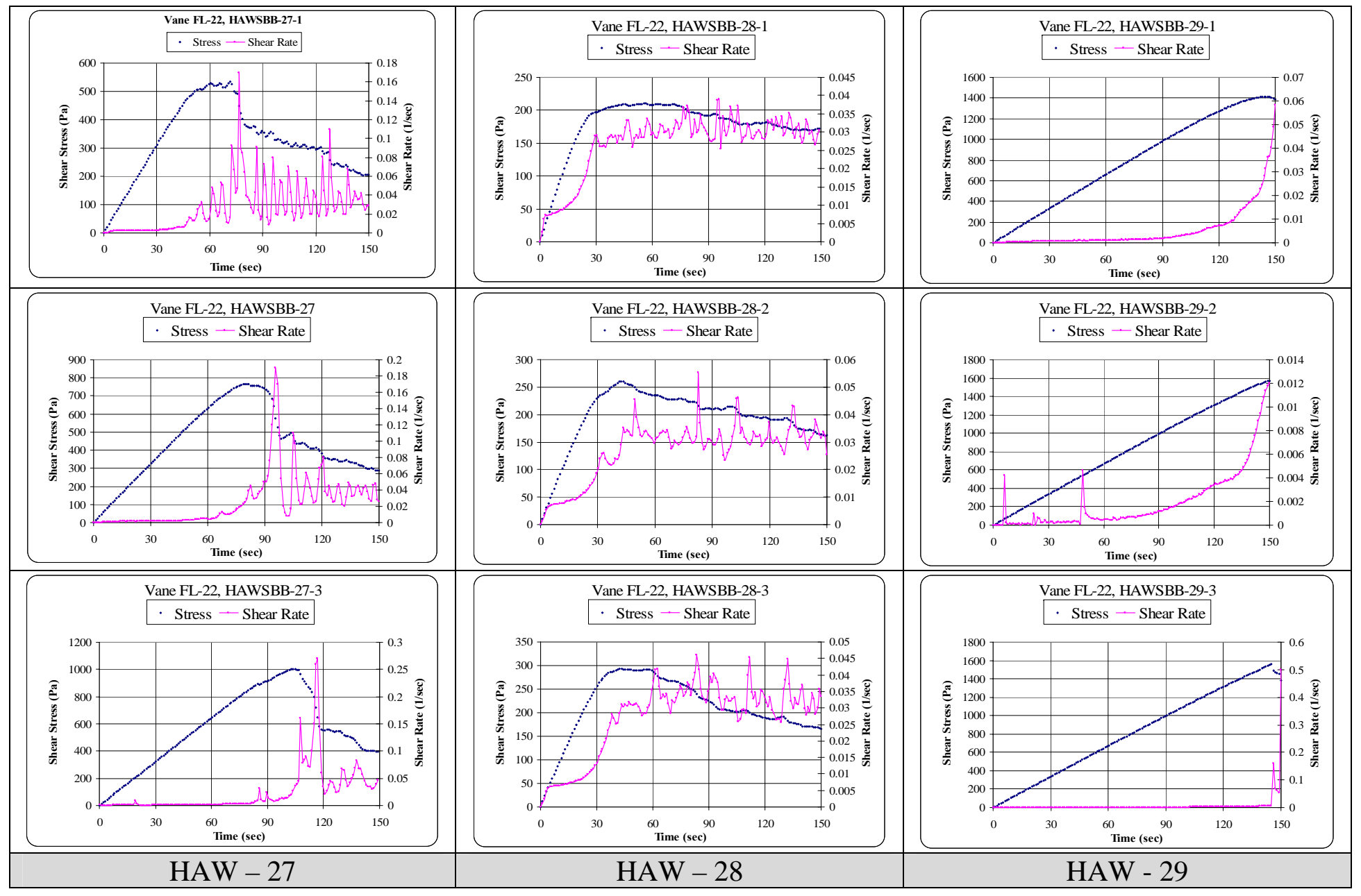

Figure D - 10 Vane Measurements for HAW-27, HAW-28, and HAW-29 


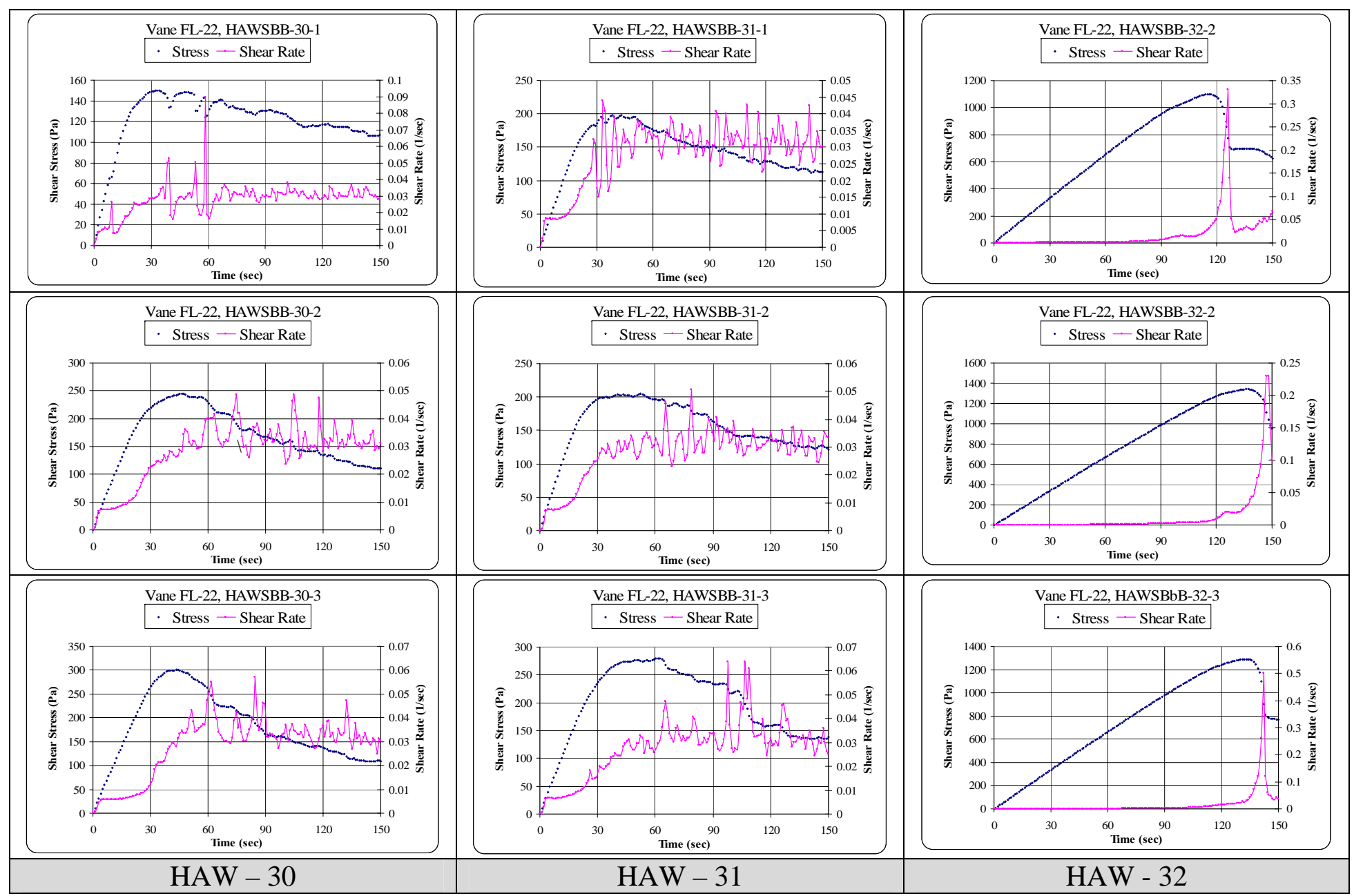

Figure D - 11 Vane Measurements for HAW-30, HAW-31, and HAW-32 


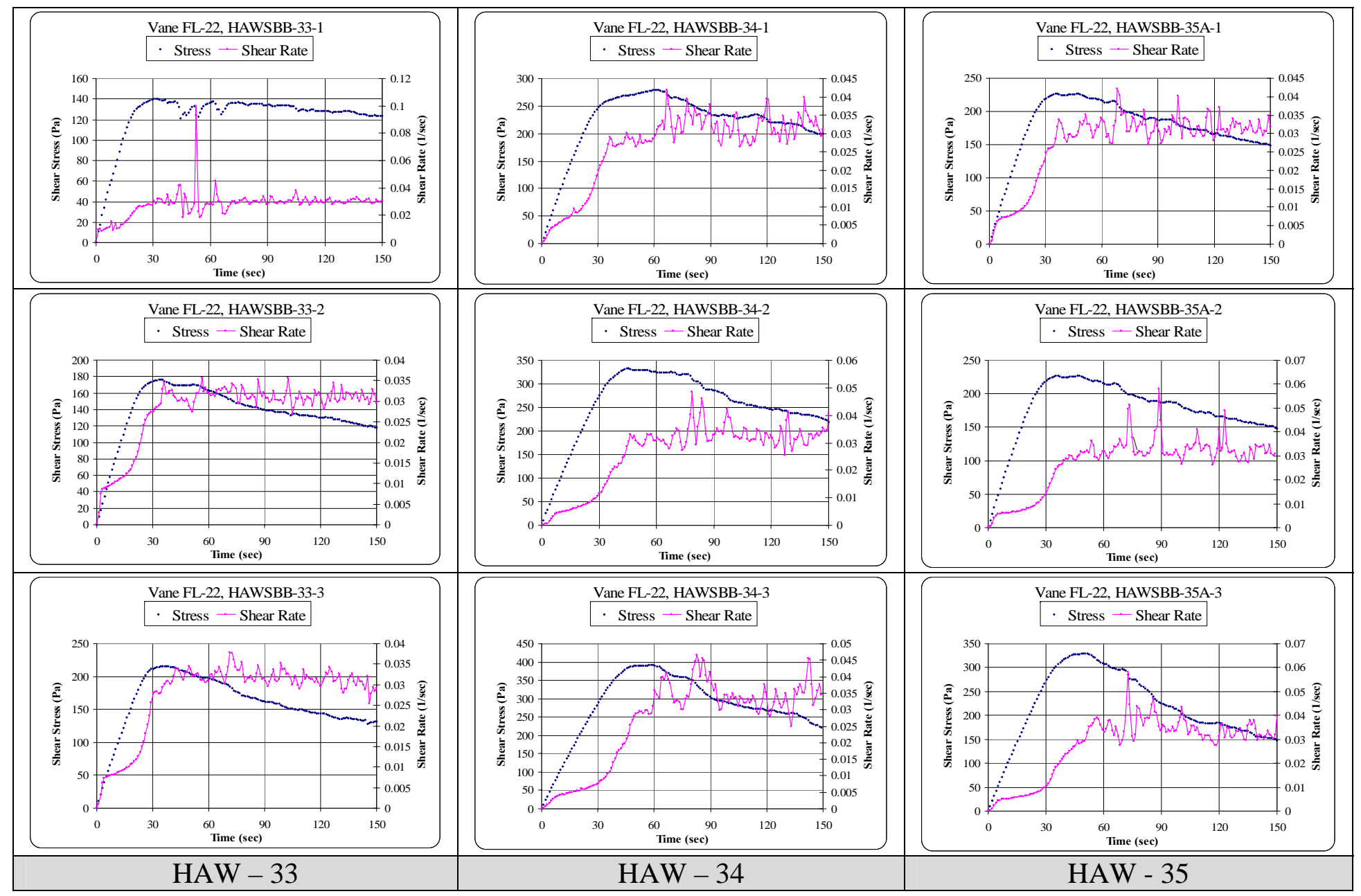

Figure D - 12 Vane Measurements for HAW-33, HAW-34, and HAW-35 


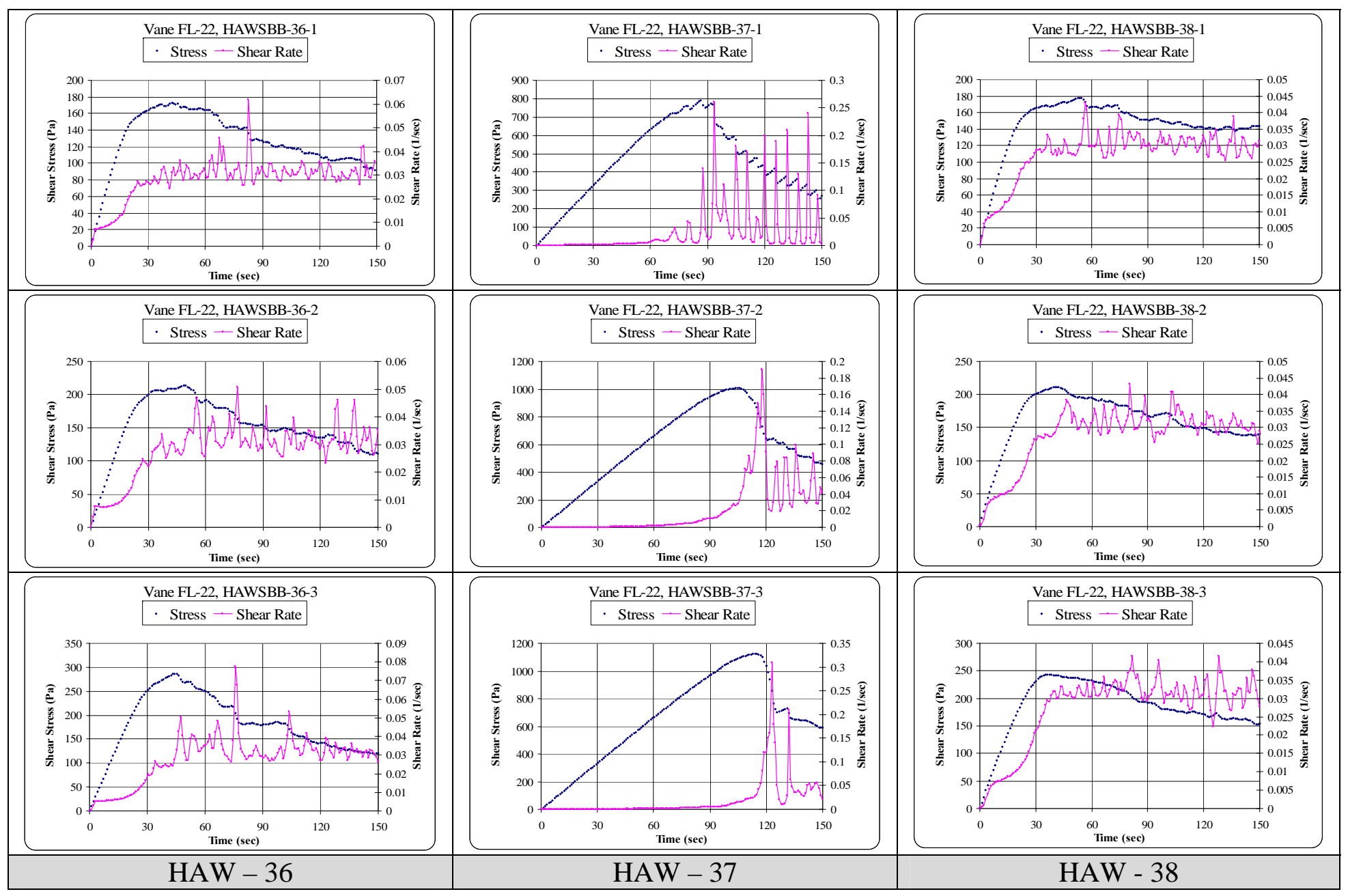

Figure D - 13 Vane Measurements for HAW-36, HAW-37, and HAW-38 


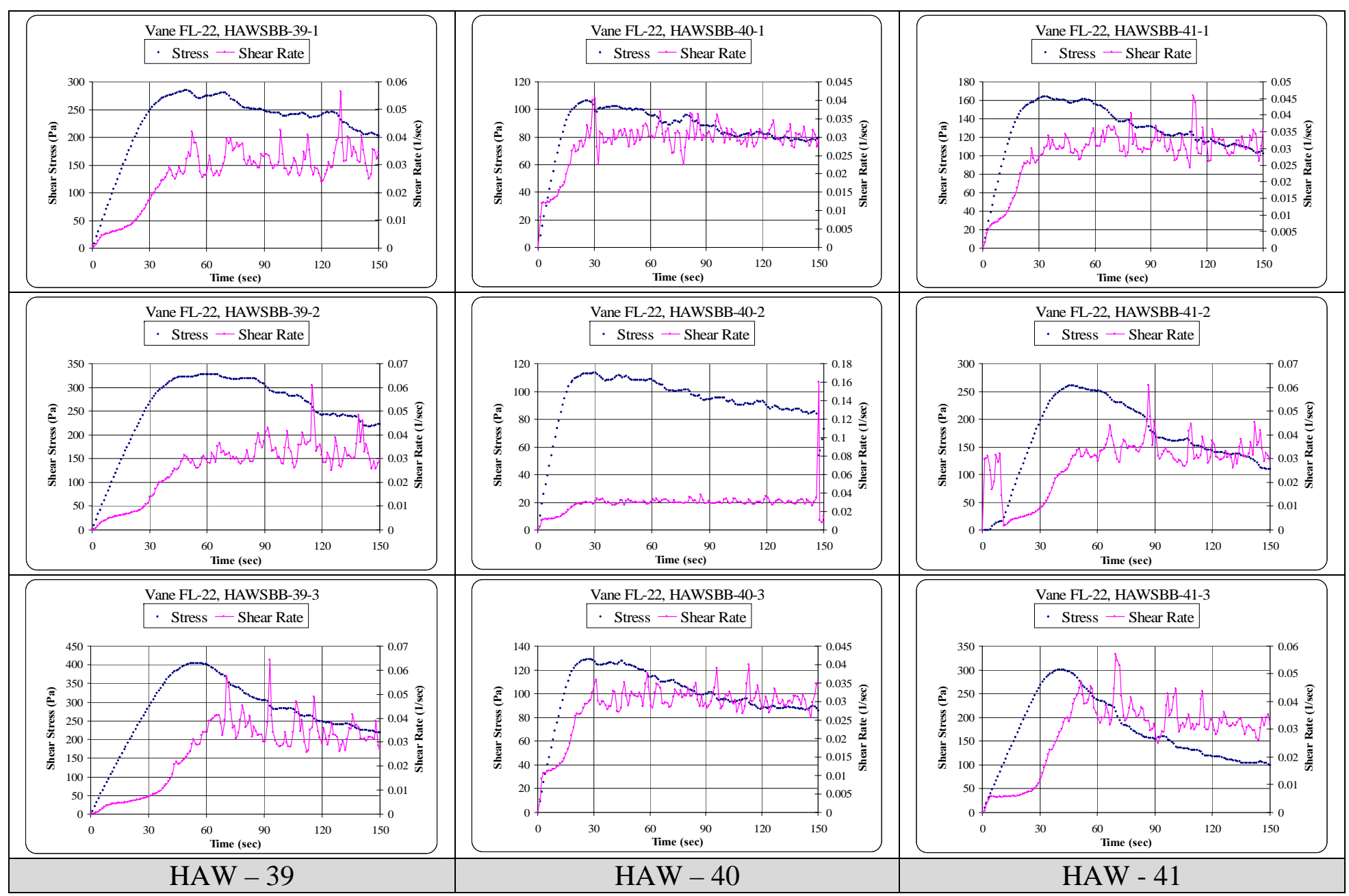

Figure D - 14 Vane Measurements for HAW-39, HAW-40, and HAW-41 


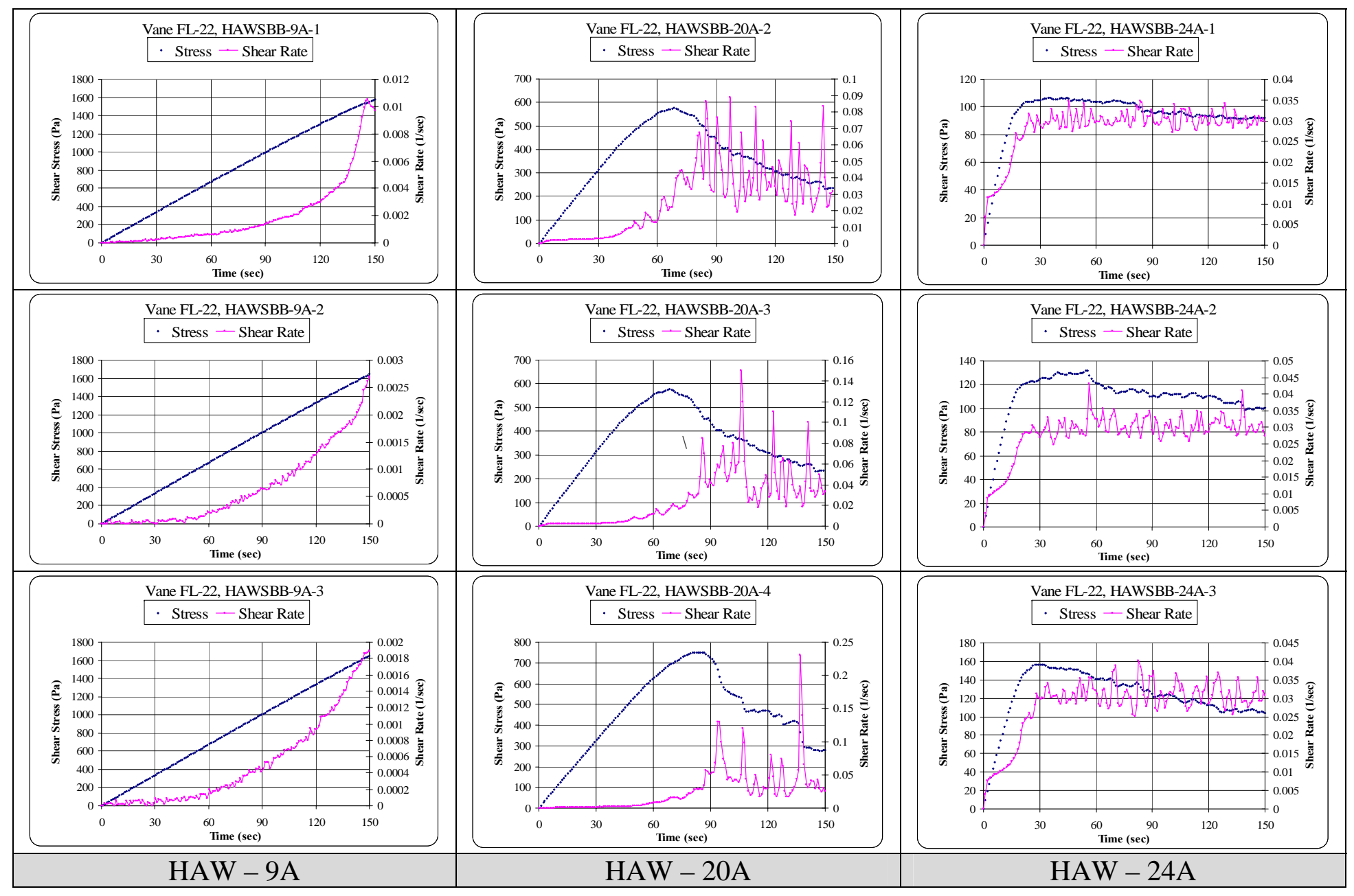

Figure D - 15 Repeated Vane Measurements for HAW-9A, HAW-20A, and HAW-24A 


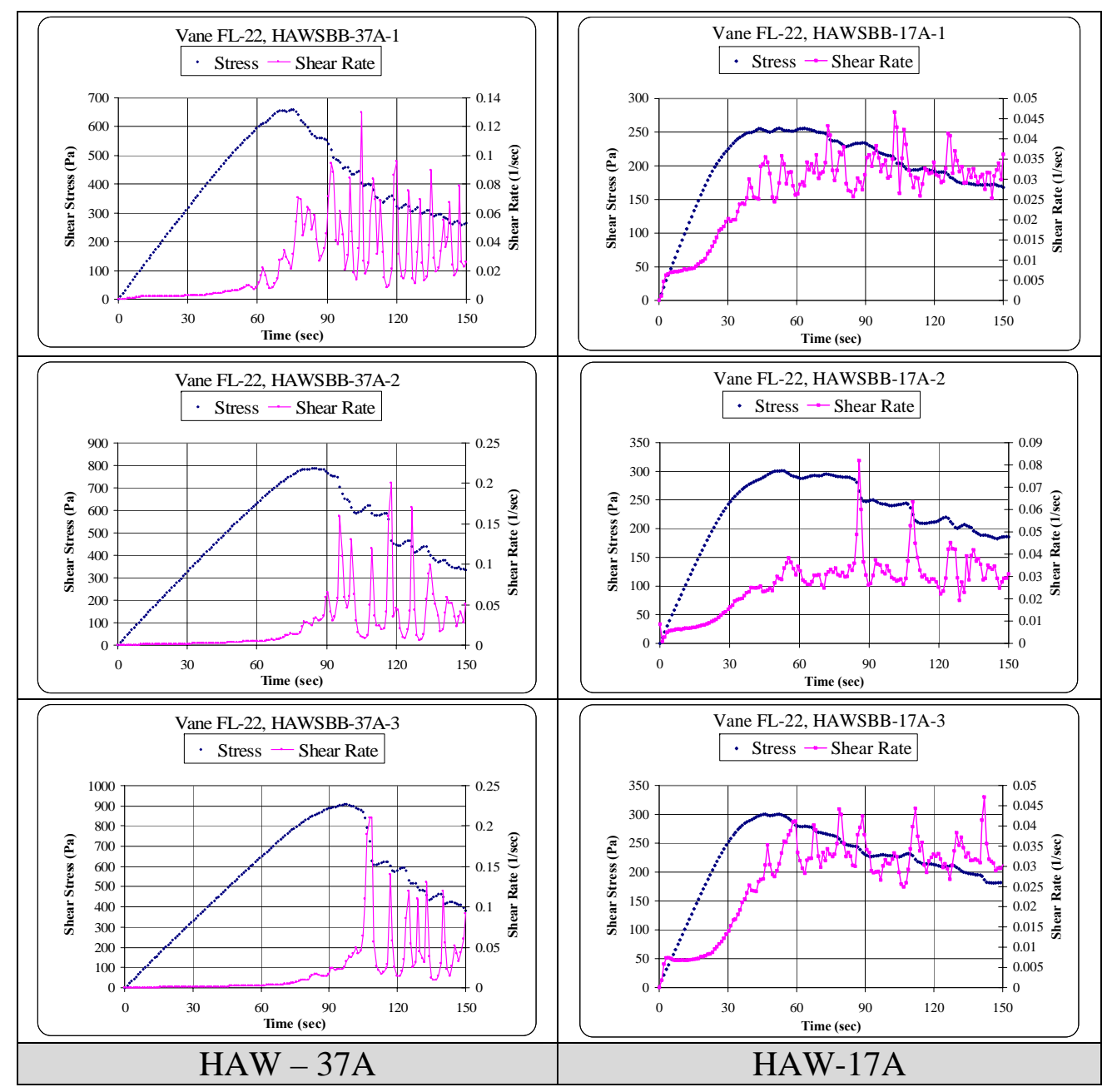

Figure D - 16 Repeated Vane Measurements for HAW-37A and HAW-17A 
SRNL-STI-2009-00101, REVISION 0

\section{APPENDIX E. STATISTICAL ANALYSIS FIGURES}

Page 91 of 100 


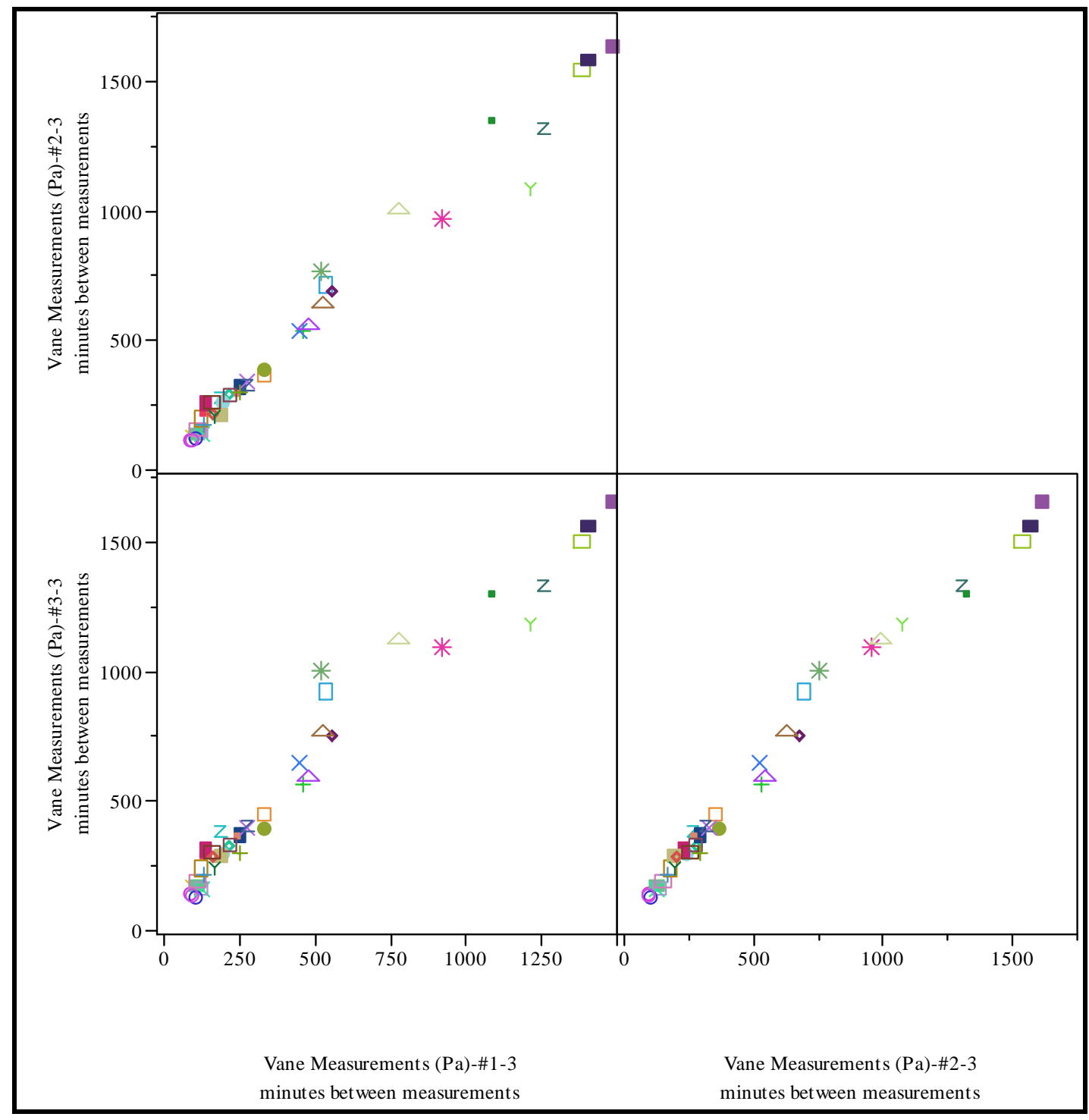

Figure E - 1 Linear Correlations Among Set of Yield Stress Measurements 


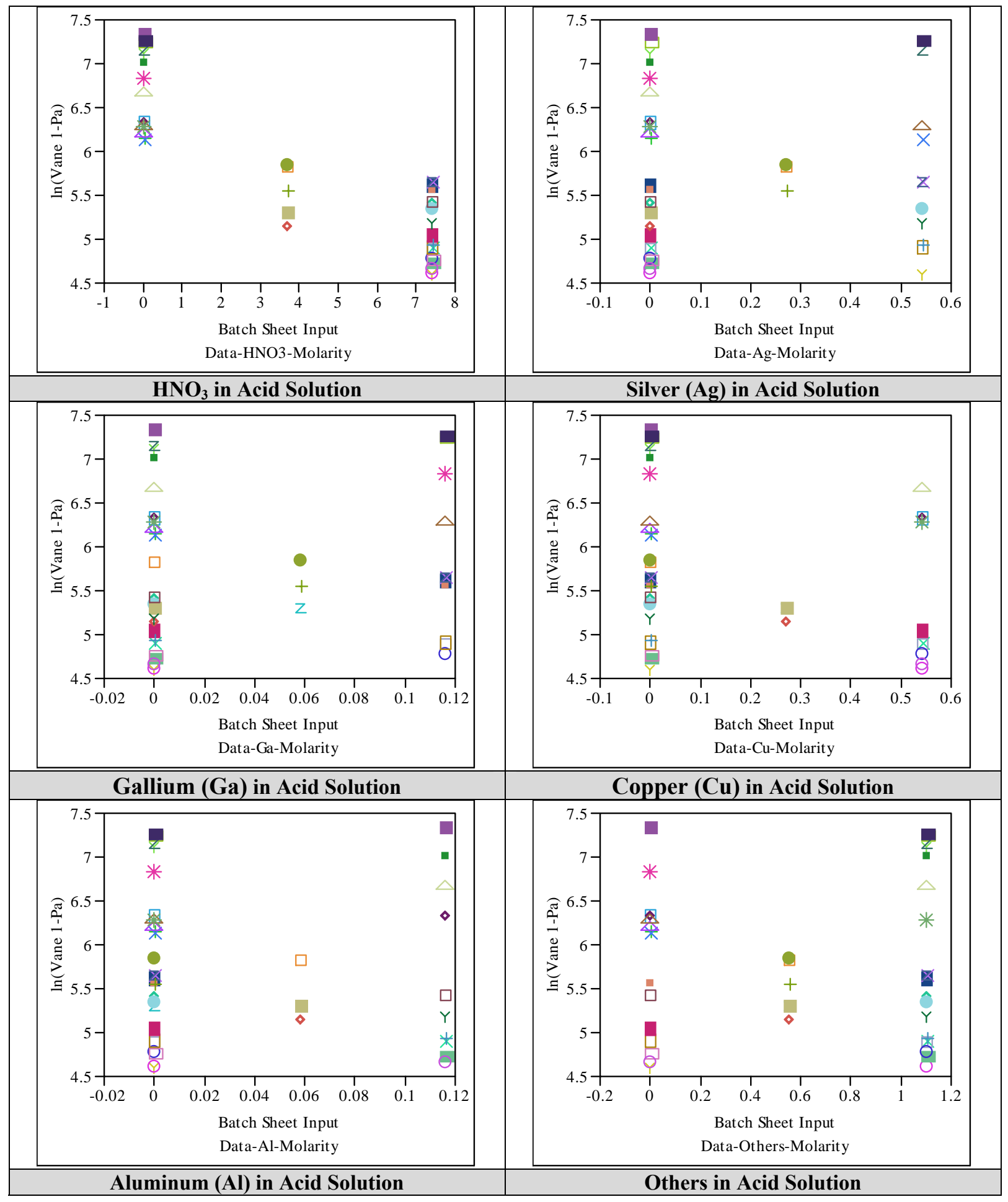

Figure E - 2 Plot of $\ln \left(1^{\text {st }}\right.$ yield stress $)$ Versus Molarity of Batch Sheet Input Data $\mathrm{HNO}_{3}, \mathrm{Ag}, \mathrm{Ga}, \mathrm{Cu}, \mathrm{Al}$, and Others 
SRNL-STI-2009-00101, REVISION 0

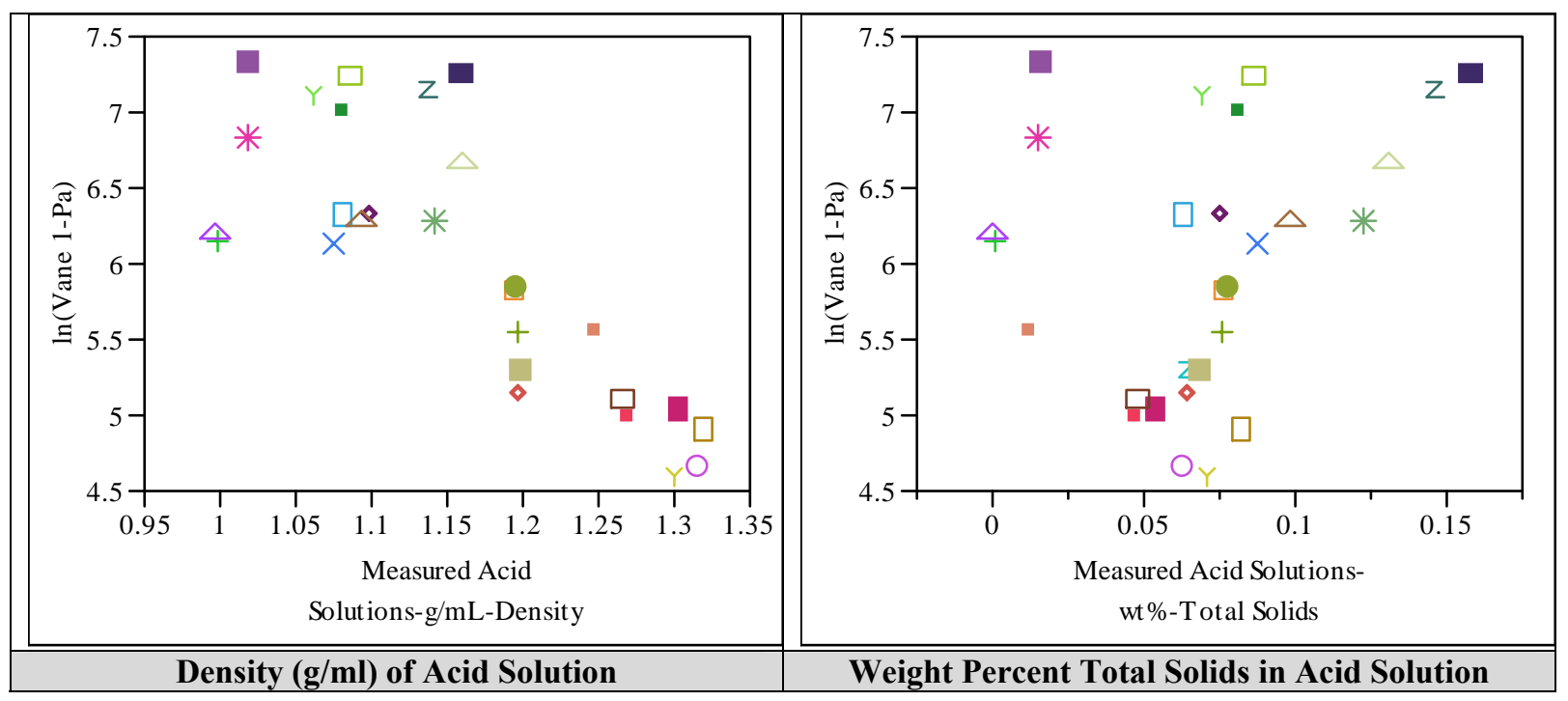

Figure E - 3 Plot of $\ln \left(1^{\text {st }}\right.$ yield stress $)$ Versus Density and Wt\% TS of Acid Solutions 

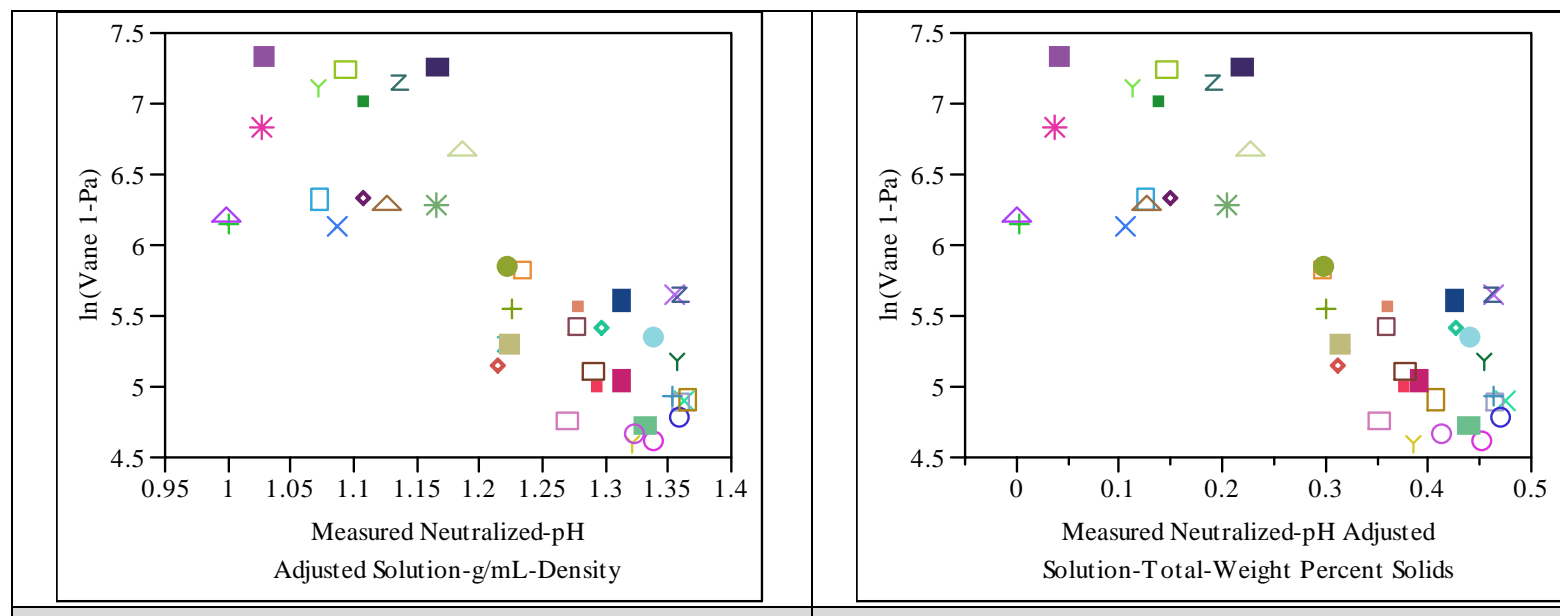

Density (g/ml) of Neutralized/pH adjusted fluid

Weight Percent Total Solids in Neutralized/pH

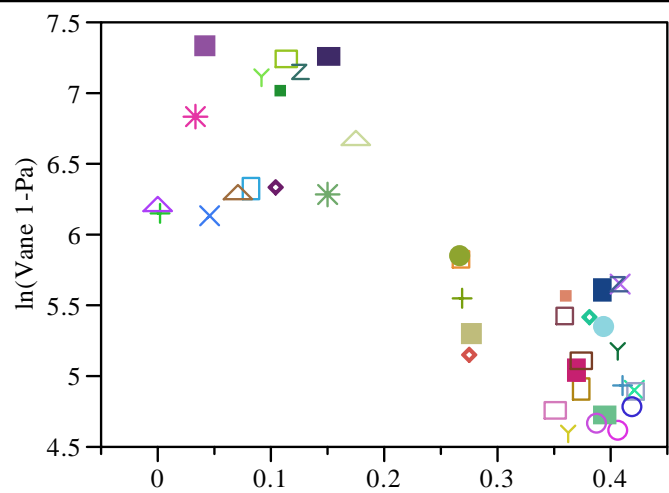

Measured Neutralized-pH Adjusted

Solution-Sol. In Sup-Weight Percent Solids adjusted fluid

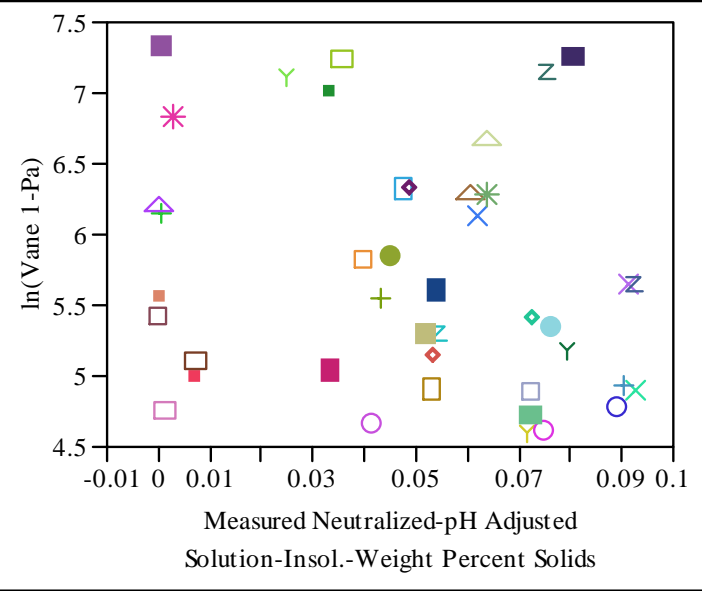

Weight Percent Soluble Solids in Supernate of Neutralized/pH adjusted fluid

Weight Percent Undissolved Solids in Neutralized/pH adjusted fluid

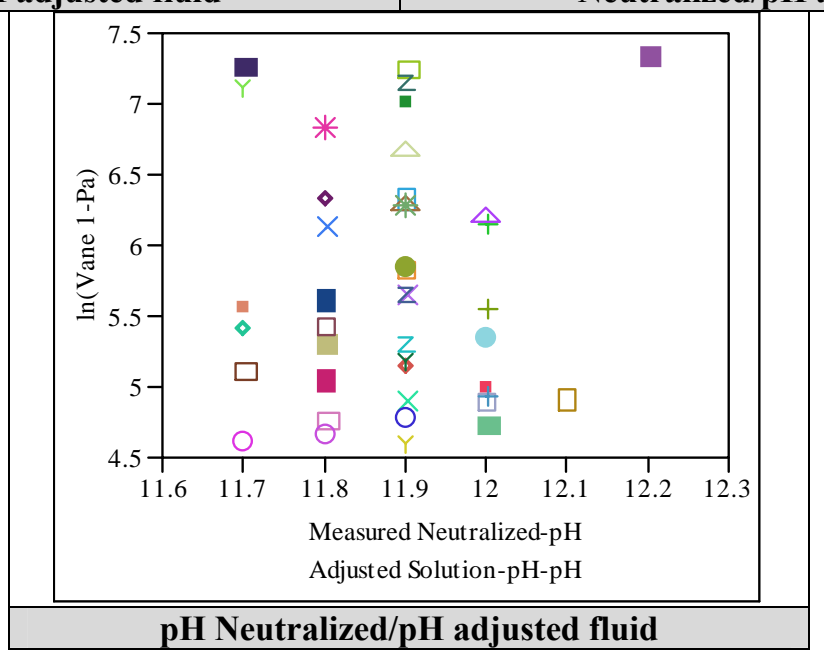

Figure E - 4 Plot of $\ln \left(1^{\text {st }}\right.$ yield stress $)$ Versus Physical Properties of Neutralized-pH Adjusted Fluids; Density, Wt\% TS, Wt\% SSS, Wt\% UDS, and pH 


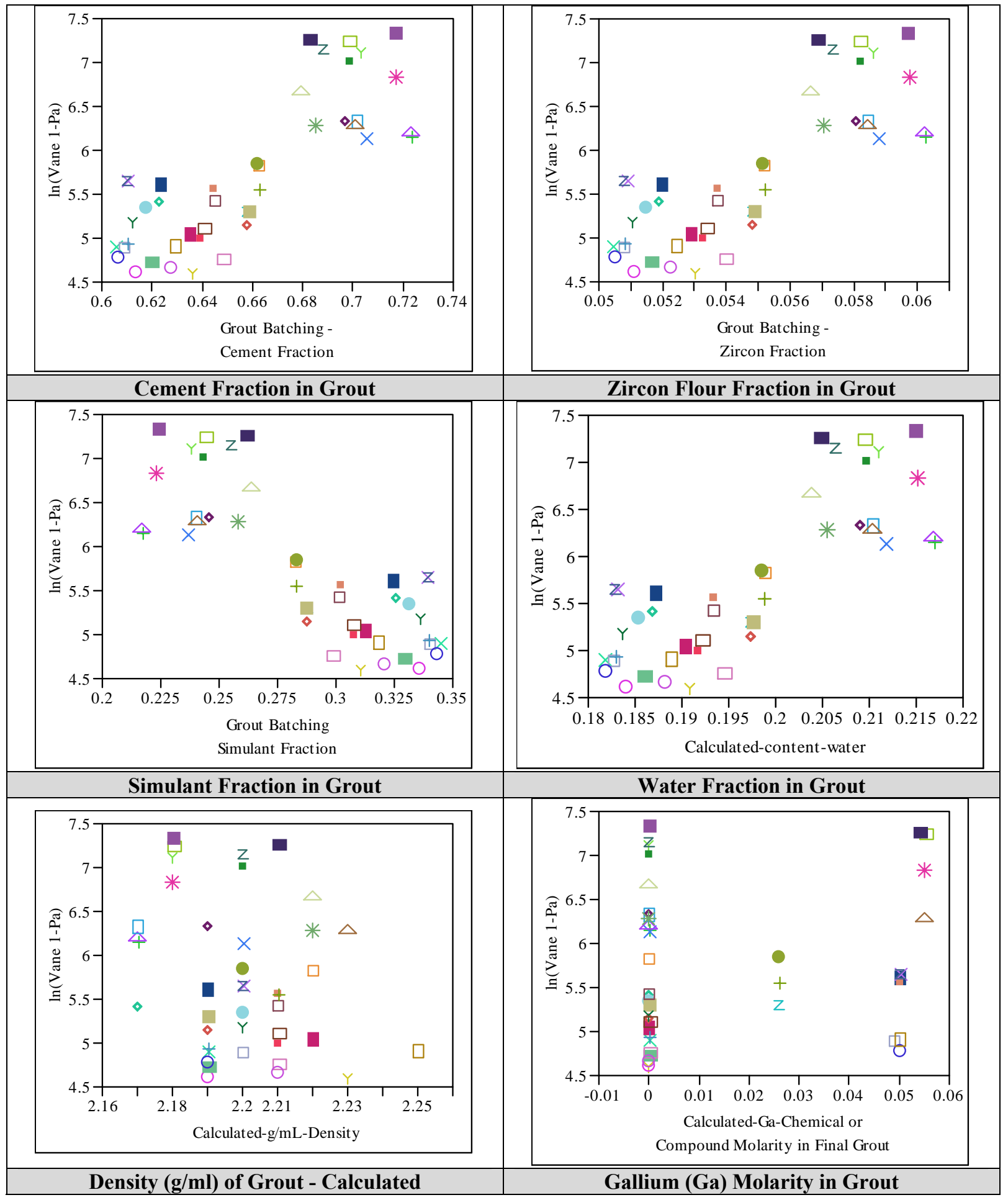

Figure E - 5 Plot of $\ln \left(1^{\text {st }}\right.$ yield stress $)$ Versus Mass Fraction of Cement, Zircon Flour, Simulant, and Water and Density and Ga Molarity in Final Grout 


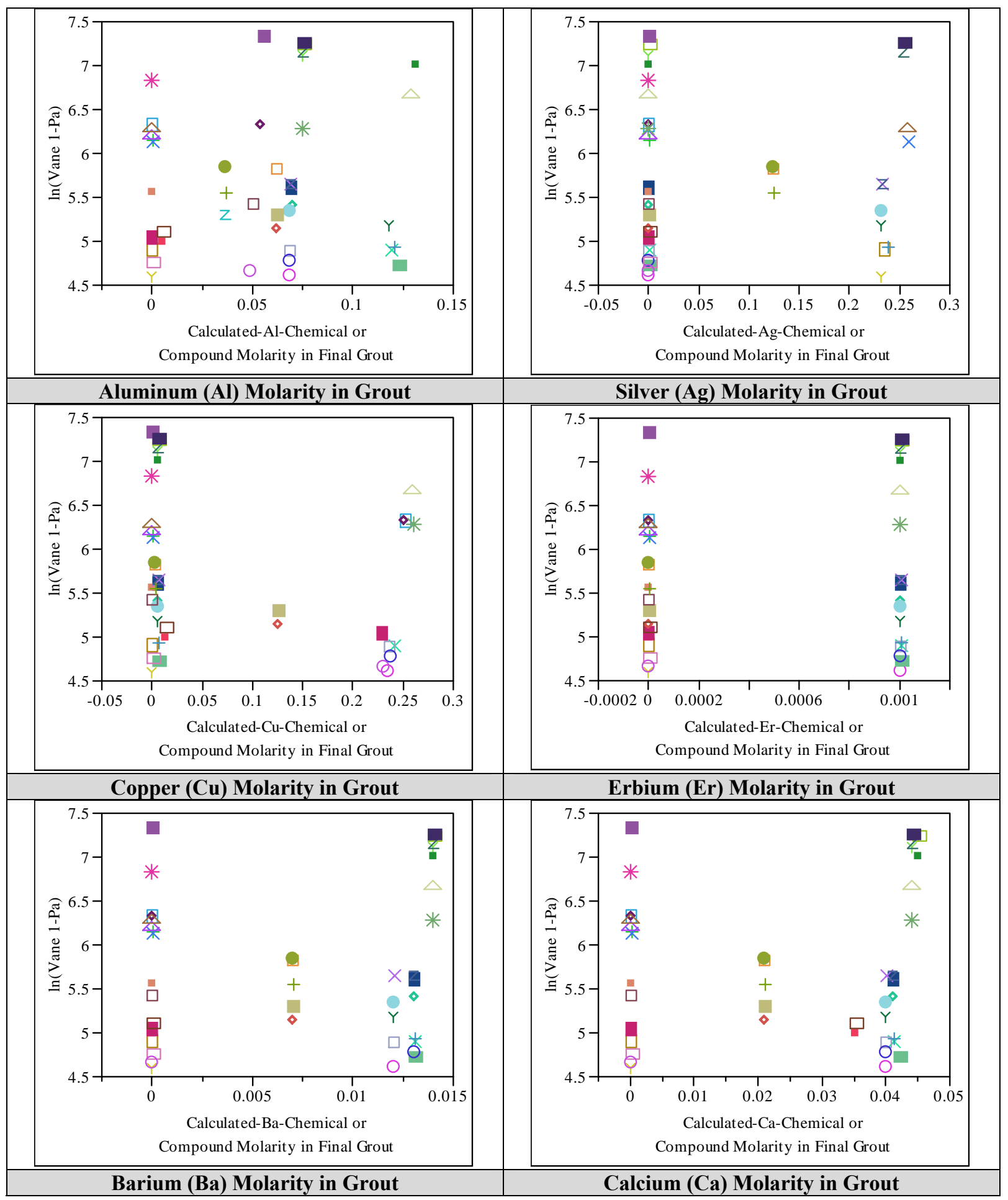

Figure E - 6 Plot of $\ln \left(1^{\text {st }}\right.$ yield stress $)$ Versus Molarity of $\mathrm{Al}, \mathrm{Ag}, \mathrm{Cu}, \mathrm{Er}, \mathrm{Ba}$, and $\mathrm{Ca}$ in Final Grout 


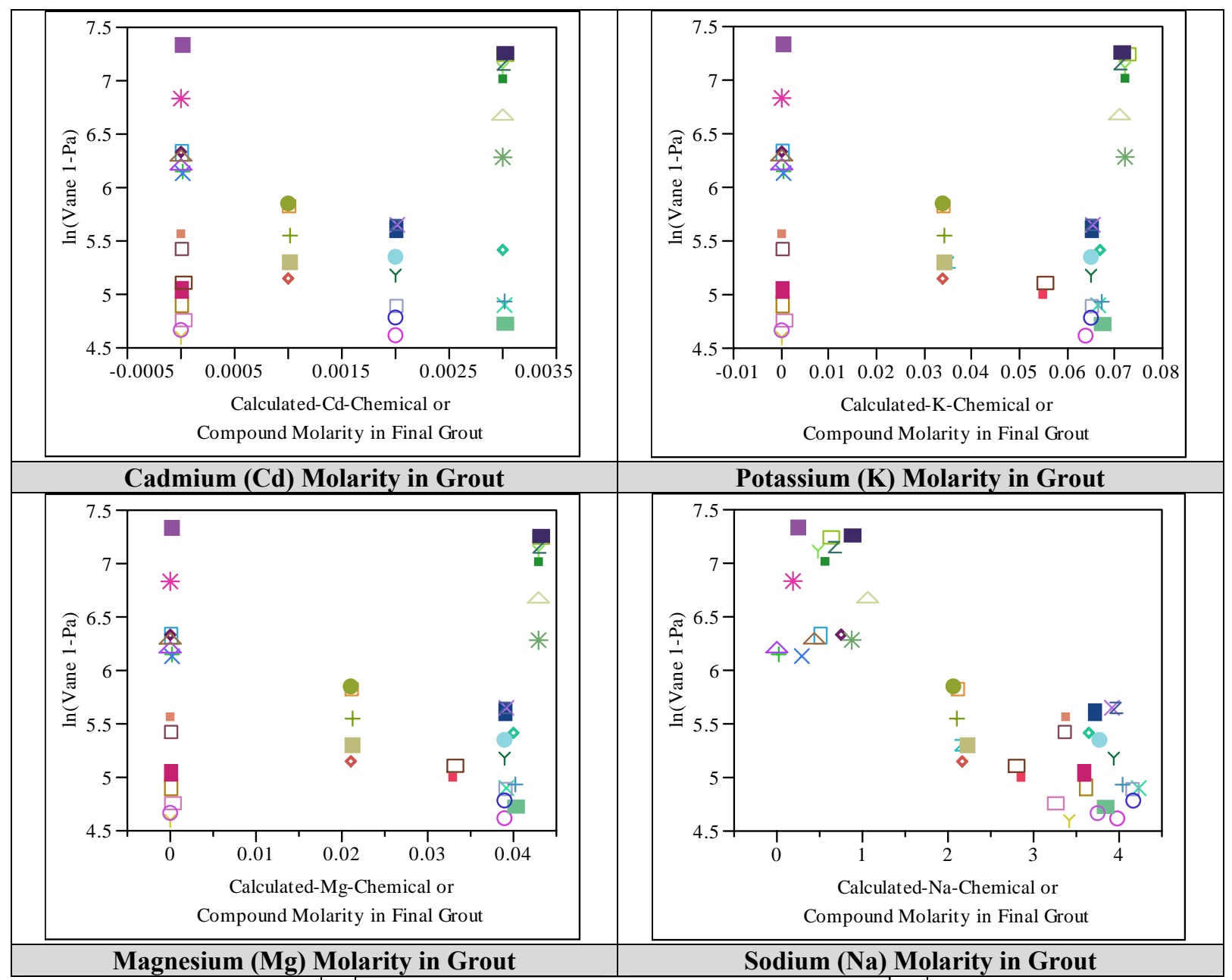

Magnesium (Mg) Molarity in Grout

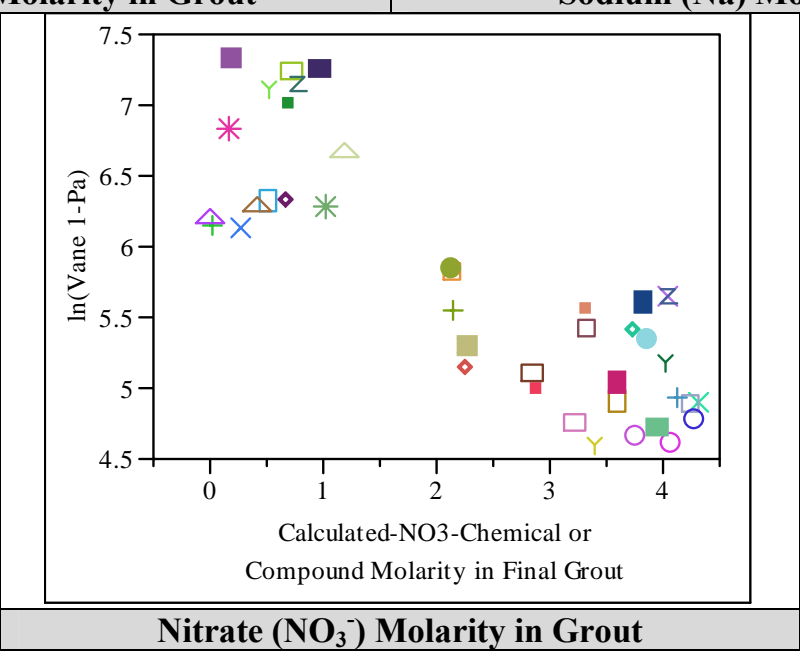

Figure E - 7 Plot of $\ln \left(1^{\text {st }}\right.$ yield stress $)$ Versus Molarity of $\mathrm{Cd}, \mathrm{K}, \mathrm{Mg}, \mathrm{Na}$, and $\mathrm{NO}_{3}{ }^{-}$in Final Grout 


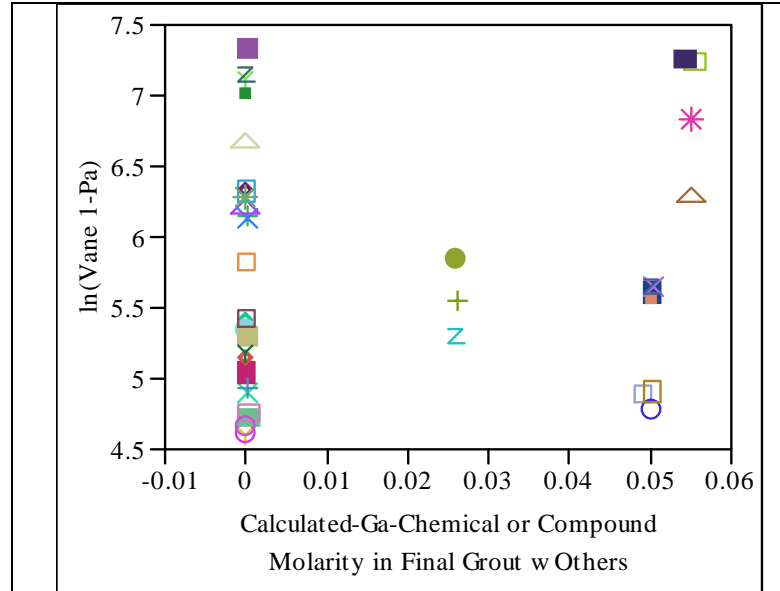

Gallium (Ga) Molarity in Grout with "Others" grouped

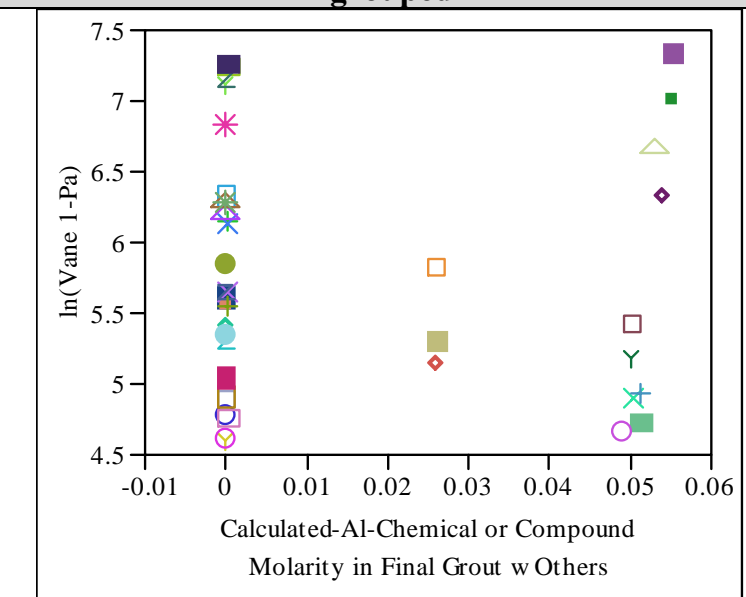

Aluminum (Al) Molarity in Grout with "Others" grouped

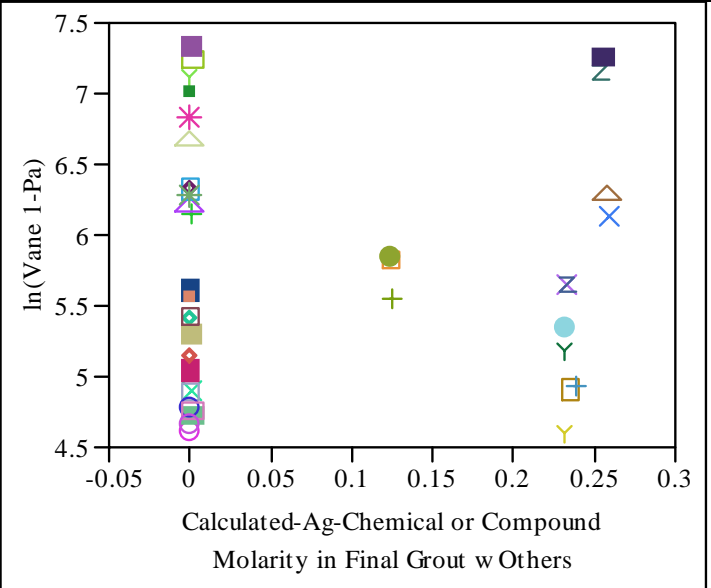

Silver (Ag) Molarity in Grout with "Others" grouped

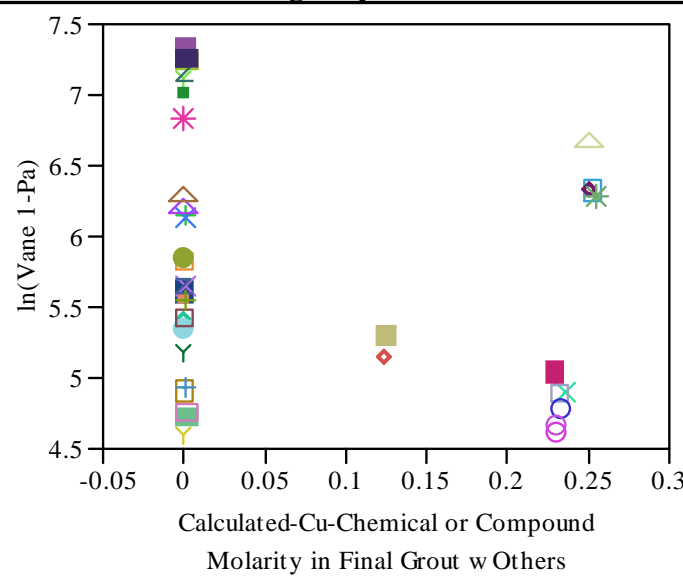

Copper (Cu) Molarity in Grout with "Others" grouped

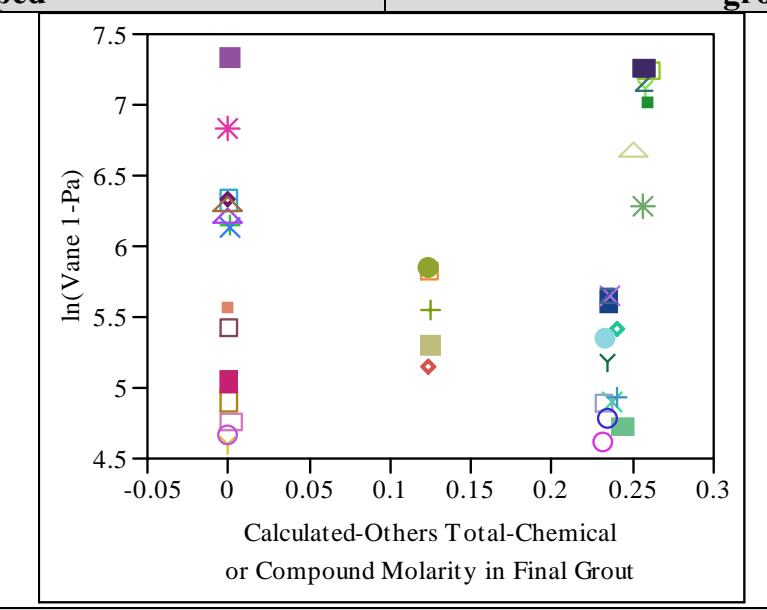

Others Molarity in Grout with "Others" grouped

Figure E - 8 Plot of $\ln \left(1^{\text {st }}\right.$ yield stress) Versus Molarity of Ga, $\mathrm{Ag}, \mathrm{Al}, \mathrm{Cu}$ and "Others" in Final Grout Keeping "Others" as a Group 


\section{Distribution:}

J. C. Griffin, 773-A

S. L. Marra, 773-A

A. B. Barnes, 999-W

D. A. Crowley, 773-43A

S. D. Fink, 773-A

C. W. Gardner, 773-A

B. J. Giddings, 786-5A

C. C. Herman, 999-W

F. M. Pennebaker, 773-42A

E. K. Hansen, 999-W

T. M. Jones, 999-W

T. B. Edwards, 999-W

A. D. Cozzi, 999-W

R. E. Eibling, 999-W

S. J. Robertson, 724-20E

J. R. Schafner, 724-20E

D. T. Conrad, 724-20E

D. R. Melton, 724-20E

J. T. Salley, 724-20E

W. B. Pool, 724-21E

P. D. Patel, 724-21E

J. M. Munie, 724-21E

N. J. Shah, 724-20E

M. R. Kesterson, 724-20E

J. A. Clark, 245-9F

D. M. Tanner, 245-9F

D. E. Berning, 245-8F

W. T. Davis, 730-2B

R. A. Knodel, 742-2A

R. P. Cullen, 742-2A

J. J. Hill, 245-8F

K. A. Brooks, 730-1B

D. M. Grimm, 730-2B

D. L. Saccone, 245-8F

P. W. Stanley, 245-8F

A. B. Chestnut, 245-8F

T.A. Cantey, 730-2B

L. T. McGuire, 730-2B

T. J. Richardson, 245-7F

R. J. Jordon, 724-36E

W. H. Gooding, 707-45B

S. G. Patterson, 730-4B

M. J. Brisson, 707-F 